\title{
Mortgage Market Design: Lessons from the Great Recession
}

\begin{abstract}
The rigidity of mortgage contracts and a variety of frictions in the design of the market and the intermediation sector hindered efforts to restructure or refinance household debt in the aftermath of the financial crisis. In this paper, we focus on understanding the design and implementation challenges of ex ante and ex post debt relief solutions that are aimed at a more efficient sharing of aggregate risk between borrowers and lenders. Using a simple framework that builds on the mortgage design literature, we illustrate that ex ante-designed, automatically indexed mortgages and policies can facilitate a quick implementation of debt relief during a crisis. However, the welfare benefits of such solutions are substantially reduced if there are errors in understanding the underlying structure of income and housing risk and their relation to the indexes on which these solutions are based. Empirical evidence reveals significant spatial heterogeneity and the time-varying nature of the distribution of economic conditions, which pose a significant challenge to the effective ex ante design of such solutions. The design of ex post debt relief policies can be more easily fine-tuned to the specific realization of economic risk. However, the presence of various implementation frictions and their spatial heterogeneity can significantly hamper their effectiveness. Consequently, we argue that effective mortgage market design will likely involve a combination of ex ante and ex post debt relief solutions, with state contingencies. We conclude by discussing the potential gains - which can be large, given significant regional heterogeneityfrom tying mortgage terms and policies to local indicators, as well as mechanisms that may alleviate the adverse effects of ex post implementation frictions.
\end{abstract}

Conflict of Interest Disclosure: Conflict of Interest Disclosure: The authors received financial support for this work from the National Science Foundation under grant no. 1628895. With the exception of the aforementioned, the authors did not receive financial support from any firm or person for this paper or from any firm or person with a financial or political interest in this paper. They are currently not officers, directors, or board members of any organization with an interest in this paper. No outside party had the right to review this paper before publication. 
$\mathrm{T}$ he recent U.S. housing boom saw an unprecedented increase in household mortgage debt (Keys and others 2013). This buildup of mortgage debt held by vulnerable households has been partly seen as having particularly exacerbated the severity of the aftermath (Mian and Sufi 2009, 2011, 2014b). ${ }^{1}$ However, the characteristics of borrowers and loans originated before the crisis is not the only key factor that affected the severity of the housing market downturn during the Great Recession. A series of papers have argued that a number of factors related to the rigidity of contract terms, along with a variety of frictions in the design of the mortgage market and the intermediation sector, hindered efforts to restructure or refinance household debt, exacerbating the foreclosure crisis (Piskorski, Seru, and Vig 2010; Mayer and others 2014; Di Maggio and others 2017; Fuster and Willen 2017).

In response, the Federal Reserve altered its monetary policy by lowering short-term interest rates to historic lows. Also, the administration passed two unprecedented, large-scale debt relief programs: the Home Affordable Refinancing Program (HARP), which aimed to stimulate mortgage refinancing activity for up to 8 million heavily indebted borrowers; and the Home Affordable Modification Program (HAMP), which aimed to stimulate a mortgage restructuring effort for up to 4 million borrowers at risk of foreclosure. Research suggests that the implementation of the low-interest-rate policy and these debt relief programs had mixed success (Agarwal and others 2017a, 2017b; Di Maggio and others 2017).

What can we learn from extant research for the potential design of more effective debt relief solutions in the future? In this paper, we focus on understanding the design and implementation challenges of ex ante and ex post debt relief solutions. In doing so, we also analyze the benefits of indexing such solutions to local economic conditions relative to aggregate indicators. The objective of this paper is to draw on lessons from prior research and provide evidence-based guidance on both these issues.

We start by discussing the literature that documents various frictions that hindered efforts to refinance or restructure mortgages during the Great Recession. The main frictions that have been documented center on (i) contract rigidity, due to which most contracts that were fixed-rate mortgages were locked in at high rates; (ii) equity refinancing constraints,

1. For recent quantitative equilibrium models of housing booms and busts, see Landvoigt, Piazzesi, and Schneider (2015); Kaplan, Mitman, and Violante (2017); Guerrieri and Uhlig (2016); and Favilukis, Ludvingson, and Van Nieuwerburgh (2017). For an alternative view of the reasons behind the housing boom and bust, see Adelino, Schoar, and Severino (2016). 
due to which refinancing mortgages was not feasible for many distressed borrowers with insufficient equity; (iii) intermediary organizational constraints, due to which refinancing or debt relief was not passed on to borrowers; (iv) agency conflicts in servicing mortgages that were largely securitized, which prevented restructuring; (v) a lack of competition in the refinancing market that blunted the extent of the pass-through to borrowers, lowering their incentives to refinance; and (vi) the ex post moral hazard concerns of intermediaries, whereby offering debt relief to distressed borrowers could alter the incentives of many solvent borrowers to continue making payments.

There is a large body of literature showing that these frictions, each in part, might have prevented debt relief from reaching distressed households. Consequently, there is an ongoing debate regarding the reform of the mortgage market to alleviate the impact of such frictions in the future. At the center of this debate are a variety of proposals concerning the redesign of mortgage contracts, as well as future debt relief policies. These proposals start from the premise that the current risk-sharing arrangement between borrowers and lenders in the mortgage market particularly relies on an option to default that can induce a large number of foreclosures during the crisis, with significant associated deadweight losses. In essence, these proposals argue for more efficient risk-sharing between borrowers and lenders to lower the incidence of costly foreclosures and the severity of future housing market downturns (Shiller 2008; Caplin and others 2008; Piskorski and Tchistyi 2011; Campbell 2013; Keys and others 2013; Mian and Sufi 2014a; Eberly and Krishnamurthy 2014). Because we want to use the lessons from the literature to assess the design of future mortgages and debt relief policies, we start with the theoretical insights from the research on mortgage design. This allows us to think about various economic forces that should be in the consideration set as we make our assessment.

The main collective insights from this work (Piskorski and Tchistyi 2010, 2011, 2017; Eberly and Krishnamurthy 2014; Greenwald, Landvoigt, and Van Nieuwerburgh 2018; Guren, Krishnamurthy, and McQuade 2017) are as follows. In general, contracts or policies that temporarily reduce mortgage payments during recessions can potentially result in significant welfare gains by preventing costly foreclosures and providing consumptionsmoothing benefits to households. This is especially the case for borrowers who face more income variability and can afford only a small down payment. To the extent possible, it would therefore be beneficial to design mortgages or debt relief programs that index mortgage payments to measures that capture the state of the local housing and labor markets. This would 
allow mortgage payments to be lower in states of the world when local labor markets and housing markets experience a downturn. Such indexation programs need to take into account their impact on the market equilibrium, including the incentives of households to borrow and repay their debt. Empirically relevant informational asymmetries and other frictions may limit the set of state-contingent contracts that are sustainable in market equilibrium. Risk aversion and other constraints may also curtail the ability of financial intermediaries to insure the aggregate risk, limiting the effectiveness of state-contingent mortgages or debt relief policies. Finally, contracts or debt relief policies based on other indexes-for example, interest rate indexation, in the case of adjustable-rate mortgages (ARMs) - may perform quite well in providing household debt relief during downturns, as long as such indexes closely co-move with home prices and borrowers' incomes.

Next, we use a simple framework that builds on these insights to illustrate how automatically indexed mortgage contracts or debt relief policies can lead to significant welfare gains for borrowers. The main channel, as mentioned above, is by reducing the debt burden during economic downturns and lowering the incidence of costly foreclosures. Using this framework, we illustrate two points. First, and very intuitively, a mortgage contract or debt relief policy contingent on some index is more efficient if the index is highly correlated with variables capturing relevant (for example, local) economic conditions for borrowers, and if these variables co-move with each other. Second, we show that the benefits of such solutions are substantially reduced if there are errors in understanding the underlying structure of income and housing risk and their relation to the indexes on which such contracts or policies are based.

Although the main insight behind why such contracts or types of debt relief might be efficient seems relatively straightforward, we spend the next section of the paper on explaining the design and implementation challenges of ex ante and ex post debt relief solutions in practice. A key insight of our framework is that successful implementations of ex ante debt relief solutions rely on a correct understanding of the underlying structure of income and housing risk and its relation to the indexes on which such contracts or policies will be based. ${ }^{2}$ This observation is also consistent with the quantitative life cycle models of households' decisions,

2. In particular, even the best-designed automatically indexed mortgage contract can perform quite poorly ex post if the lenders or policymakers have incorrect understanding of the true distribution of relevant risk. 
which emphasize the importance of recognizing a specific nature of household risk for an appropriate mortgage contract choice (Campbell and Cocco 2003, 2015).

To better explain this aspect, we analyze simple measures of housing and income risk and their co-movements across time, regions, and borrowers. We document empirical evidence pointing to significant spatial heterogeneity and to the time-varying nature of the distribution of economic conditions. Our spatial analysis starts at the state level and shows that states' local business cycles have quite different frequencies. For instance, using principal component analysis, we find that a national economic factor explains, on average, about 52 percent of the variation in the time series of a state's economic factor, and that this association varies substantially across states. Moreover, though we find that all state economic factors decline sharply during the Great Recession, substantial dispersion remains. Consistent with this observation, we find that the state-level economic variables are on average more correlated with the local economic factor than the national ones. A direct implication of this analysis is that spatial heterogeneity may limit the effectiveness of mortgage contracts or debt relief policies based on the national-level indexes.

Next, we zoom in to more granular geographical regions and conduct an analysis at the county level, with variables that both capture the risk of regions and that are available at high frequency. We find that, as within states, there are large spatial variations in delinquency rates and the equity positions of borrowers. At one end, even during the depths of the Great Recession, many counties have sizable housing equity on average and relatively low levels of unemployment and mortgage delinquencies. At the other end, some counties consist of a severely distressed pool of borrowers with depleted home equity.

We also consider the stability of relationships between county-level variables. We find that county-level mortgage default rates are positively related to increases in the unemployment rate and are negatively related to house price growth. This is not surprising, because the extensive empirical literature identifies these two factors as key drivers of mortgage defaults (Foote, Gerardi, and Willen 2008). However, we also find that the strength of these associations varies substantially over time. Moreover, the strength of the relationship between housing and income risk does not appear to be stable over time, pointing to a time-varying distribution of these variables. This evidence is also broadly consistent with research by Erik Hurst and others (2016) and by Martin Beraja and others (2017), who argue that regional shocks are an important feature of the U.S. economy and that the 
regional distribution of housing equity and income varies substantially over time.

Zooming in further, we show that within a county, there is significant heterogeneity at the ZIP code and individual levels. For instance, we find that there is again a large degree of heterogeneity in the distribution of negative equity and defaults in the U.S. population across time. It is particularly important that this evidence also shows that, even during the crisis, there was a large variation among borrowers within counties in delinquency and their home equity positions.

To investigate this issue more formally, we analyze how much variation in local variables - which might be used in ex ante and ex post policiescan be explained by variables at different levels of geographic granularity. The first exercise we undertake is a simple statistical analysis of what fraction of local variation can be explained at various levels of aggregation by considering an upper bound to the informativeness of various economic variables by their level of geographic aggregation. In our analysis, we focus on house prices, combined loan-to-value ratios, debt-to-income ratios, delinquency rates, and foreclosures. We show that explained variation monotonically decreases as we consider coarser geographic areas. For example, the fraction of ZIP code-level mortgage delinquency and foreclosure rates that can be explained by the corresponding county-level variables is, respectively, about 43 and 35 percent. This pattern suggests a large local variation at the ZIP code level that is not captured by county, state, or national data. We also assess the actual association of various national-, county-, and ZIP code-level variables with ZIP code-level delinquency and foreclosure rates and find similar evidence. We also examine the predictability of local housing-related variables with corresponding lagged variables at different levels of geographic aggregation. We again find that predictability worsens as we consider coarser geographic areas.

Next, we ask what the evidence documented above implies for the design of mortgage contracts and debt relief policies. Recall that for solutions such as automatically indexed contracts or debt relief policies to be effective, one needs to have a good ex ante understanding of the underlying distribution of the relevant economic risk and its relation to indexes on which such contracts or policies are based. Given the evidence of significant heterogeneity in space and time, along with limited data on crisis episodes, this can be quite challenging. Moreover, a major change in the nature of mortgage contracts or housing policy is likely to significantly alter market equilibrium, including future joint distribution of such economic outcomes as house prices, housing supply, homeownership rates, and household debt 
levels (Piskorski and Tchistyi 2017; Guren, Krishnamurthy, and McQuade 2017; Greenwald, Landvoigt, and Van Nieuwerburgh 2018). This further complicates an effective use of historical data in the design and parametrization of future contracts or policies. ${ }^{3}$

Ex post debt relief policies have the advantage of being more fine-tuned to the specific realization of economic risk, and hence they can alleviate the ex ante design challenges discussed above. However, various implementation frictions can hamper the effectiveness of ex post solutions. We provide evidence that there is significant spatial heterogeneity of frictions that can differentially affect the pass-through of ex post debt relief policies implemented by financial intermediaries. The presence of such factors and the difficulty of identifying them ex ante pose a significant challenge for implementing effective ex post debt relief policies. For instance, though HARP was largely indexed to the local economic conditions of the borrower, because it was based on the current loan-to-value ratio, it was not as effective as anticipated. In particular, because the implementation was through intermediaries, its effectiveness was hampered by intermediary frictions - such as capacity constraints - and also by market design, such as competition in the refinancing market (Agarwal and others 2017b; Fuster, Lo, and Willen 2017). Similar observations apply to HAMP, which based its eligibility criteria on the current debt-to-income ratio of the borrower, yet performed below its potential, due to the limited ability of intermediaries to conduct loan modifications (Agarwal and others 2017a).

Finally, our empirical analysis also sheds light on the benefits of indexing ex ante and ex post debt relief solutions to local economic indicators. In particular, our evidence of significant spatial heterogeneity suggests that there might be substantial gains from fine-tuning debt relief solutions to more granular regional conditions and that one-size-fits-all policies might not be that efficient. For instance, ignoring the heterogeneity in space, though ARM contracts indexed on national interest rate indexes might be helpful during periods of low interest rates, they may also exacerbate distress during periods of higher interest rates, as was the case in the late 2006, early 2008 period. Indexing policies and contracts to variables capturing local components of housing market risk (for example, ZIP code-level house price indexes and other local variables) could be more effective than policies based on national indexes. We note, however, that a full assessment of the relative benefits of

3. See also Rajan, Seru, and Vig 2015, who illustrate that the changed nature of intermediation in the mortgage market (Keys and others 2010; Purnanandam 2011) may alter the stability of statistical relationships between key variables. 
such programs also requires a careful consideration of their implementation costs relative to more traditional contracts and policies.

Overall, our paper highlights an important trade-off between design and implementation when thinking about debt relief policies in the future. The precrisis-designed, automatically indexed mortgage contracts or policies have the advantage of circumventing financial intermediary and other frictions by facilitating a quick implementation of debt relief during economic downturns. However, for such solutions to be cost-effective, lenders, policymakers, and borrowers may need to have a good ex ante understanding of the underlying distribution of the relevant economic risk and its relation to the indexes on which such contracts are based. Given the evidence we have discussed above, this can be challenging.

Ex post debt relief solutions, conversely, have the advantage of being more fine-tuned to the specific realization of economic risk. In other words, unlike precrisis-designed contracts or policies, ex post policy interventions do not need to rely as much on a good ex ante understanding of the underlying distribution of the relevant economic risk and frictions and their relation to the severity of the crisis. However, ex post policy interventions can also delay debt relief and subject it to various implementation frictions that could hinder their effectiveness.

Consequently, we conclude that effective mortgage market design will likely involve a combination of ex ante and ex post debt relief solutions, with state contingencies. Finally, given our evidence, both types of solutions (ex ante and ex post) may benefit from the use of more granular conditions (regional or individual), as opposed to one-size-fits-all indicators.

\section{Frictions to Mortgage Debt Relief: Evidence from the Great Recession}

The recent literature has documented how several frictions had an impact on the effectiveness of debt relief, thereby exacerbating the foreclosure crisis. The first such friction relates to mortgage contract rigidity-that is, the notion that most mortgage contracts were fixed-rate mortgages (FRMs) that were locked in at high rates. Marco Di Maggio and others (2017) and Andreas Fuster and Paul Willen (2017) show that as interest rates reached historic lows during the Great Recession, borrowers with certain types of ARMs received automatic debt relief. ${ }^{4}$ This experiment is useful for

4. We note that subprime ARM contracts featuring the rate-adjustment floors limited the extent of debt relief received by these borrowers. 
quantifying the effects of debt relief because it was received by every borrower with certain types of ARM contracts, regardless of any other frictions in the market that potentially could have hindered the extent of this debt relief.

In particular, exploiting variation in the timing of rate resets of ARMs during the aftermath of the recent crisis, Di Maggio and others (2017) find that a sizable decline in mortgage payments (up to 50 percent) induces a significant increase in car purchases (up to 35 percent) and a decline in mortgage defaults. Borrowers with lower incomes and less housing wealth have a significantly higher marginal propensity to consume. Areas with a larger share of ARMs were more responsive to lower interest rates and saw a relative decline in defaults and an increase in house prices, car purchases, and employment. Di Maggio and others' (2017) evidence, along with that of Fuster and Willen (2017), highlights the importance of contract rigiditythat is, rigid FRMs versus flexible contracts, such as ARMs-for understanding the pass-through of debt relief to the real economy during periods of low interest rates. ${ }^{5}$

The next friction that hampers debt relief relates to equity refinancing constraints - that is, the notion that the refinancing of mortgages may not be feasible because many distressed borrowers may not have enough equity to refinance. This friction is particularly important for FRMs, the predominant financial obligation of U.S. households. ${ }^{6}$ For such borrowers, automatic debt relief, such as that provided to ARM borrowers, is not feasible. Instead, refinancing constitutes one of the main direct channels through which households can get debt relief from the low-interest-rate environment induced by monetary policy.

Sumit Agarwal and others (2017b) study how this constraint hampered the effectiveness of debt relief by examining the effects of HARP — again, a government program that allowed for the refinancing of insufficiently collateralized agency mortgages with government credit guarantees. The authors find that relaxing the equity constraint for refinancing led more than 3 million borrowers to refinance their loans, and that they experienced more than $\$ 3,000$ in annual savings on average. Many of these borrowers subsequently increased their purchases of durable goods, such as automobiles,

5. This evidence is also consistent with Auclert (2017), who provides a model evaluating the role of redistribution in the transmission mechanism of monetary policy to consumption and predicts that if all U.S. mortgages had adjustable rates, the effect of monetary policy shocks on consumer spending would be significantly higher.

6. See Green and Wachter (2005) for a discussion of the historical evolution of U.S. mortgage contracts. 
with larger effects among more indebted borrowers. A life cycle model of refinancing quantitatively rationalizes these patterns and produces significant welfare gains for borrowers from relaxing the housing equity eligibility constraint during a crisis. ${ }^{7}$ There is, again, spatial heterogeneity in the effects. Regions more exposed to the program — based on the percentage of eligible borrowers in the region-saw a relative increase in consumer spending, a decline in foreclosure rates, and a faster recovery in house prices. This evidence is also consistent with the work of Beraja and others (2017), who document that before HARP, low interest rates mainly benefited borrowers in regions with relatively high housing equity, exacerbating regional economic inequality (see also Di Maggio, Kermani, and Palmer 2016).

Agarwal and others (2017a) also illustrate that a lack of competition in the refinancing market blunted the extent of pass-through to borrowers, lowering their incentives to refinance. These frictions reduced the take-up rate among eligible borrowers by 10 to 20 percent and cost borrowers who refinanced their loans between $\$ 400$ and $\$ 800$ in annual savings from relief. Strikingly, the largest effects were among the most indebted borrowersthe primary target of HARP - where competitive frictions had the most bite. As before, there was spatial variation in these effects, depending on the degree of competitiveness in the refinancing market. These findings resonate well with those of David Scharfstein and Adi Sunderam (2016) and also with those of Itamar Drechsler, Alexi Savov, and Philipp Schnabl (2017) — who show that the extent of the pass-through of low interest rates in the refinancing and bank deposit market is affected by the degree of competition. They are also broadly connected with the findings of Agarwal and others (2018) — and of Efraim Benmelech, Ralf Meisenzahl, and Rodney Ramcharan (2017) — who demonstrate the importance of financial intermediaries for the pass-through of interest rate shocks in the credit card and auto loan markets.

Directly restructuring borrower debt through loan renegotiation is another feasible channel for offering debt relief. Despite the surge in distressed borrowers, the U.S. economy experienced limited loan restructuring activity early in the crisis, significantly exacerbating the high number of foreclosures. Research attributes this limited restructuring activity to institutional frictions due to securitization, which prevented renegotiation (Piskorski, Seru, and Vig 2010; Agarwal and others 2011; Kruger,

7. For recent quantitative models emphasizing the importance of refinancing for household consumption, see, among others, Chen, Michaux, and Roussanov (2013); Wong (2018); Greenwald (2018); Beraja and others (2017); and Guren, Krishnamurthy, and McQuade (2017). 
forthcoming; Maturana 2017) and to lender concerns about strategic defaults, an inability to evaluate the repayment ability of borrowers, and concerns about the adverse impact of wide-scale renegotiations on future repayment incentives (Mayer and others 2014; Adelino, Gerardi, and Willen 2014). Motivated by such frictions and perceived negative externalities of debt overhang and foreclosures (Campbell, Giglio, and Pathak 2011; Melzer 2017), the federal government implemented HAMP. In brief, the program provided substantial financial incentives to financial intermediaries (servicers) for renegotiating loans.

Agarwal and others (2017a) study the effects of this program and find that, when employed, the debt relief due to these renegotiations led to a lower rate of delinquencies and foreclosures for borrowers and higher consumer spending and house prices in more exposed regions. Peter Ganong and Pascal Noel (2017) further show that temporary mortgage interest rate reductions induced by HAMP played the major role in explaining these effects. Of particular importance, Agarwal and others (2017a) show that the program reached just one-third of the eligible 3 to 4 million indebted households and that there is large heterogeneity across the financial intermediaries in the implementation of debt relief. These differences strongly correlate with banks' organizational design before the program was introduced: Banks that previously had fewer loans per employee, more training for staff, and shorter waiting times for telephone calls took more advantage of HAMP. Because about 75 percent of loans were serviced by banks with a low capability to restructure loans, the program's impact was severely curtailed. Finally, as before, there was significant spatial variation in the implementation of debt relief that relates to the regional share of loans handled by banks with more conducive organization design. These findings also resonate well with those of Fuster and others (2013) and Fuster, Stephanie Lo, and Willen (2017), who argue that intermediary capacity constraints had an impact on the extent of the pass-through of debt relief through lower interest rates in the refinancing market. ${ }^{8}$

To summarize, a large body of literature shows that several frictions, each in part, might have prevented debt relief from reaching distressed households, thereby significantly exacerbating the foreclosure crisis. These frictions pertain to both the rigid nature of mortgage designs and to various frictions in the implementation of debt relief policies, including

8. We note that the demand-driven factors, such as borrower inertia and inattention, can also limit the extent of interest rate pass-through through mortgage refinancing. For recent evidence on these factors, see Keys, Pope, and Pope (2016); and Andersen and others (2014). 
intermediary constraints. Moreover, there is significant regional variation in how much debt relief was passed through to borrowers. We next turn to explaining the key forces that should drive such policies in order to make them more effective. We use insights from the theoretical literature on mortgage design and build a simple illustrative framework.

\section{The Mortgage Design Literature and a Simple Framework}

A key lesson of the research discussed so far is that the rigidity of mortgage contract terms, along with a variety of other frictions, prevented effective renegotiation or refinancing of distressed borrowers' loans during the recent crisis. Consequently, there is an ongoing debate regarding the reform of the mortgage market to alleviate the impact of such frictions in the future. At the center of this debate are a variety of proposals concerning the redesign of mortgage contracts and debt relief policies that would allow for a more efficient sharing of risk between borrowers and lenders. The hope is that the new mechanisms will lower the incidence of costly foreclosures and the severity of future housing market downturns (Shiller 2008; Caplin and others 2008; Piskorski and Tchistyi 2011; Campbell 2013; Keys and others 2013; Mian and Sufi 2014a; Eberly and Krishnamurthy 2014). There are also lessons related to the design and implementation of debt relief policies that require the intermediary sector for implementation. We now discuss implications that emerge from this literature and then use these insights to develop a framework that allows us to highlight the benefits of the automatically indexed mortgage contracts or debt relief policies relative to simple FRMs.

\section{II.A. Implications of the Mortgage Design Literature}

The debate on the first issue is informed by the growing body of literature that addresses the questions of mortgage contract design and mortgage choice, and their implications for the broader economy. In particular, Tomasz Piskorski and Alexei Tchistyi $(2010,2011)$ characterize optimal long-term mortgage contracts for borrowers with risky and hard-to-verify incomes in settings with costly foreclosure and stochastic interest rates, house prices, and employment. They show that efficient contracts should generally depend on house price and income indexes in a manner that reduces debt payments during economic downturns. ${ }^{9}$ This can be done in a

9. Such state-contingent contracts could be accompanied by refinancing penalties to enhance longer-term risk-sharing between borrowers and lenders; for analyses of the benefits of such solutions, see Dunn and Spatt (1985) and Mayer, Piskorski, and Tchistyi (2013). 
way that does not erode borrowers' incentives to repay their debts. Piskorski and Tchistyi (2010) show that when interest rate indexes are a good measure of a relevant risk ("state of the economy"), the optimal contract takes the form of an ARM, whereby the borrower can decide how much to pay until his or her balance reaches a certain limit (the so-called option ARM). ${ }^{10}$ They also show that such solutions benefit most the borrowers who can afford only a small down payment and face substantial income risk.

These findings underscore the importance of recognizing the interplay between mortgage contracts and the nature of labor income, house prices, and interest rate risk. In this regard, they are related to the research using quantitative life cycle models of mortgage contract choice, such as that by John Campbell and João Cocco (2003, 2015), which study the implications of such factors for contract choice, consumer welfare, and default patterns.

A number of recent papers extend this literature by studying the implications of state-contingent mortgage contracts in general equilibrium frameworks. Piskorski and Tchistyi (2017) develop a tractable general equilibrium framework of the housing and mortgage markets with aggregate and idiosyncratic risks, costly liquidity and strategic defaults, empirically relevant informational asymmetries, and an endogenous mortgage design. They focus on the designs that could be sustained in a competitive market equilibrium. They show that though, in general, one would like to index mortgage payments to both labor and housing market conditions, the empirically relevant frictions-including the possibility of strategic defaults discussed in section I-may result in equilibrium contracts that only tie mortgage payments to house prices. ${ }^{11}$ The adoption of such home equity insurance mortgages would require timely and accurate regional house price indexes. Alternatively, appropriately structured ARM contracts may preserve the benefits of such solutions as long as the interest rate indexes closely co-move with home prices and borrowers' income. Piskorski and Tchistyi (2017) also show that unrestricted competition in mortgage design may lead to the nonexistence of equilibrium in some cases, suggesting a

10. The option to pay less than the minimum monthly interest owed on the loan is valuable for borrowers with fluctuating incomes and provides them effectively with an embedded credit line feature. The fact that the loan is an ARM is valuable, because it reduces the chance of foreclosures when it is relatively more costly (for example, during recessions when interest rates and returns to capital are low).

11. Piskorski and Tchistyi (2017) show that, though beneficial for most borrowers, there are cases when such contracts may decrease the homeownership rate and the welfare of marginal homebuyers. 
potential role for public policy in implementing new mortgage designs (for example, through subsidies from the government-sponsored enterprises). We come back to this issue in section IV.

The work discussed above is complemented by recent studies of mortgage contracts in quantitative dynamic equilibrium models of housing markets. ${ }^{12}$ In particular, Guren, Krishnamurthy, and McQuade (2017) use a quantitative equilibrium life cycle model with aggregate shocks, longterm mortgages, and an equilibrium housing market, focusing on mortgage designs that index payments to interest rates. They find that the welfare benefits are quantitatively substantial; ARMs improve household welfare relative to FRMs by the equivalent of 1 percent of annual consumption if the central bank lowers interest rates during a bust. Their findings are consistent with research by Di Maggio and others (2017) and Fuster and Willen (2017), who show that mortgage interest rate declines during the Great Recession due to ARM contracts resetting to a low rate had a positive impact on borrowers and regions exposed to such reductions. Guren, Krishnamurthy, and McQuade (2017) find that an FRM that is convertible to an ARM, a contract similar to the one proposed by Janice Eberly and Arvind Krishnamurthy (2014), may perform better than more standard contracts. However, they also point out that an endogenous response by households to such designs can significantly reduce their benefits.

Daniel Greenwald, Tim Landvoigt, and Stijn Van Nieuwerburgh (2018) study the implications of shared appreciation mortgages that feature mortgage payments that adjust with house prices in a quantitative general equilibrium model with financial intermediaries. They show that if financial intermediaries retain a significant share of mortgages on their balance sheets, the indexation of mortgage payments to aggregate house prices may increase financial fragility, reduce risk-sharing, and lead to expensive financial sector bailouts. In contrast, the indexation to local house prices can reduce financial fragility and improve risk-sharing. The two types of indexation have opposite implications for wealth inequality.

Taken together, a number of key lessons can be derived from this literature. In general, contracts or policies that temporarily reduce mortgage payments during recessions can potentially result in significant welfare gains. To the extent possible, it would be beneficial to index mortgage

12. This line of work is also related to Kung (2015), who explores a number of counterfactuals related to credit availability and mortgage contract forms in a quantitative equilibrium model of the housing market. 
payments to measures capturing the state of the local labor and housing markets, with mortgage payments being lower in states when these markets experience a downturn. Such indexation programs need to take into account their impact on the market equilibrium, including the incentives of households to borrow and repay their debt. In addition, empirically relevant informational asymmetries and other frictions may limit the set of contracts that are sustainable in equilibrium. Risk aversion and other constraints may also limit the ability of financial intermediaries to insure against the aggregate risk, limiting the effectiveness of state-contingent mortgages or debt relief policies. Finally, contracts or policies based on indexes not directly tied to the housing or labor markets (for example, interest rate indexation, in the case of ARMs) may perform quite well in providing debt relief during downturns, as long as such indexes closely co-move with home prices and borrowers' incomes.

This discussion implies that one of the fundamental requirements for the successful implementation of new mortgage designs or debt relief policies is a thorough understanding of the underlying structure of the economic risk faced by borrowers. Moreover, one needs to understand how the relevant risk relates to a variety of possible indexes that can be used in the design of mortgage contracts or debt relief policies in practice. In the next subsection, we illustrate the importance of these factors in a simple, stylized, illustrative framework. In section III, we then provide empirical evidence on these issues as they relate to the actual design of mortgage contracts and debt relief.

\section{II.B. A Simple Illustrative Framework}

THE SETUP We now discuss a simple illustrative framework that draws on insights from the literature we discussed above and will allow us to highlight the benefits of the automatically indexed mortgage contracts or debt relief policies relative to simple FRMs. The key benefit of the indexed mortgage contracts in our setting is that they can reduce the incidence of costly foreclosures due to their state-contingent repayment rates without eroding lenders' ability to break even on their loans. We use this framework to explore two issues. First, we illustrate, through a few numerical examples, how the benefits of such indexed contracts or policies relate to the type of index used by lenders or policymakers and its relation to the underlying structure of economic risk. Second, we investigate how the benefits of such solutions change if there are errors in understanding the underlying structure of income and housing risk and their relation to the indexes 
on which such contracts or policies are based. Although our framework has a number of important limitations, we believe that the key insights we develop here will also be applicable in much richer settings. ${ }^{13}$

We consider a simple, stylized, partial equilibrium mortgage lending framework, where a risk-neutral borrower with linear utility buys a home worth $P_{0}$ by borrowing $P_{0}-D$ from a risk-neutral lender; hence, the down payment is $D$. If $D=0$, then the borrower pays zero down payment. The borrower can down-pay $D$ equal to his or her initial personal wealth, $W_{0}$, upon buying the house. For simplicity, we normalize the discount factor and risk-free rate to be 1 . We first consider an FRM, the most commonly used residential mortgage contract in the United States. Under the terms of an FRM, the borrower faces a fixed mortgage interest rate of $\bar{r}$.

The borrower derives utility of $\theta$ from living in the home. During the next period, after the loan is made, the borrower realizes his or her income $y$ drawn from a normal distribution $f^{y}$, with $y \sim N\left(\bar{y}, \sigma_{y}^{2}\right)$. Furthermore, he or she sees the updated home price $P_{1}$ drawn from a normal distribution $f^{P}$, with $P_{1} \sim N\left(\bar{P}, \sigma_{P}^{2}\right)$. If the borrower sells his or her home at $P_{1}$ or defaults, he or she loses $\theta$ of utility. If the borrower defaults, the lender receives only $\delta \in(0,1)$ of $P_{1}$, where $\delta$ captures some liquidation costs and the borrower suffers a utility cost of $\bar{v}$. We further assume that $\theta+\bar{v}>(1+\bar{r}) P_{0}$, implying that the borrower has an incentive to repay his or her debt. Given this setting, the borrower's optimal strategy can be described as follows:

-If realized income is such that $y<(1+\bar{r})\left(P_{0}-D\right)$, and the realized house price is such that $P_{1}<(1+\bar{r})\left(P_{0}-D\right)$, then the borrower has no choice but to default. His or her realized lifetime utility will be $u\left(y, P_{1}\right)=$ $y-\bar{v}-D$.

-If realized $y<(1+\bar{r})\left(P_{0}-D\right)$ and $P_{1} \geq(1+\bar{r})\left(P_{0}-D\right)$, then the borrower cannot repay the loan but can sell the home. His or her realized lifetime utility will be $u\left(y, P_{1}\right)=y+P_{1}-(1+\bar{r})\left(P_{0}-D\right)-D$.

13. Notably, among others, (i) we restrict the contract choice to a simple linear rule as a function of a given index; (ii) we only focus on liquidity-driven defaults, neglecting strategic defaults that also accounted for a substantial amount of defaults during the Great Recession; (iii) we do not incorporate empirically relevant informational asymmetries between borrowers and lenders; (iv) we do not model the long-term aspect of mortgage contracts and the possibility of loan refinancing; (v) we do not analyze the impact of borrower and lender risk aversion on consumer welfare and mortgage terms; (vi) we do not take into account general equilibrium effects of changes in contract terms, including the impact of indexation on house prices; and (vii) we set aside the question of what mortgage contracts would be sustainable in the competitive market equilibrium with relevant frictions and whether there is a scope of welfare-improving public policy intervention in such settings. The literature discussed in subsection II.A addresses mortgage contract design and its implications, capturing many such factors and complications. 
-If realized $y \geq(1+\bar{r})\left(P_{0}-D\right)$ and $\theta \geq P_{1}$, then the borrower repays the loan without selling the house. His or her realized lifetime utility will be $u\left(y, P_{1}\right)=y+\theta-(1+\bar{r})\left(P_{0}-D\right)-D$.

-If realized $y \geq(1+\bar{r})\left(P_{0}-D\right)$ and $\theta<P_{1}$, then the borrower sells the home, and his or her realized lifetime utility will be $u\left(y, P_{1}\right)=y+P_{1}-$ $(1+\bar{r})\left(P_{0}-D\right)-D$.

We note that a default occurs if both house prices and income are sufficiently low, consistent with the "double trigger" notion in the literature (Foote, Gerardi, and Willen 2008). The competitive FRM mortgage interest rate will be the lowest $\bar{r}$-because the lower is $\bar{r}$, the higher is the borrower's utility — such that the lender breaks even.

Formally, we formulate this problem as follows. First, we define the distribution of income and house prices as follows:

$$
X=\left[\begin{array}{l}
y \\
P_{1}
\end{array}\right], \mu=\left[\begin{array}{l}
\bar{y} \\
\bar{P}
\end{array}\right], \Sigma=\left[\begin{array}{cc}
\sigma_{y}^{2} & \rho_{y P} \sigma_{y} \sigma_{P} \\
\rho_{y P} \sigma_{y} \sigma_{P} & \sigma_{P}^{2}
\end{array}\right] \text {, and } X \sim N(\mu, \Sigma) \text {. }
$$

Given the above discussion, under the FRM contract, the consumer's expected utility maximization problem, subject to the lender's break-even condition, can be formulated as a function of defaulting, selling, and paying states:

$$
\begin{gathered}
\max _{\bar{r}} \operatorname{Pr}_{\text {def }} \times E(y-\bar{v} \mid \text { def })+\operatorname{Pr}_{\text {sel }} \times E\left[y+P_{1}-(1+\bar{r})\left(P_{0}-D\right) \mid \text { sel }\right] \\
+\operatorname{Pr}_{\text {pay }} \times E\left[y+\theta-(1+\bar{r})\left(P_{0}-D\right) \mid \text { pay }\right]-D \\
\text { s.t. } P_{0}-D=\operatorname{Pr}_{\text {def }} \times E\left(\delta P_{1} \mid \text { def }\right)+\operatorname{Pr}_{\text {sel }} \times(1+\bar{r})\left(P_{0}-D\right) \\
+\operatorname{Pr}_{\text {pay }} \times(1+\bar{r})\left(P_{0}-D\right),
\end{gathered}
$$

where we define the probabilities given above as follows:

$$
\begin{aligned}
\operatorname{Pr}_{\text {def }}= & \operatorname{Pr}\left[y<(1+\bar{r})\left(P_{0}-D\right), P_{1}<(1+\bar{r})\left(P_{0}-D\right)\right], \\
\operatorname{Pr}_{\text {sel }}= & \operatorname{Pr}\left[y<(1+\bar{r})\left(P_{0}-D\right), P_{1} \geq(1+\bar{r})\left(P_{0}-D\right)\right] \\
& +\operatorname{Pr}\left[y \geq(1+\bar{r})\left(P_{0}-D\right), \theta<P_{1}\right], \\
& \operatorname{Pr}_{\text {pay }}=\operatorname{Pr}\left[y \geq(1+\bar{r})\left(P_{0}-D\right), \theta \geq P_{1}\right] .
\end{aligned}
$$


In the calculations given above, we assume that the borrower uses all his or her initial wealth for a down payment. It is worth noting that in our simple, stylized setting, the borrower will generally have an incentive to down-pay as much as possible because this reduces the expected mortgage cost, which is weakly higher than the riskless saving rate. In a later discussion, we focus on two particular cases: (i) a zero down payment $(D=0)$; and (ii) a 20 percent down payment $\left(D=0.2 P_{0}\right)$. The former case is meant to represent highly indebted borrowers with very little initial housing equity, and the latter represents more creditworthy prime borrowers who can afford a substantial down payment.

We next consider an indexed-rate mortgage (IRM) contract of the form $r=\alpha_{0}+\alpha_{1} i$, where $i$ is an index drawn from a standard normal distribution $f^{i}$, with $i \sim N(0,1)$. Hence, $r \sim N\left(\alpha_{0}, \alpha_{1}^{2}\right)$, and the overall distribution of stochastic variables is defined as follows:

$$
X=\left[\begin{array}{l}
y \\
P_{1} \\
r
\end{array}\right], \mu=\left[\begin{array}{l}
\bar{y} \\
\bar{P} \\
\alpha_{0}
\end{array}\right], \Sigma=\left[\begin{array}{ccc}
\sigma_{y}^{2} & \rho_{y P} \sigma_{y} \sigma_{P} & \rho_{y i} \sigma_{y} \alpha_{1} \\
\rho_{y P} \sigma_{y} \sigma_{P} & \sigma_{p}^{2} & \rho_{P i} \sigma_{P} \alpha_{1} \\
\rho_{y i} \sigma_{y} \alpha_{1} & \rho_{P i} \sigma_{P} \alpha_{1} & \alpha_{1}^{2}
\end{array}\right] \text {, and } X \sim N(\mu, \Sigma) \text {. }
$$

We note that the borrower's optimal behavior and lifetime realized utility are the same as described above for the FRM contract, except replacing $\bar{r}$ with the realization of $r \sim N\left(\alpha_{0}, \alpha_{1}^{2}\right)$.

In offering this contract, lenders optimally choose the parameters $\alpha_{0}$ and $\alpha_{1}$, while taking the distribution of the index as given. For example, we could think of an ARM contract as a special case of an IRM contract, where the index $i$ is just some spread over realization of the interest rate index (for example, that of 1-year Treasuries or the London Interbank Offered Rate). We could also think of the IRM as representing a state-contingent debt relief policy that depends on the policy index $i$ coupled with simpler contracts (for example, an FRM). ${ }^{14}$

We further assume that the introduction of IRM contracts may be subject to a certain up-front fixed cost $c$ per borrower that is faced by lenders relative to a setting with FRM contracts. This cost represents some additional unmodeled cost of issuing more complex contracts or implementing a debt relief policy - such as the potential costs of educating borrowers,

14. Implementation of such a debt relief policy with simpler contracts may require an ex ante commitment from policymakers, lenders, and borrowers. 
costs of unmodeled uncertainty about the actual distribution of the index, some additional hedging costs for the lender, or some administrative costs of implementing a debt relief policy.

Given the above-noted setup under any particular correlation schedule $\rho_{y p}, \rho_{y i}$, and $\rho_{P i}$, the competitive equilibrium IRM contract maximizes the consumer's expected utility across the three states, subject to lender breakeven condition:

$$
\begin{gathered}
\max _{\alpha_{0}, \alpha_{1}} \operatorname{Pr}_{\text {def }} \times E(y-\bar{v} \mid \text { def })+\operatorname{Pr}_{\text {sel }} \times E\left[y+P_{1}-(1+r)\left(P_{0}-D\right) \mid \text { sel }\right] \\
+\operatorname{Pr}_{\text {pay }} \times E\left[y+\theta-(1+r)\left(P_{0}-D\right) \mid \text { pay }\right]-D \\
\text { s.t. } P_{0}-D=\operatorname{Pr}_{\text {def }} \times E\left(\delta P_{1} \mid \text { def }\right)+\operatorname{Pr}_{\text {sel }} \times E\left[(1+r)\left(P_{0}-D\right) \mid \text { sel }\right] \\
\quad+\operatorname{Pr}_{\text {pay }} \times E\left[(1+r)\left(P_{0}-D\right) \mid \text { pay }\right]-c
\end{gathered}
$$

where

$$
\begin{gathered}
\operatorname{Pr}_{\text {def }}=\operatorname{Pr}\left[y<(1+r)\left(P_{0}-D\right), P_{1}<(1+r)\left(P_{0}-D\right)\right], \\
\operatorname{Pr}_{\mathrm{sel}}=\operatorname{Pr}\left[y<(1+r)\left(P_{0}-D\right), P_{1} \geq(1+r)\left(P_{0}-D\right)\right] \\
+\operatorname{Pr}\left[y \geq(1+r)\left(P_{0}-D\right), \theta<P_{1}\right], \\
\operatorname{Pr}_{\mathrm{pay}}=\operatorname{Pr}\left[y \geq(1+r)\left(P_{0}-D\right), \theta \geq P_{1}\right], \\
r=\alpha_{0}+\alpha_{1} i .
\end{gathered}
$$

This problem has no closed-form solution, so to gain insights, we focus on numerical solutions for a set of parameters given in table 1 . We note that the main insights from our illustrative framework are valid across a wide range of parameters.

It is worth noting, as will become clear shortly, that if the additional cost of issuing IRM contracts is equal to zero, the IRM loans will always be weakly better for borrowers than the FRMs. The reason is that the IRM contracts nest the FRM ones. As we illustrate below, with the positive fixed cost of issuing a more complex mortgage, whether such a mortgage will be better than an FRM depends on how closely $i, y$, and $P_{1}$ co-move with each other. 
Table 1. Base Parameter Values for the Simple Framework

\begin{tabular}{llc}
\hline Parameter & Definition & Value \\
\hline$y$ & Income average & 200 \\
$\sigma_{\mathrm{y}}$ & Income standard deviation & 70 \\
$P_{1}$ & House price average & 150 \\
$\sigma_{P}$ & House price standard deviation & 50 \\
$\delta$ & Recovery rate when in default & 0.7 \\
$P_{0}$ & Initial house price & 100 \\
$\bar{v}$ & Loss of utility when in default & 50 \\
$\theta$ & Utility of living in a house & 200 \\
$c$ & Fixed cost of indexed mortgage contract & 0 or $0.01 P_{0}$ \\
$D$ & Down payment of house & 0 or $0.20 P_{0}$ \\
\hline
\end{tabular}

BENEFITS OF MORTGAGE DEBT INDEXATION First, let us consider the case of no-fixed-cost index mortgages compared with FRMs. We start by showing the borrower's utility gain (in percentage terms) under an IRM compared with an FRM, assuming that $(P, y)$ are perfectly correlated. The top panel of figure 1 plots this result: On the horizontal axis, we have varying degrees of correlation between $i$ with $y$. Because $y$ and $P$ are perfectly correlated, this is also the correlation between $i$ and $P$.

The top panel of figure 1 shows an important feature of our setting: An IRM without a fixed issuing cost would never do worse than an FRM, provided that the lenders correctly assess the distribution of the underlying risk. The reason is that by optimally choosing $r=\alpha_{0}+\alpha_{1} i$ in the contract, one can always reduce $\alpha_{1}$ to zero when the index correlation with $y$ or $P$ is approaching zero. In this sense, the FRM would simply be a special case of an IRM. As soon as the index correlation with $y$ or $P$ turns positive, there is always some benefit from reducing the default probability. Hence, the optimal contract would also have $\alpha_{1}>0$, turning on the volatility of the index mortgage interest rate. Therefore, as is evident from figure 1, the benefit of an index mortgage contract for avoiding costly foreclosures generally is larger when the correlation between the index and income or the house price is higher. We also note that in a setting with borrower risk aversion, state-contingent lending contracts may provide additional benefits to households by partially insuring their labor income risk and hence allowing them to better smooth their consumption profiles. This additional benefit should increase the value of state-contingent contracts relative to FRMs.

In reality, house prices and household incomes are not perfectly correlated. To explain how our insights might change due to this, we next consider two cases: (i) $\operatorname{Corr}(y, P)=.25$ (low correlation); and (ii) $\operatorname{Corr}(y, P)=.75$ (high correlation). The results are shown in figure 2 . The following results 
Figure 1. Utility Gains from Mortgage Indexation under the Simple Framework: Perfectly Correlated Income and Housing Risk ${ }^{\mathrm{a}}$

\section{Without indexation cost}

Percentage gain in consumer welfare

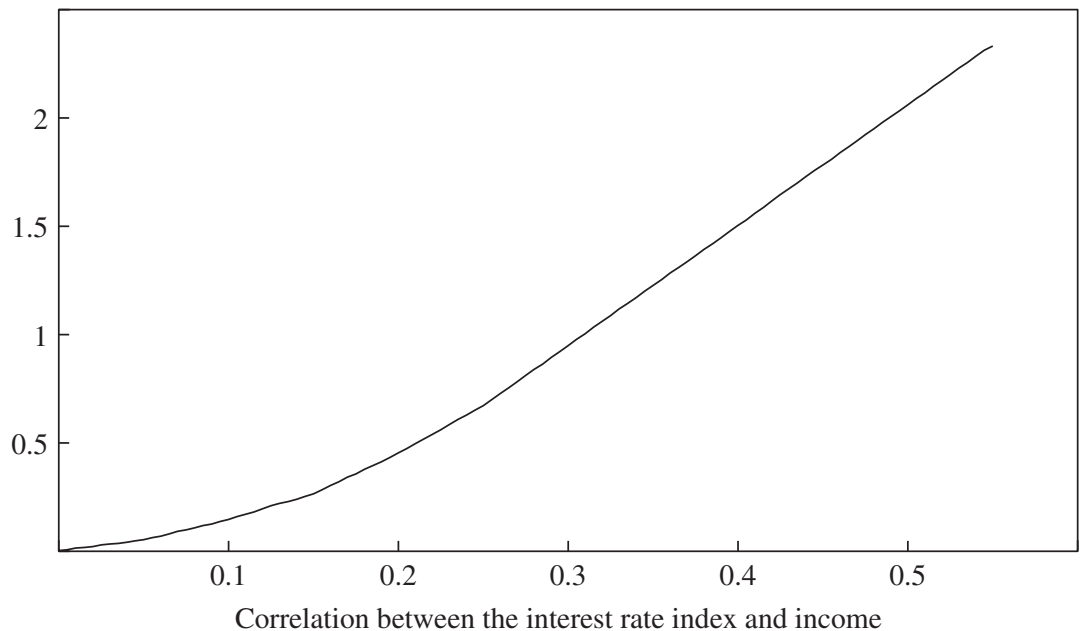

With indexation cost

Percentage gain in consumer welfare

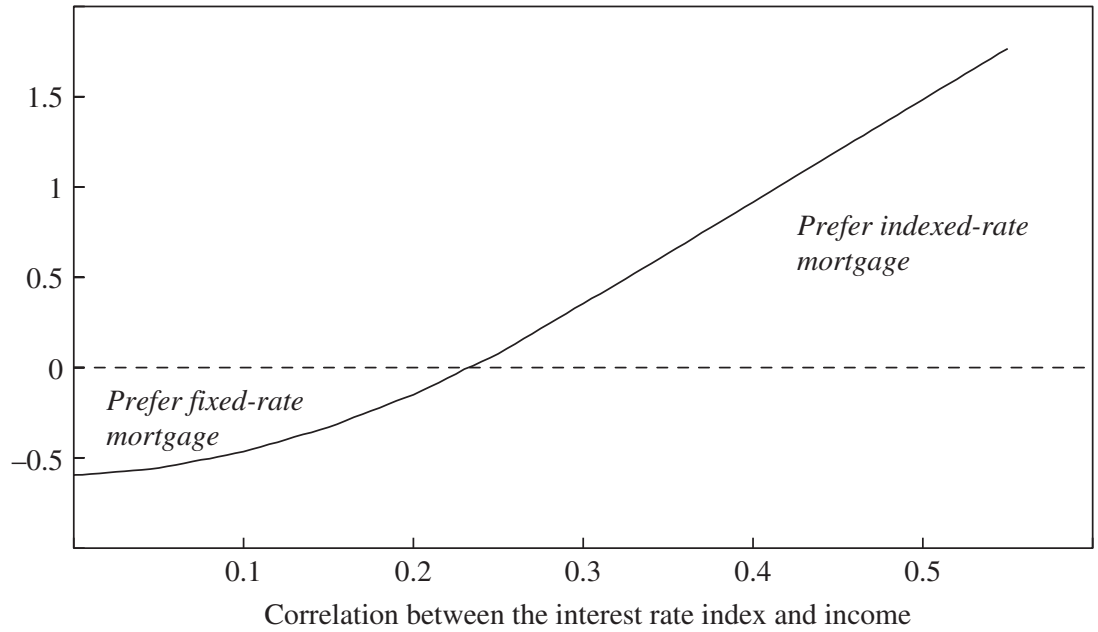

Source: Authors' calculations.

a. This figure assumes house price shocks and income shocks are perfectly correlated. The base parameters are from table 1. 
Figure 2. Utility Gains from Mortgage Indexation under the Simple Framework: No Indexation Cost and Imperfectly Correlated Income and Housing Risk ${ }^{\mathrm{a}}$

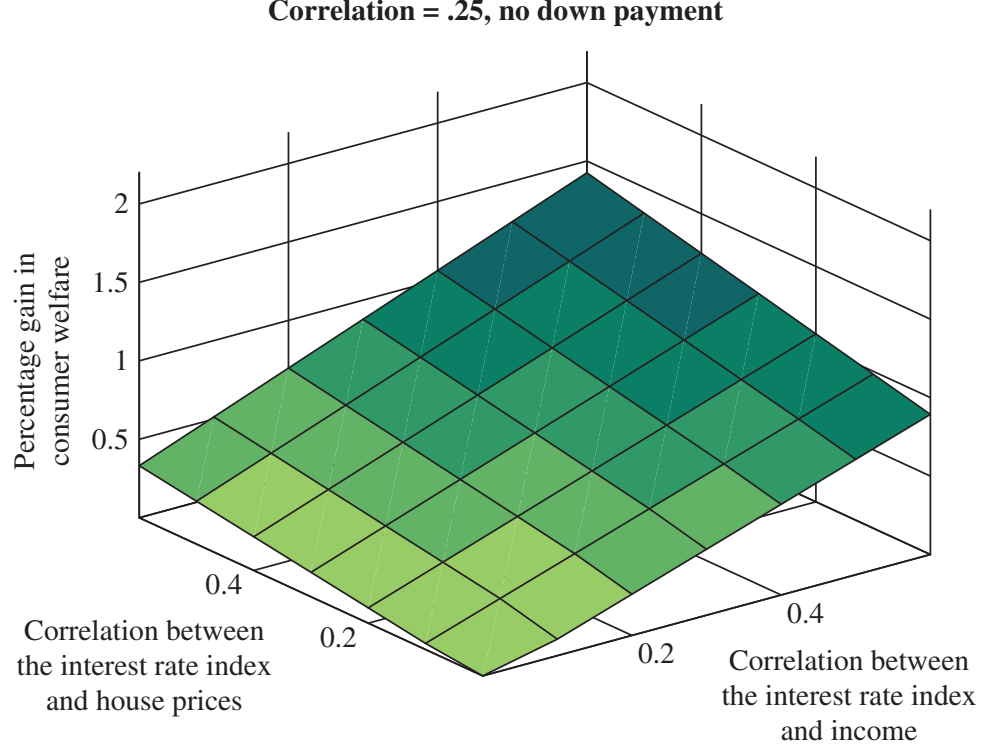

Correlation $=.25,20$ percent down payment

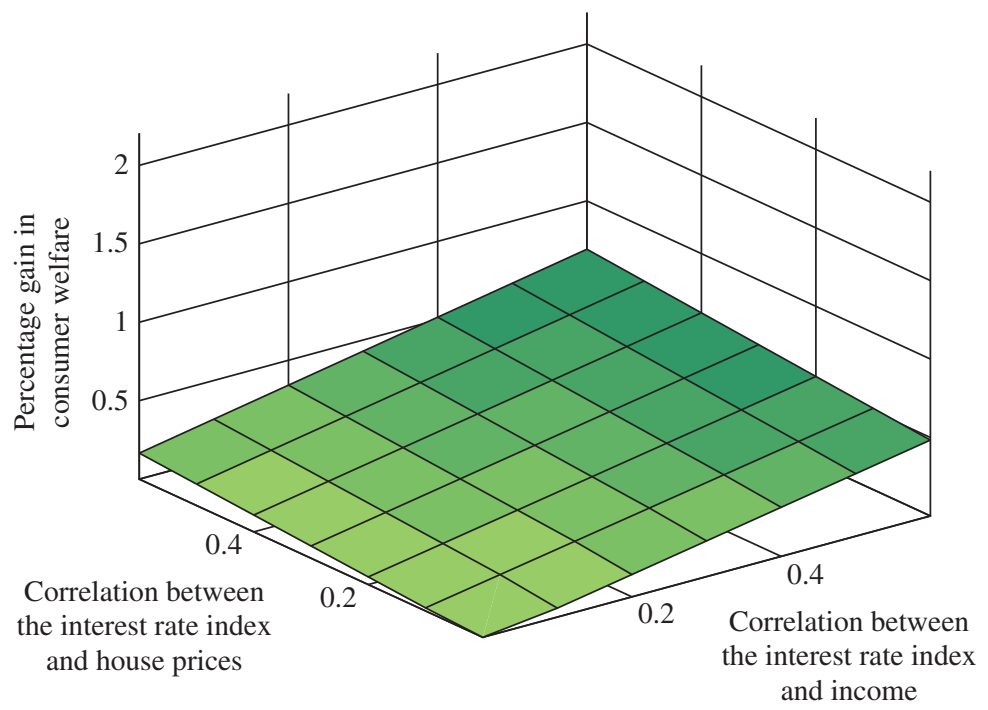


Figure 2. Utility Gains from Mortgage Indexation under the Simple Framework: No Indexation Cost and Imperfectly Correlated Income and Housing Risk ${ }^{\mathrm{a}}$ (Continued)
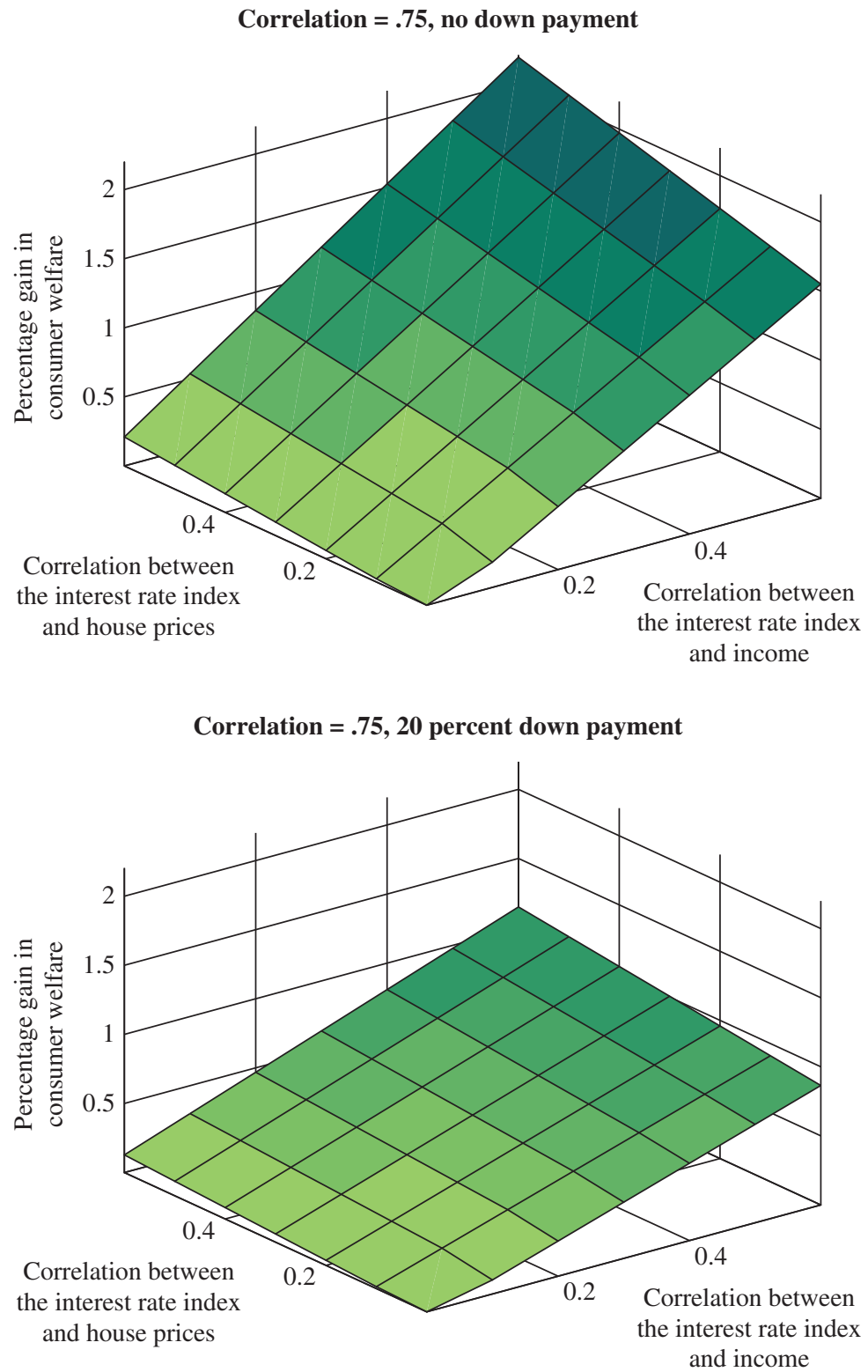

Source: Authors' calculations.

a. This figure shows the borrower's utility gain under an indexed-rate mortgage versus a fixed-rate mortgage. The top two panels assume a correlation of .25 between house price shocks and income shocks. The bottom two panels assume a correlation of .75 between house price shocks and income shocks. All panels assume no indexation cost. The base parameters are from table 1. 
emerge: (i) An IRM is never worse than an FRM, because an FRM is a special case of the IRM contract when $\alpha_{1}=0$; (ii) generally, the higher are $\operatorname{Corr}(P, i)$ and $\operatorname{Corr}(y, i)$, the larger is the gain from an indexed loan relative to an FRM; and finally, (iii) the utility gains under IRMs are generally higher, given that $\operatorname{Corr}(P, y)$ is higher.

Next, we take into account the possibility of a down payment for a house purchase. As formulated in the model, we consider the case of a 20 percent down payment in both an FRM and IRM. Figure 2 shows the corresponding results. We see that for the case of a 20 percent down payment with significant positive home equity, the gain from indexed contracts is smaller. This is intuitive, because the down payment lowers the default probability and the associated deadweight losses from having a rigid contract.

Now we consider the case where issuing an IRM has a fixed cost for the lender-in particular, 1 percent of the initial house price. Again, we start by showing the utility gain (or loss) of an IRM compared with an FRM, assuming that house prices and incomes are perfectly correlated. The bottom panel of figure 1 shows these results. Compared with the top panel, the bottom panel shows that for our parameters with a fixed cost of issuing an indexed loan, there is a range of correlations where utility under the indexed loan is lower than under the FRM. In general, this plot indicates that with the additional cost of issuing an IRM loan, there may be a range of correlations where utility under the indexed loan may be lower than under the FRM.

To shed more light on this issue, figure 3 reproduces the analysis in figure 2, but with an additional cost of indexation equal to 1 percent of the initial house price per borrower. This figure consistently shows that an IRM contract is more likely to benefit consumers when the index correlation with income and house price is sufficiently high. When the index correlation with income and house price is not sufficient, there can be a utility loss compared with an FRM, due to the IRM's issuing cost.

Our simple framework shows that a successful implementation of indexed mortgages crucially relies on a correct understanding of the underlying structure of income and housing risk and its relation to the indexes on which such contracts or policies will be based. To illustrate this point, figure 4 shows the borrower's utility (in percentage terms) under an IRM designed for an incorrectly projected high correlation between income and house prices (equal to .75) and a high projected correlation between the index and income and house prices (equal to .60). These are compared with scenarios of indexed mortgages that are correctly designed knowing 
Figure 3. Utility Gains from Mortgage Indexation under the Simple Framework: Positive Indexation Cost and Imperfectly Correlated Income and Housing Risk ${ }^{\mathrm{a}}$
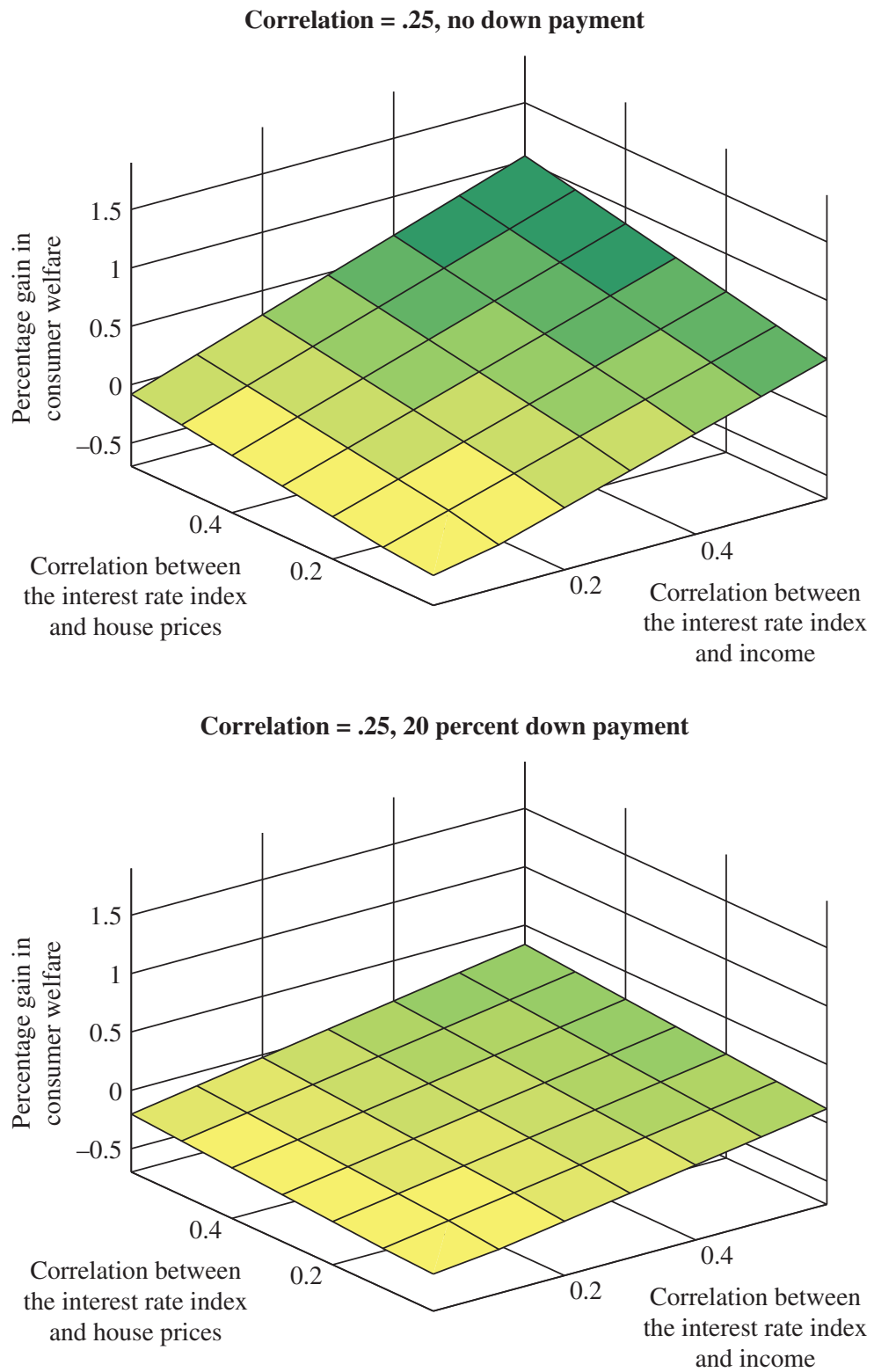

(continued on next page) 
Figure 3. Utility Gains from Mortgage Indexation under the Simple Framework: Positive Indexation Cost and Imperfectly Correlated Income and Housing Risk ${ }^{\mathrm{a}}$ (Continued)
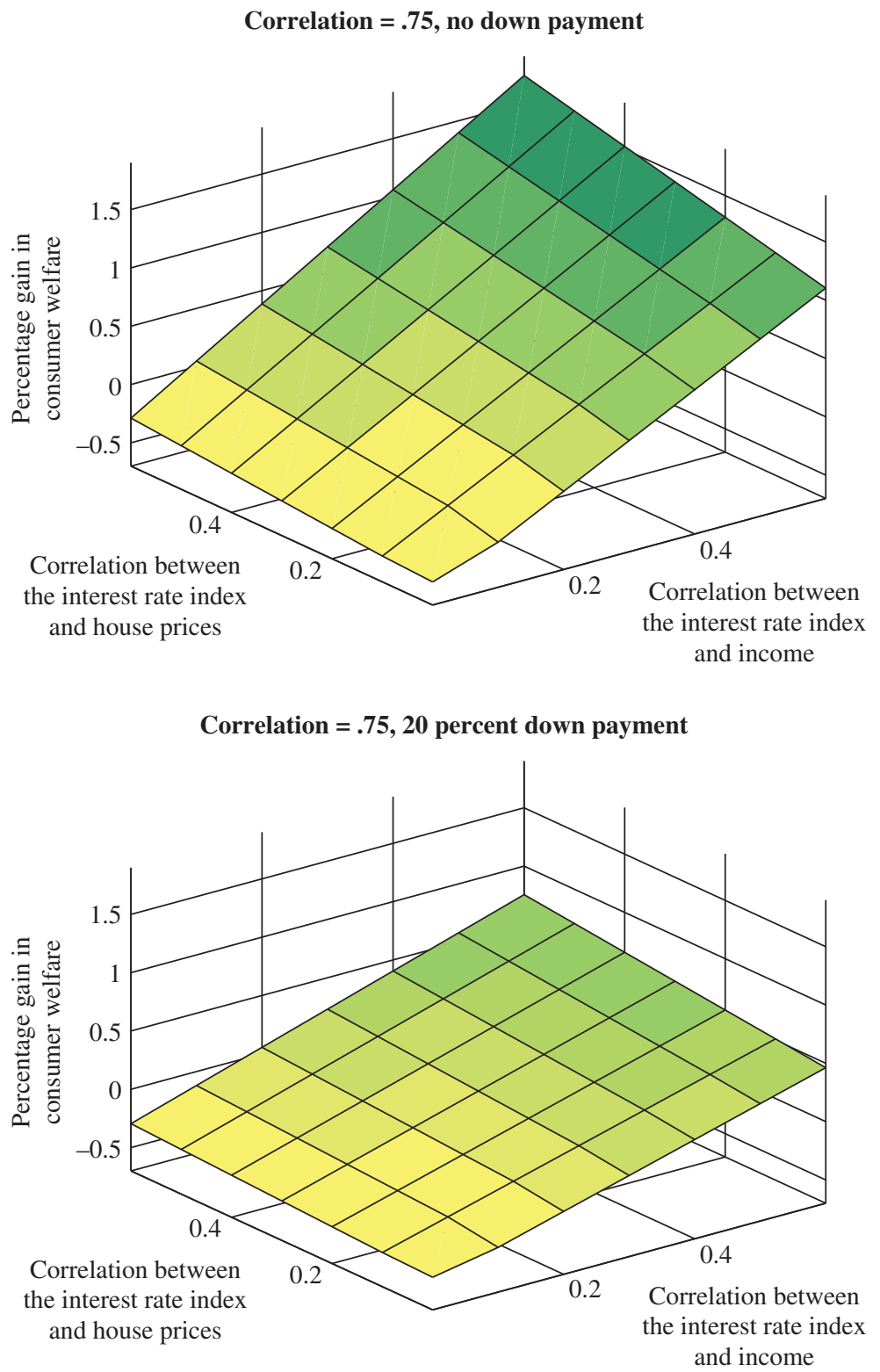

Source: Authors' calculations.

a. This figure shows the borrower's utility gain under an indexed-rate mortgage versus a fixed-rate mortgage. The top two panels assume a correlation of .25 between house price shocks and income shocks. The bottom two panels assume a correlation of .75 between house price shocks and income shocks. All panels assume positive indexation cost. The base parameters are from table 1 . 
Figure 4. The Effect of Incorrect Beliefs about the Distribution of Relevant Economic Risk under the Simple Framework

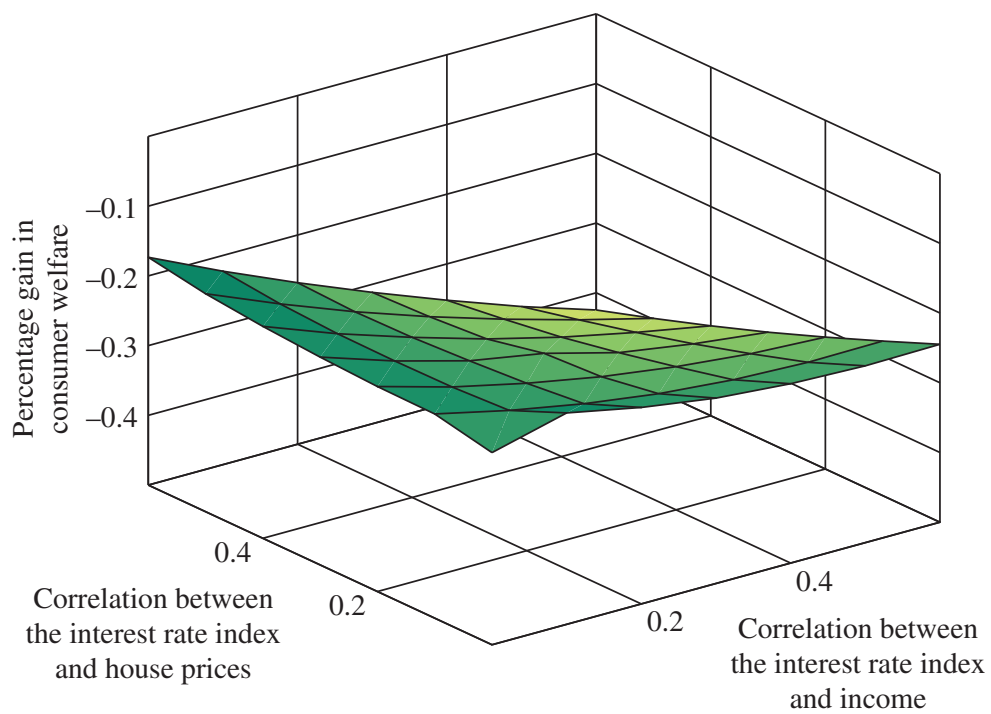

Source: Authors' calculations.

a. This figure shows the borrower's utility gain under an indexed-rate mortgage designed for incorrect beliefs about the distribution of relevant economic risk versus correct beliefs. Under the incorrect beliefs scenario, the borrower believes the correlation between income and house prices is high (.75), that the correlation between the interest rate index and income is high (.60), and that the correlation between the interest rate index and house prices is high (.60). In the correct beliefs scenario, the borrower believes that the correlation between income and house prices (.25), and the correlation between the interest rate index and income and house prices, are as shown in the figure. The figure assumes no indexation cost and no down payment. The base parameters are from table 1 .

that the actual correlation between income and house prices is low (equal to .25) and that the actual correlation between the index and income and house prices is as shown in figure 4. The computation assumes no down payment and no indexation cost. As we observe, incorrect beliefs about the distribution of key economic variables result in a substantial decline in efficiency relative to a contract designed under the correct distribution of economic variables. This is because there are instances when the borrower faces a substantial increase in the interest rate during periods of low income and house prices, which increases the risk of a costly foreclosure. We note that more elaborate indexation programs-such as an FRM with an option to be converted to an ARM, a contract proposed by Eberly and Krishnamurthy (2014)—could partly alleviate the impact of such ex ante design errors. 
Based on our numerical results, presented in figures 1 through 4 , we summarize the main insights of our simple framework:

-Without the additional cost of indexation, an IRM contract is always weakly better than an FRM contract.

- The higher the correlation between income and house prices with the index, the bigger the gain from an indexed loan relative to an FRM.

- The utility gains under an indexed loan or an indexed debt relief policy are generally higher when the correlation between house prices and income is higher.

-With the additional cost of issuing an indexed loan, there is a range of correlations where utility under the indexed loan is lower than under the FRM. Besides, it is possible that when the index is sufficiently correlated with income and house price, the indexed contract is better than the FRM.

- Gains from indexed contracts are much higher for borrowers who make only a small or no down payment (and thus have little housing equity).

-Benefits of indexed mortgages or debt relief policies crucially depend on a correct understanding of the underlying structure of income and housing risk and its relation to the indexes on which such contracts or policies will be based. In the case of incorrect beliefs about these relationships, the benefits of such solutions can decrease substantially.

Our simple framework highlights the importance of understanding the underlying structure of income and housing risk and its relation to the indexes on which contracts or debt relief policies will be based. More broadly, this includes an assessment of the expected degree of heterogeneity across regions and borrowers, the stability of such relations over time, and the relative value of policies based on national versus local indexes.

\section{Spatial and Individual Variation in Income and Housing Risk}

In this section, we analyze the structure of income and house price risk across regions and assess their relation to mortgage defaults and the home equity positions of borrowers. We also discuss how this risk relates to possible indexes that could be used in future mortgage contracts or debt relief policies.

\section{III.A. Evidence from the U.S. States}

To measure local economic conditions, we take a stance on variables that summarize business conditions. These variables include real GDP 
Table 2. National- and State-Level Economic Variables ${ }^{\mathrm{a}}$

\begin{tabular}{lcccr} 
Variable & Mean & $\begin{array}{c}\text { Standard } \\
\text { deviation }\end{array}$ & Minimum & Maximum \\
\hline National-level & & & & \\
Real GDP growth & 2.28 & 2.14 & -4.78 & 7.50 \\
Real income growth & 2.46 & 2.22 & -5.95 & 6.21 \\
Unemployment rate & 6.35 & 1.66 & 3.90 & 10.80 \\
Real house price growth & 0.97 & 5.46 & -11.97 & 9.96 \\
State-level & & & & \\
Real GDP growth & 2.25 & 3.69 & -27.49 & 31.12 \\
Real income growth & 2.43 & 2.95 & -14.77 & 20.25 \\
Unemployment rate & 6.02 & 2.13 & 2.20 & 18.30 \\
Housing price growth & 0.55 & 6.42 & -43.72 & 47.99 \\
\hline
\end{tabular}

Sources: U.S. Bureau of Economic Analysis; U.S. Bureau of Labor Statistics; Zillow; Freddie Mac; Standard \& Poor's; Federal Reserve Economic Data.

a. All values are expressed as percentages.

growth, personal income growth, unemployment, and house price growth. Real GDP growth measures the output of the economic area. Real personal income growth measures changes in the wealth of local consumers. Both GDP and income data are from the U.S. Bureau of Economic Analysis. We deflate using the CPI-U from FRED (a database maintained by the Federal Reserve Bank of Saint Louis). Because unemployment is a permanent loss to income, we include the local unemployment rate. Unemployment data are from the U.S Bureau of Labor Statistics. To measure expectations about future economic conditions, we use changes in the market value of real estate. When available, we use data from Zillow; otherwise, we use data from the Freddie Mac House Price Index. For national housing data, we use the S\&P/Case-Shiller U.S. National Home Price Index. Table 2 displays summary statistics for the national- and state-level economic series.

We assume that the local business cycle influences output, income, unemployment, and house prices. For each state, we extract this common component through a principal component analysis. The first component explains, on average, 60 percent of the variation in these four series. This component loads positively on output, income, and house prices, but negatively on unemployment. Table 3 displays the summary statistics for the weights of the first component and its explained variation. The large explained variation and loadings are consistent with a proxy for local economic conditions. Figure 5 plots its mean and the 10th-90th percentile range over time. Note that the economic factor declines sharply during the financial crisis of 2008, but dispersion remains rather stable. 
Table 3. Principal Component Analysis ${ }^{a}$

\begin{tabular}{lcccc} 
Weight & Mean & $\begin{array}{c}\text { Standard } \\
\text { deviation }\end{array}$ & Minimum & Maximum \\
\hline Real GDP growth & 56 & 4 & 46 & 69 \\
Real income growth & 53 & 5 & 45 & 73 \\
Unemployment rate & -44 & 8 & -54 & -1 \\
Real house price growth & 43 & 11 & -8 & 53 \\
Explained variation & 60 & 9 & 32 & 73 \\
\hline
\end{tabular}

Sources: U.S. Bureau of Economic Analysis; U.S. Bureau of Labor Statistics; Zillow; Freddie Mac; Standard \& Poor's; Federal Reserve Economic Data; authors' calculations.

a. The weights are the relative loadings on the first principal component. The analysis is at the state level. All values are expressed as percentages.

\section{Figure 5. Regional Heterogeneity and the Evolution of the State Economic Factor,} $1980-2016^{a}$

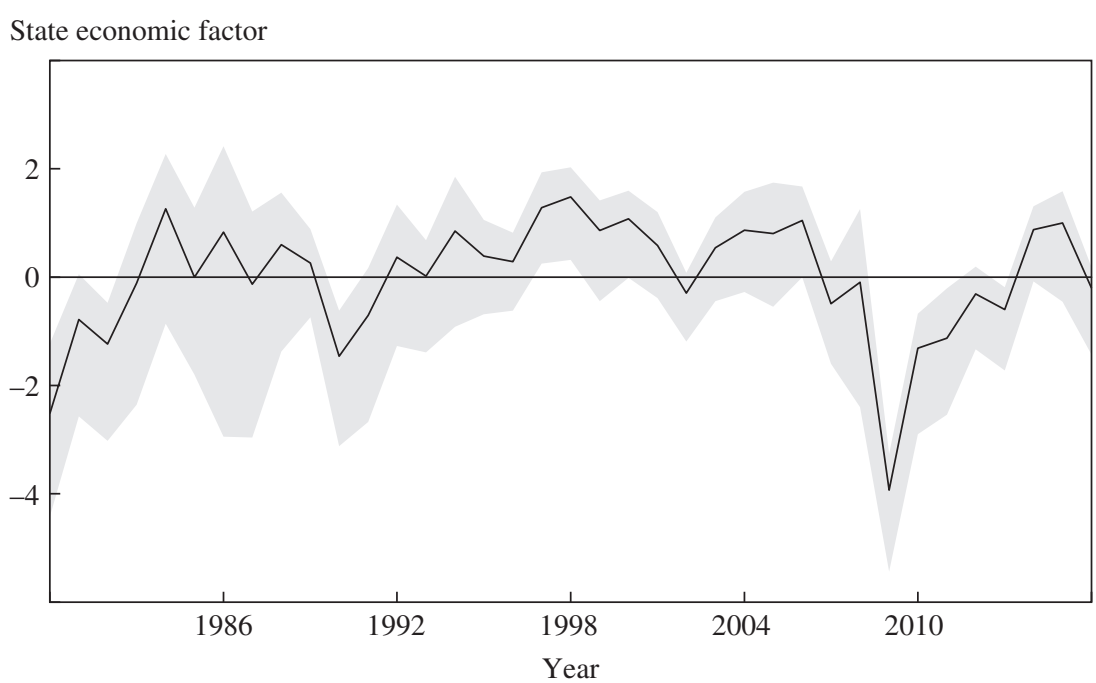

Sources: U.S. Bureau of Economic Analysis; U.S. Bureau of Labor Statistics; Zillow; Freddie Mac; Standard \& Poor's; Federal Reserve Economic Data; authors' calculations.

a. The solid black line is the mean across the 50 U.S. states and the District of Columbia of the state economic factor, a measure of local economic conditions. The shaded area denotes the 10th-90th percentile range of the distribution. 
To further characterize the cross-sectional heterogeneity of state-level economic conditions, we regress the local economic factor on a constant and the national economic factor. The data cover all 50 states and the District of Columbia from 1980 to 2016. A national economic factor explains, on average, 52 percent of the variation in the time series of a state. However, this explanatory power varies substantially across states. ${ }^{15}$ Local economic conditions in Alaska are least represented by the national economic factor, with an $R^{2}$ near 0 , whereas Minnesota is most represented, with 82 percent of the variation explained. Online appendix figure A1 illustrates the distribution of $R^{2} \cdot{ }^{16}$ The fraction of variation explained is closely related to the correlation between local and national economic conditions. The heterogeneity in correlation is also illustrated by variation in the sensitivity of local economic conditions to that of the nation. An improvement in national economic conditions of 1 standard deviation, on average, improves local economic conditions by 0.70 standard deviation. However, this varies substantially, as is illustrated in online appendix figure A1. For example, North Dakota has a beta of 0.08, while California has a beta of 0.94 .

Other macroeconomic variables perform similarly in explaining the variation in state-level business cycles. We consider the underlying macroeconomic variables to the national factor (GDP growth, income growth, house price growth, and unemployment), macroprudential policy rates (the federal funds rate), interest rates (nominal and real 1-year Treasury rates), and the 30-year mortgage interest rate. The federal funds rates, Treasury rates, and mortgage interest rates are sourced from FRED. For each state, we regress local economic conditions on a constant and the underlying macroeconomic variable iteratively. All these national-level macroeconomic variables differ substantially in explanatory power and betas across states. Table 4 provides summary statistics detailing the variation.

Using local economic variables to explain local business conditions is both intuitive and more effective. For all economic series, the state-specific series are, on average, more correlated with the local economic factor. The average correlation between the state-level change in unemployment and the local economic factor is -.68 , but the correlation between the national change in unemployment is, on average, -.50 . For house prices, there is

15. This national economic factor is constructed similarly to the state-level economic factors. The national economic factor is the first component of a principal component analysis on real GDP growth, income growth, house price growth, and unemployment.

16. The online appendixes for this and all other papers in this volume may be found at the Brookings Papers web page, www.brookings.edu/bpea, under "Past BPEA Editions." 
Table 4. Heterogeneity in State-Level Economic Factors ${ }^{a}$

\begin{tabular}{|c|c|c|c|c|}
\hline Factor & Mean & $\begin{array}{l}\text { Standard } \\
\text { deviation }\end{array}$ & Minimum & Махітит \\
\hline \multicolumn{5}{|l|}{ Fraction of variation explained } \\
\hline National economic factor ${ }^{\mathrm{b}}$ & 52.04 & 24.10 & 0.00 & 82.11 \\
\hline Real GDP growth & 42.53 & 21.15 & 1.05 & 68.77 \\
\hline Unemployment & 27.95 & 14.10 & 0.08 & 59.19 \\
\hline Unemployment change & 18.17 & 12.03 & 0.15 & 53.40 \\
\hline Real income growth & 35.37 & 15.40 & 3.71 & 65.08 \\
\hline Real house price growth & 21.51 & 15.90 & 0.00 & 55.91 \\
\hline Federal funds rate & 5.62 & 6.50 & 0.02 & 26.83 \\
\hline Treasury rate & 4.74 & 4.92 & 0.06 & 21.43 \\
\hline Real Treasury rate & 13.97 & 12.78 & 0.00 & 45.78 \\
\hline Change in real Treasury rate & 2.95 & 3.78 & 0.00 & 14.89 \\
\hline Change in real Treasury rate $(t-1)$ & 1.24 & 1.37 & 0.00 & 5.81 \\
\hline Mortgage interest rate & 5.77 & 6.08 & 0.01 & 26.06 \\
\hline \multicolumn{5}{|l|}{ Coefficient estimate } \\
\hline National economic factor ${ }^{\mathrm{b}}$ & 0.70 & 0.24 & 0.00 & 0.94 \\
\hline Real GDP growth & 44.91 & 15.72 & 5.37 & 62.23 \\
\hline Unemployment & -46.96 & 17.55 & -77.48 & 15.24 \\
\hline Unemployment change & -53.94 & 31.02 & -109.69 & 31.77 \\
\hline Real income growth & 40.15 & 11.29 & 12.38 & 55.71 \\
\hline Real house price growth & 11.44 & 7.23 & -5.29 & 22.27 \\
\hline Federal funds rate & -2.69 & 8.31 & -18.12 & 12.93 \\
\hline Treasury rate & -0.46 & 9.13 & -18.08 & 16.76 \\
\hline Real Treasury rate & 18.49 & 17.81 & -22.97 & 47.54 \\
\hline Change in real Treasury rate & 11.96 & 10.29 & -14.78 & 35.33 \\
\hline Change in real Treasury rate $(t-1)$ & 6.55 & 8.24 & -13.09 & 23.67 \\
\hline Mortgage interest rate & -4.33 & 10.14 & -23.26 & 15.46 \\
\hline
\end{tabular}

Sources: U.S. Bureau of Economic Analysis; U.S. Bureau of Labor Statistics; U.S. Department of the Treasury; Zillow; Freddie Mac; Standard \& Poor's; Federal Reserve Economic Data; authors' calculations.

a. This table reports results from ordinary least squares regressions of national macroeconomic variables on state-level economic factors. The regressions are estimated separately for each state iteratively, adding one variable at a time.

b. The national economic factor is the first factor of the principal component analysis at the national level.

also a large gain: .67 for state-state correlation and .58 for state-national correlation. Figure 6 illustrates the cross-sectional distribution of correlations between state economic conditions and state economic variables (top panel) and state economic conditions and national economic variables (middle panel). Notably, the distributions tend to be shifted toward 1 for real GDP growth, income growth, and house price growth, and toward -1 for the unemployment rate. Finally, the bottom panel of figure 6 shows the substantial heterogeneity in correlations between changes in state economic conditions and national-level interest rate indexes. 
Figure 6. Correlation between State Economic Factors and Various Stateand National-Level Variables

\section{State-level variables}

Density

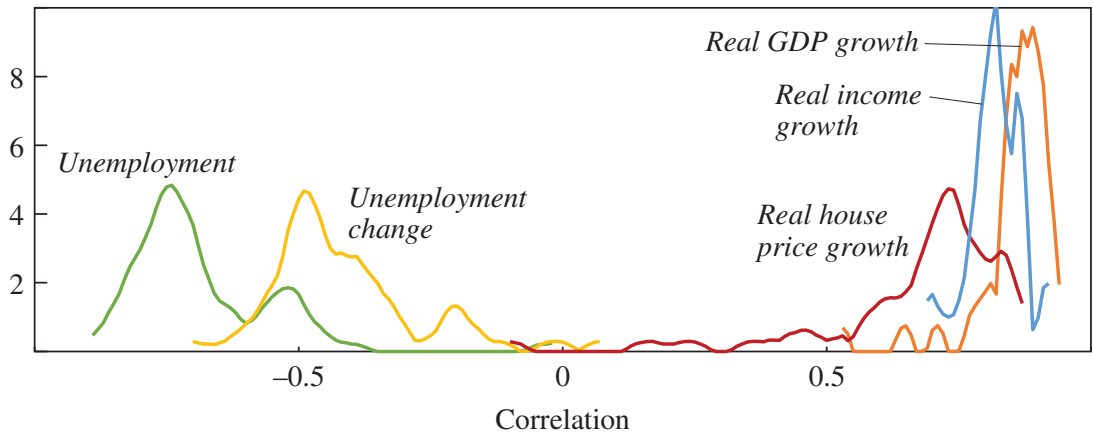

National-level variables

Density

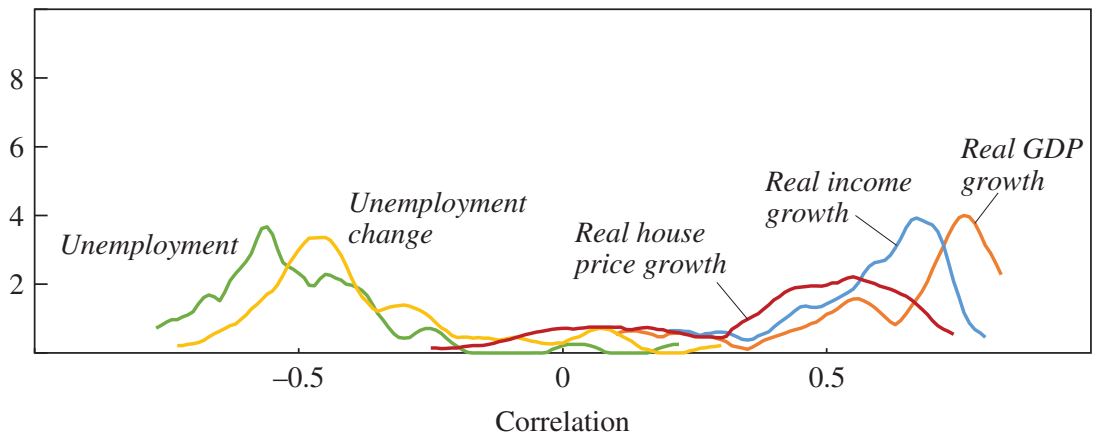

Interest rate indexes

Density

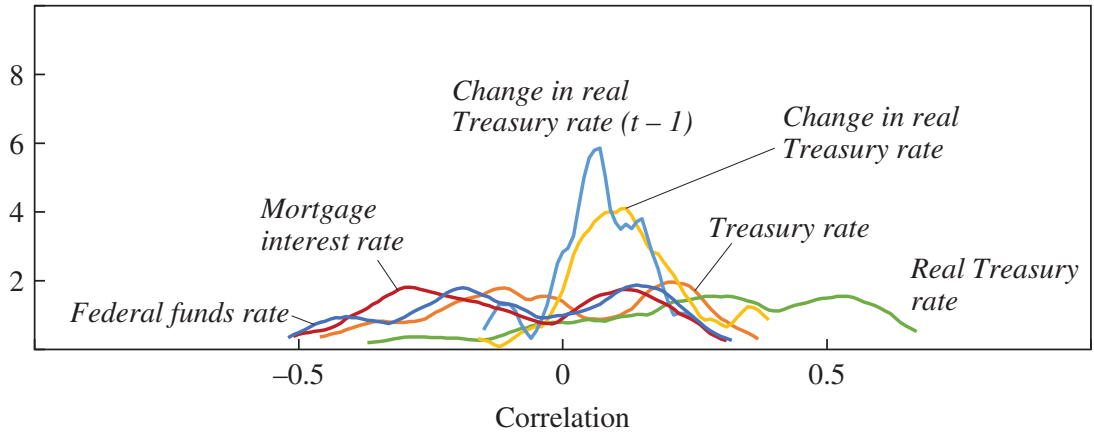

Sources: U.S. Bureau of Economic Analysis; U.S. Bureau of Labor Statistics; U.S. Department of the Treasury; Zillow; Freddie Mac; Standard \& Poor's; Federal Reserve Economic Data; authors' calculations. 
Overall, this simple analysis illustrates that local economic conditions exhibit substantial heterogeneity, which is not that closely related to national macroeconomic conditions or interest rate indexes. Furthermore, statelevel economic conditions vary in their correlation and sensitivity to national conditions. This regional heterogeneity may limit the ability of national macroprudential policy or mortgage contracts based on nationallevel indexes to comprehensively and effectively respond to local economic conditions.

\section{III.B. Evidence from U.S. Counties and ZIP Codes}

So far, we have shown that states exhibited heterogeneous business cycles from 1980 to 2016. Now we turn to the county level to show that counties also experience substantial heterogeneity. Our data come from a variety of sources. The county unemployment rate is from the U.S. Bureau of Labor Statistics, county income is from the U.S. Census Bureau, and county house prices come from Zillow's Home Value Index. We complement the county-level data with additional housing variables. County first mortgage serious delinquency rates and combined loan-to-value ratios (CLTVs) come from a 10 percent representative sample of the U.S. population provided by Equifax, covering the sample period 2005-16. ${ }^{17}$ For each county, we focus on local economic variables - unemployment rate, change in unemployment rate, real income growth—and housing variables—house prices, CLTVs, and mortgage delinquency rates. We also complement our analysis by presenting evidence on foreclosure rates, VantageScores, and debt-to-income ratios (all from Equifax data). ${ }^{18}$

We begin by examining the means and standard deviations of real income growth and the unemployment rate. The top panels of figure 7 show the means of these variables. Unsurprisingly, there is a sharp decrease in mean income growth and a sharp increase in mean unemployment in

17. We note that the Equifax data we use do not have a direct measure of current CLTVs of mortgage borrowers. We compute this variable in a region (county or ZIP code) by dividing the average combined mortgage debt level of borrowers with first mortgages on their credit files by the median house price in a region (from Zillow). We verified that our measure of average CLTV in a region is closely related to the CLTV measure from widely used Credit Risk Insight Servicing McDash (CRISM) data that cover approximately 70 percent of mortgage borrowers. We also note that our measure indicates slightly higher CLTV levels than do the CRISM data, likely due to the well-known underrepresentation of subprime borrowers in the CRISM data; see online appendix figure A2 for more details.

18. The Equifax-based DTI should be interpreted with caution because the Equifax data do not report the actual income of the borrower and instead provide the estimated income based on credit variables. 
Figure 7. County-Level Income and Unemployment Rate, 1998-2016

Mean of income growth

Percent

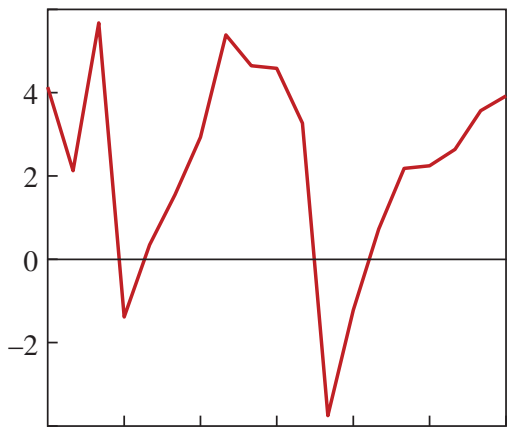

20012004200720102013

Year

Standard deviation of income growth

Percent

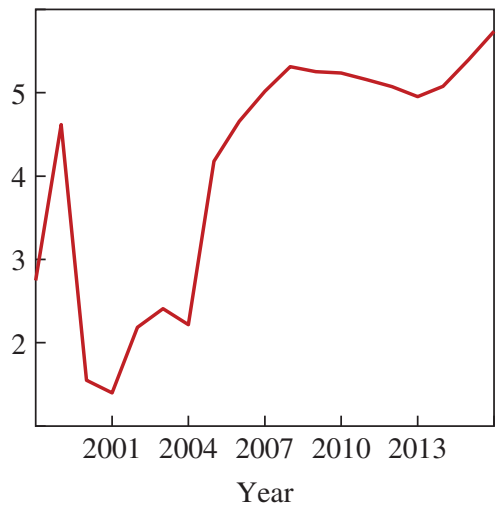

Mean of unemployment rate

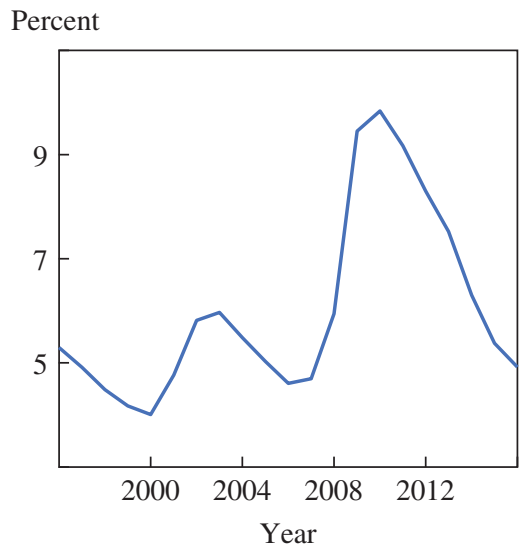

Standard deviation of unemployment rate

Percent

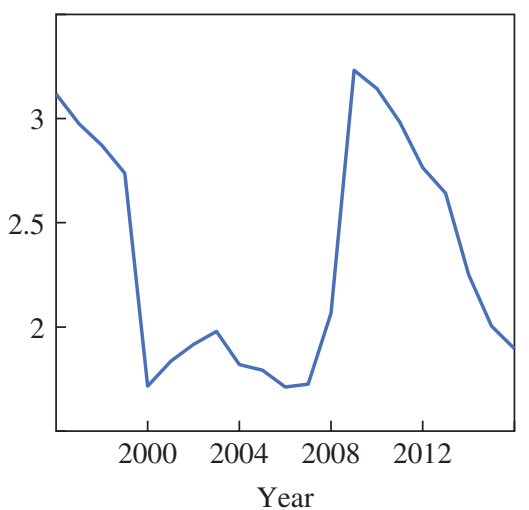

Sources: U.S. Census Bureau, Small Area Income and Poverty Estimates; U.S. Bureau of Labor Statistics, Local Area Unemployment Statistics.

about 2008. Even more important, the bottom panels of figure 7 show the standard deviations of both variables. There is considerable variation in both income and unemployment across counties for the entire time series, with spikes at 2008. Although the standard deviation of unemployment begins to decrease after 2010, the standard deviation of income growth remains at the elevated level. 
Next, we examine the mean and standard deviation of housing variables. The left panels of figure 8 show the means of house price growth, CLTVs, and delinquency rates. Again, the means vary substantially over time, with CLTVs and delinquency rates reaching their maxima in about 2010 and 2011, and with the house price index growth reaching its minimum in 2010. As the right panels of figure 8 show, the standard deviations also fluctuate throughout the time series, with the volatility of all three variables reaching a peak during the period from 2009 to 2011 . Overall, figures 7 and 8 show that both the mean values of county variables and the variability of these values across counties vary significantly over time.

Another way to view heterogeneity spatially is by presenting heat maps of county-level variables before, during, and after the financial crisis. Figure 9 does so by plotting the unemployment rate, while figure 10 plots house price growth. The top panels illustrate that even before the recession, there was some heterogeneity across counties. We can see from the middle panels that heterogeneity increased during the crisis. And the bottom panels show that most counties recover across these two variables, but some remain in a distressed state. These two figures illustrate the extent of the heterogeneity across counties in various periods across income and house price risk. This evidence is also consistent with the urban economics literature, which documents significant heterogeneity in local house price movements (Glaeser, Gyourko, and Saiz 2008; Sinai 2013).

Figure 11 similarly plots the heat map with CLTVs and delinquency, in 2010. We note that areas with high CLTV levels often correspond to the areas that experienced high house price growth before the crisis (see the top panel of figure 10). This reflects, in part, a significant amount of home equity extraction in areas that experience rapid house price growth before the bust (Mian and Sufi 2011; Bhutta and Keys 2016). Figures 10 and 11 suggest that the heterogeneity in unemployment and house price growth implies a significant heterogeneity in housing equity and mortgage defaults during the peak of the Great Recession. Many counties have high CLTVs, delinquency rates, and unemployment rates and low house price growth in 2010, but other counties continue to perform quite well. This evidence is consistent with the work of Atif Mian and Amir Sufi (2014b), who show a strong link between household leverage and the extent of house price declines at the regional level, and the subsequent increase in unemployment during the Great Recession. At the same time, though many counties have high CLTVs, delinquency rates, and unemployment rates and low house price growth in 2010, other counties continue to perform quite well. 
Figure 8. County-Level Housing Variables, 2006-16

Mean house price index growth

Percent

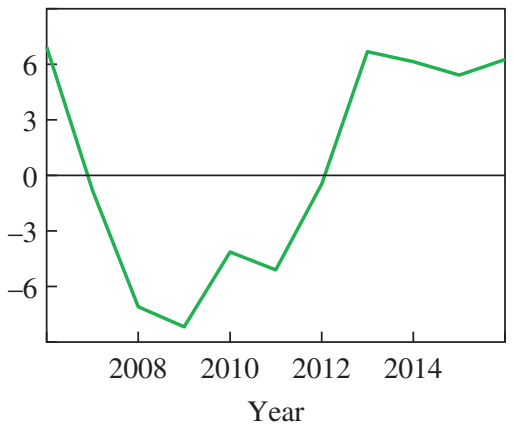

Mean CLTV ratio

Percent

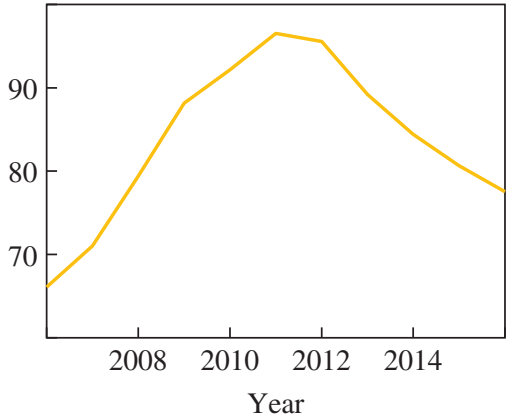

Mean delinquency rate

Percent

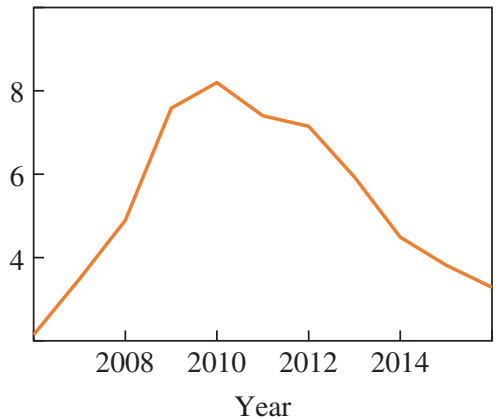

Sources: Zillow; Equifax.
Standard deviation of house price index growth

Percent

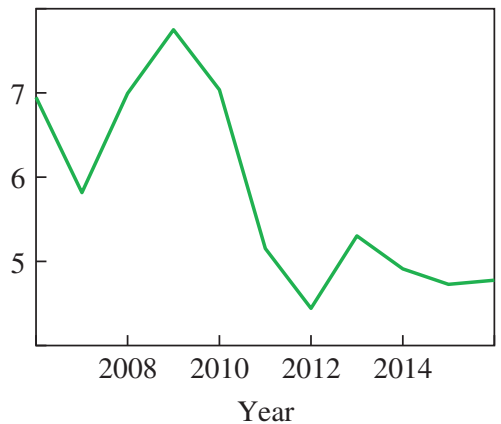

Standard deviation of CLTV ratio

Percent

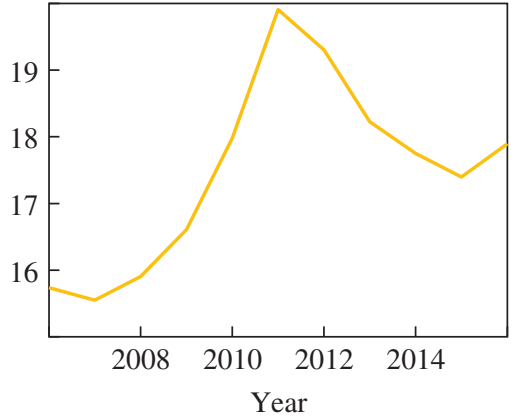

Standard deviation of delinquency rate Percent

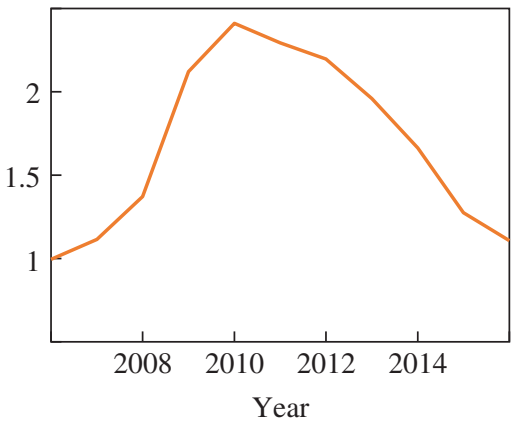


Figure 9. County-Level Unemployment Rates, 2005-16

2005

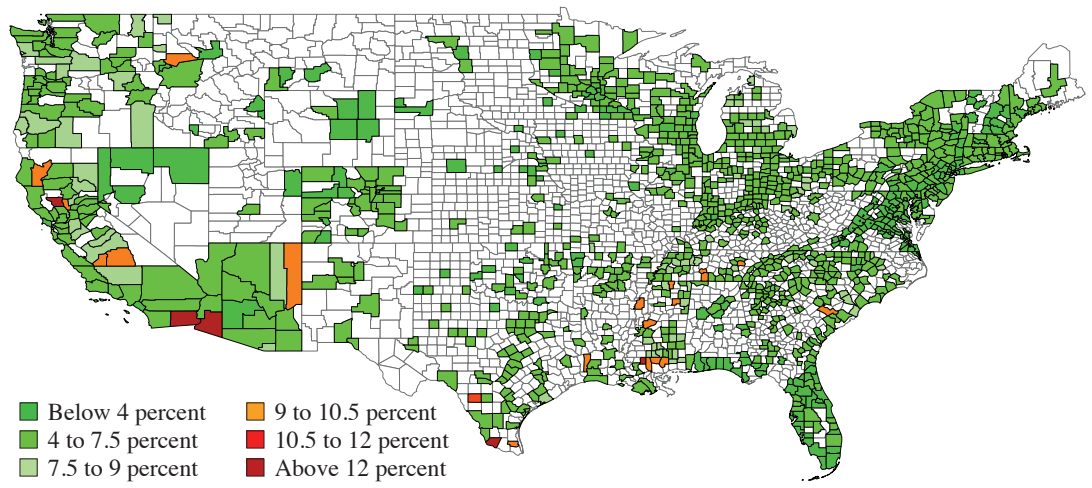

2010

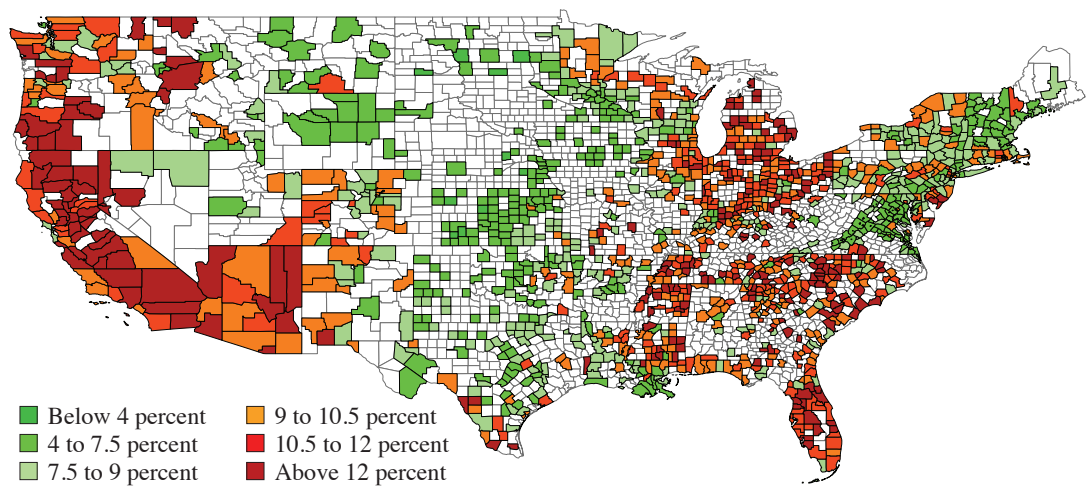

2016

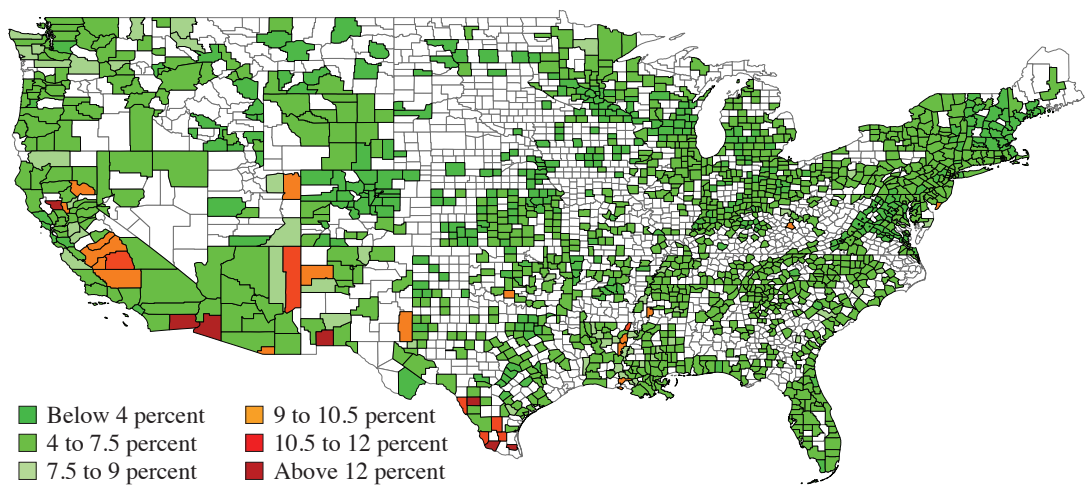

Source: U.S. Bureau of Labor Statistics, Local Area Unemployment Statistics. 
Figure 10. County-Level House Price Growth, 2005-16

\section{5-06}

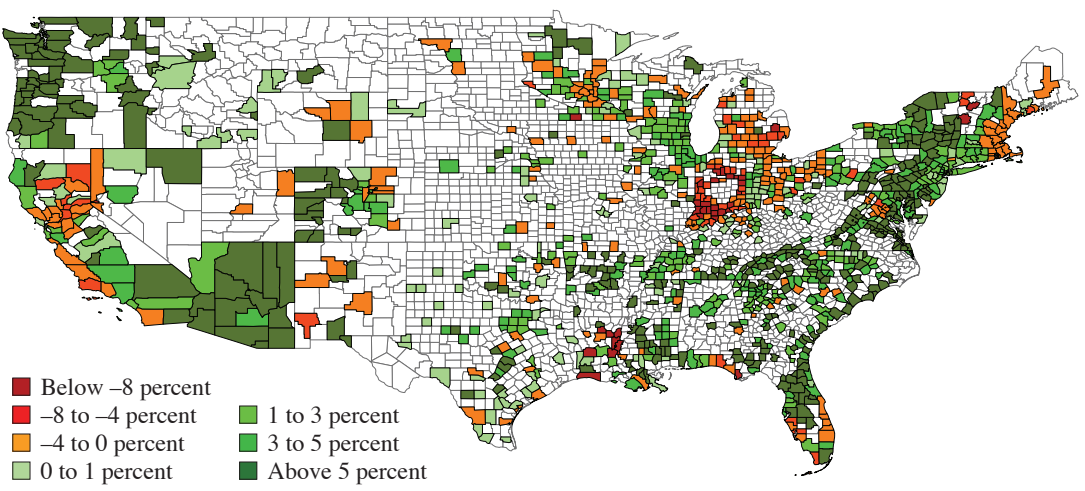

2007-09

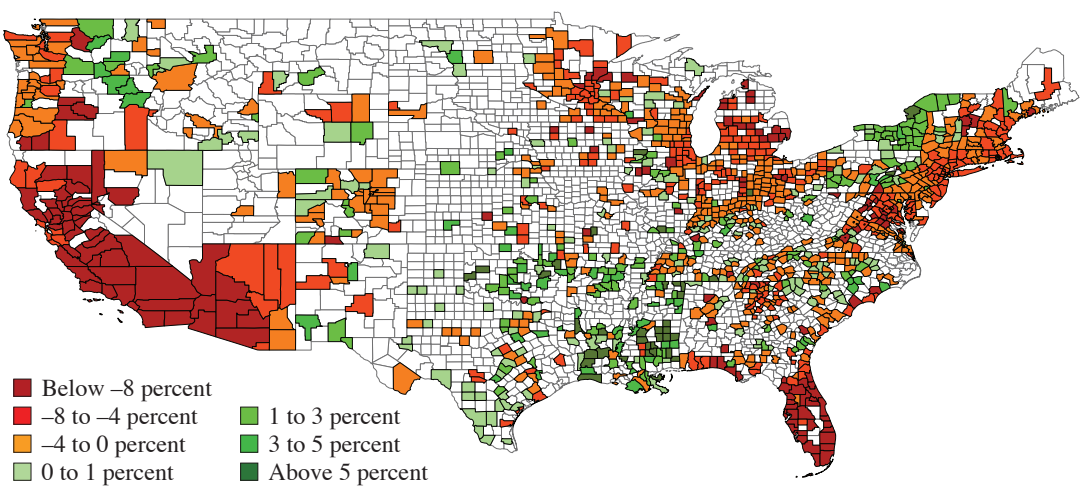

2010-16

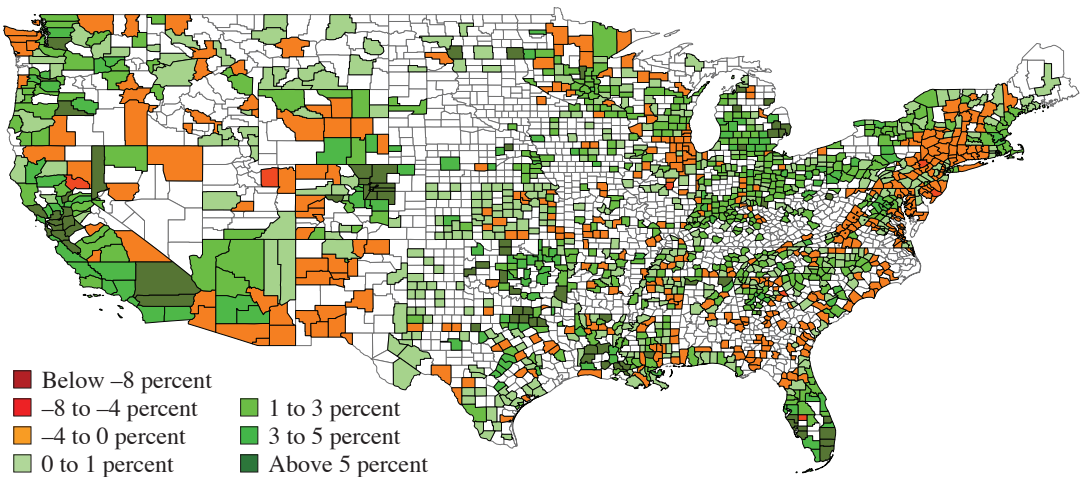

Source: Zillow. 
Figure 11. County-Level Housing Equity and Mortgage Default, 2010

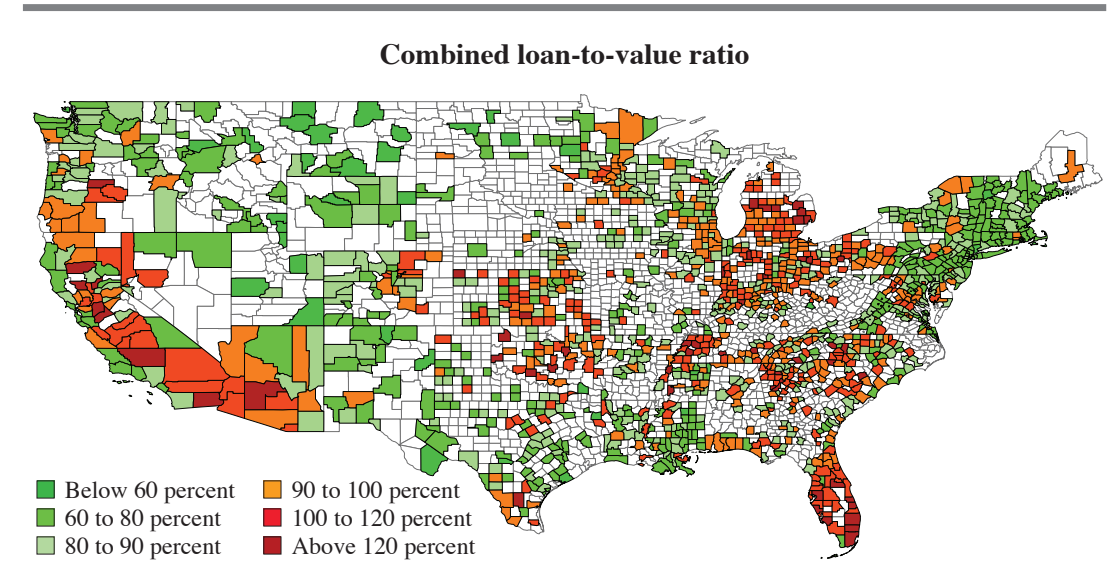

Serious mortgage delinquency rate

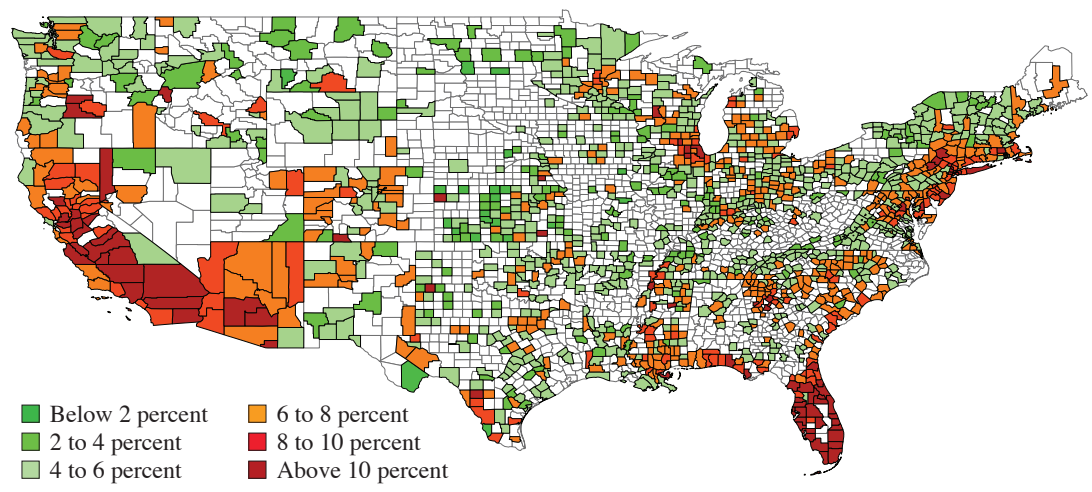

Source: Equifax.

This heterogeneity exists across years, but especially so during the financial crisis. Figures 12 and 13 show similar evidence for U.S. ZIP codes. ${ }^{19}$ Online appendix figure A3 complements this evidence by showing similar heterogeneity in foreclosure rates, debt-to-income ratios, and VantageScores. Strikingly, at this more granular level, the evidence of the heterogeneity becomes even more pronounced. Overall, this evidence indicates that the Great Recession did not affect regions uniformly, and that there is a substantial heterogeneity in housing equity and default that is also visible in the heterogeneity of unemployment and house price movements.

19. Our analysis of heterogeneity at the ZIP code level is limited because we do not have access to good unemployment data at this level. 
Figure 12. ZIP Code-Level House Price Growth, 2005-16

\section{5-06}

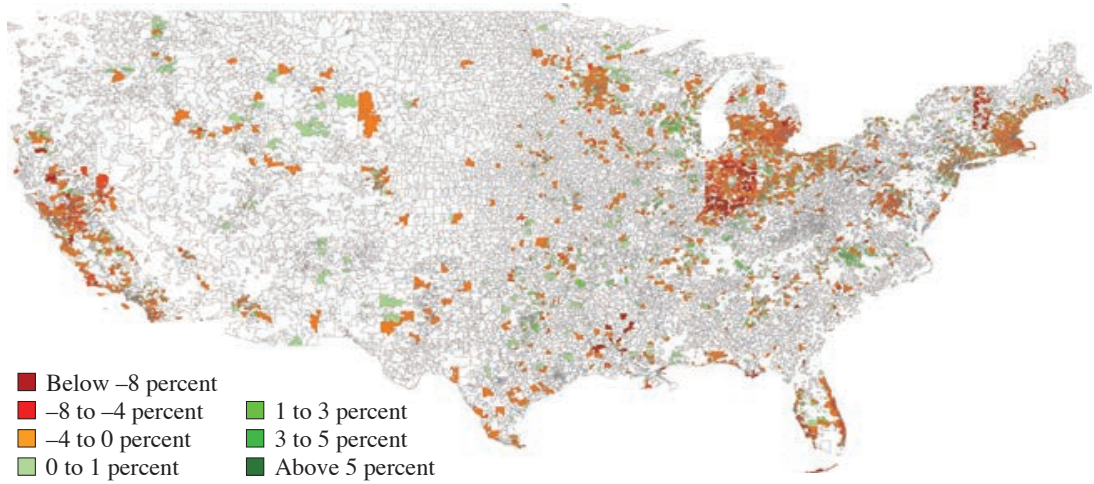

2007-09

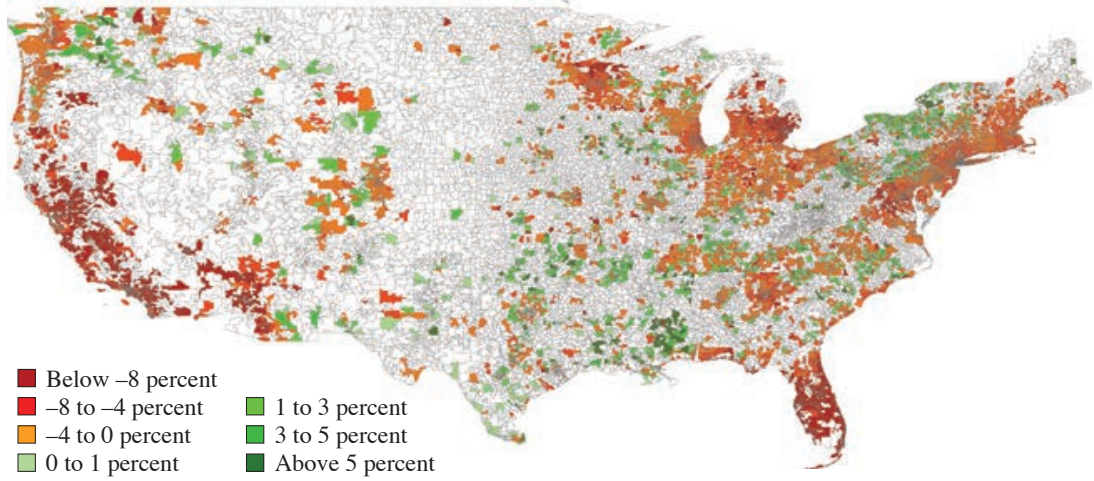

2010-16

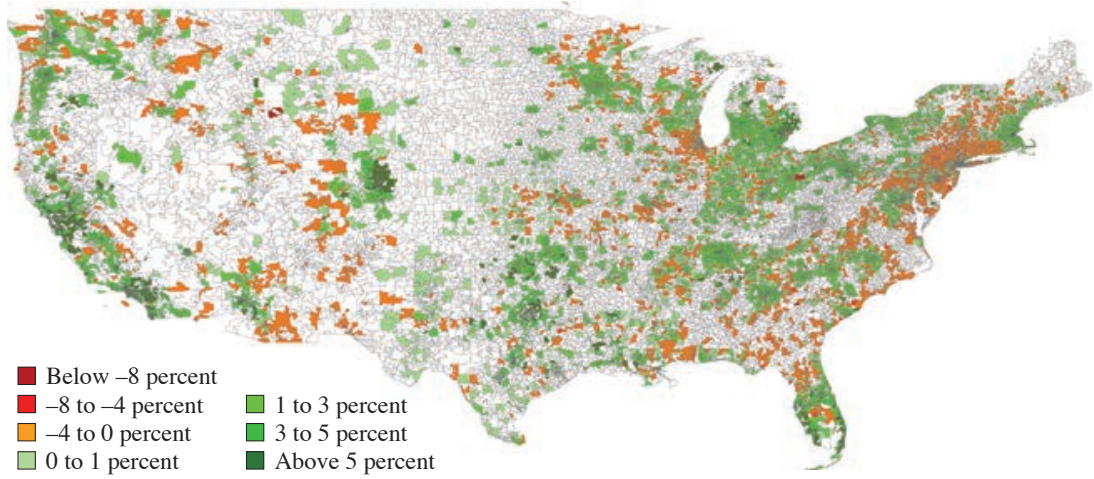

Source: Zillow. 
Figure 13. ZIP Code-Level Housing Equity and Mortgage Default, 2010

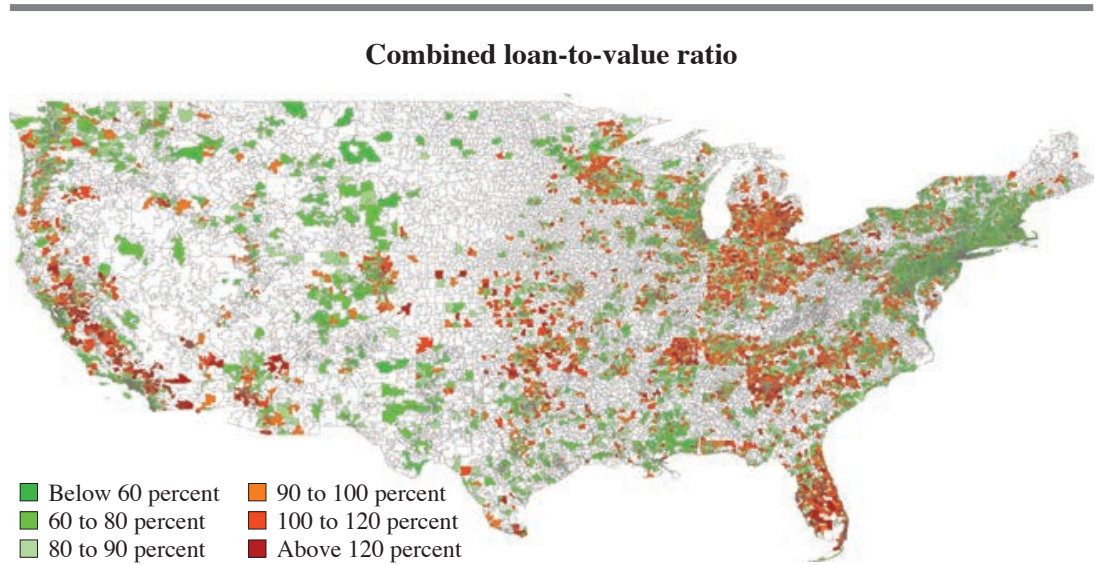

Serious mortgage delinquency rate

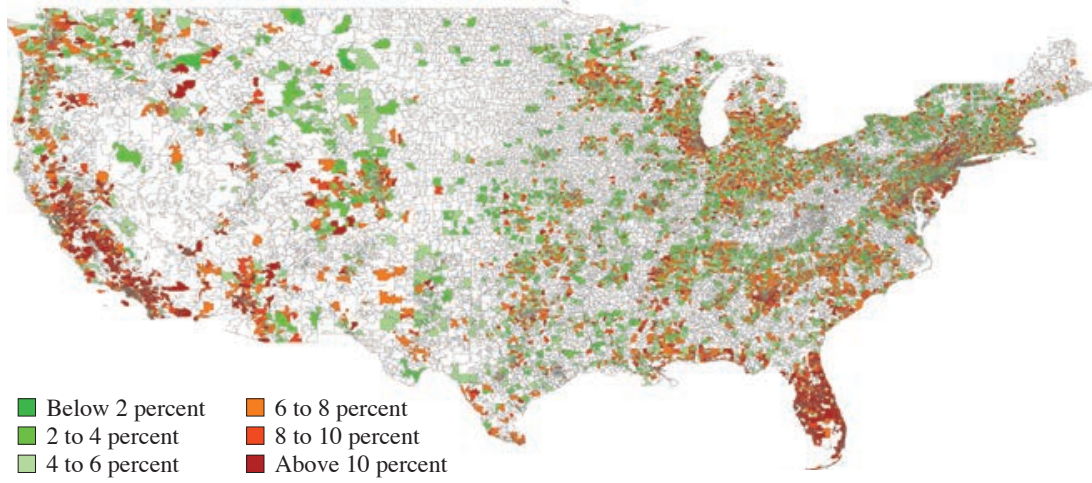

Source: Equifax.

Thus far, we have visually examined heterogeneity in space and time through means and standard deviations. Next, we consider the stability of relationships between county-level variables. We regress the dependent variable on the independent variable interacted with annual dummy variables for each year. In figure 14, we show the coefficients of such regressions, where we regress the change in the mortgage default rate on the change in unemployment rate (left panel) and on house price growth (right panel), respectively. Both panels include 95 percent confidence intervals.

Figure 14 confirms that the extent of mortgage defaults in a region is closely associated with changes in unemployment rates and house prices, with mortgage defaults being generally lower in areas experiencing lower 
Figure 14. The Relationship between County-Level Mortgage Default, House Prices, and Unemployment, 2006-16

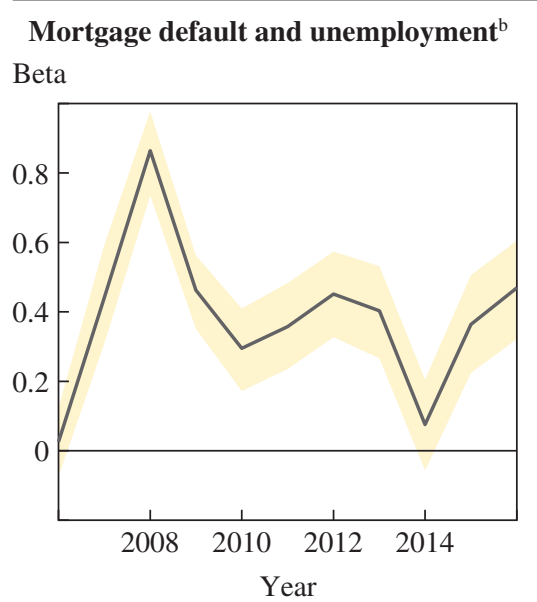

\section{Mortgage default and house prices ${ }^{\mathrm{c}}$} Beta

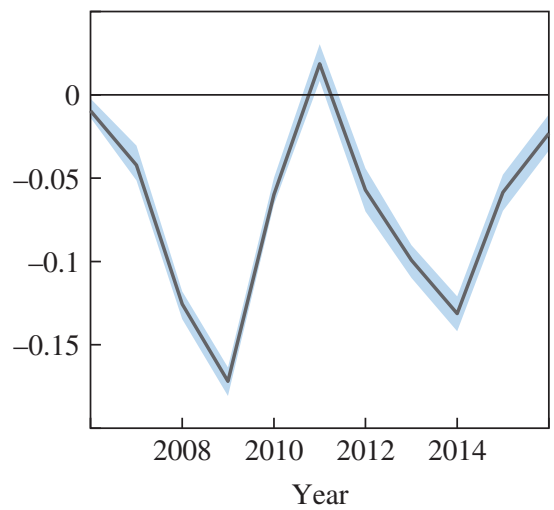

Sources: U.S. Bureau of Labor Statistics, Local Area Unemployment Statistics; Equifax; Zillow; authors' calculations.

a. This figure shows the relationship between county-level variables through simple linear regression. The dependent variable is regressed on independent variables that are interacted with annual dummies for each year. The regressions are population-weighted by county. The shaded area denotes the 95 percent confidence interval.

b. The dependent variable is the change in serious mortgage delinquency rate, and the independent variable is the change in the unemployment rate.

c. The dependent variable is the change in serious mortgage delinquency rate, and the independent variable is the house price growth rate.

levels of unemployment and higher house price growth. This is not surprising because the extensive empirical literature identifies these two factors as key drivers of mortgage defaults (Foote, Gerardi, and Willen 2008; Keys and others 2013). This is also consistent with the predictions of our simple illustrative framework presented in subsection II.B. Interestingly, though the relationships between these variables are quite strong, the strength of these relationships also varies over time. For example, the regression of mortgage defaults on unemployment rates is positive throughout the entire time series, but varies substantially (the left panel of figure 14).

Figure 15 sheds additional light on this question by examining the stability of the relationship between house price growth and the change in unemployment (left panel) and the change in CLTVs (adversely related to the change in housing equity) and the change in the unemployment rate (right panel). The evidence points to significant instability between these two key drivers of mortgage defaults. In other words, it appears that it is 
Figure 15. The Relationship between County-Level House Prices, Housing Equity, and Unemployment, 1998-16

House prices and unemployment ${ }^{\mathrm{b}}$ Beta

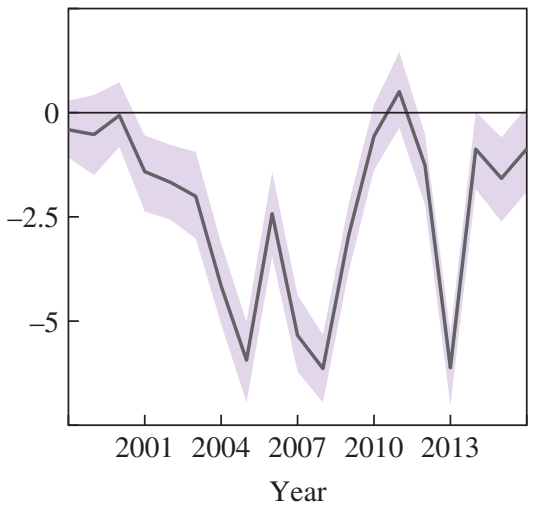

CLTV ratio and unemployment ${ }^{\mathrm{c}}$

Beta

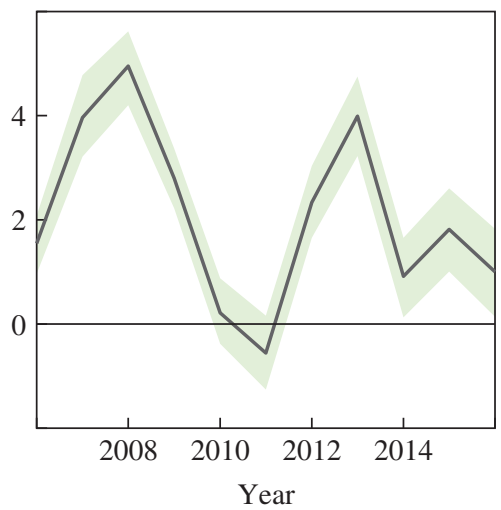

Sources: U.S. Bureau of Labor Statistics, Local Area Unemployment Statistics; Equifax; Zillow; authors' calculations.

a. This figure shows the relationship between county-level variables through simple linear regression. The dependent variable is regressed on independent variables that are interacted with annual dummies for each year. The regressions are population-weighted by county. The shaded area denotes the 95 percent confidence interval.

b. The dependent variable is the house price growth rate, and the independent variable is the change in the unemployment rate.

c. The dependent variable is the change in the combined loan-to-value ratio, and the independent variable is the change in the unemployment rate.

not always the case that regions experiencing a substantial increase in house prices (or housing equity) also experience a substantial simultaneous decrease in unemployment. For example, the regression of house price growth on the change in unemployment results in a strong negative relationship for most of the time series; but the strength of the relationship decreases from 2010 onward, and we even find positive results from 2013 to 2015. This evidence is also broadly consistent with that of Hurst and others (2016) and Beraja and others (2017), who show that regional shocks are an important feature of the U.S. economy and that the regional distribution of housing equity and income varies over time.

\section{III.C. The Relative Importance of Local Economic Indicators}

The evidence discussed above suggests that local and regional economic conditions display considerable heterogeneity that is related to the state of the housing market. This suggests that indexing mortgage contract terms or 
debt relief policies to indexes capturing the local component of economic conditions may improve the efficiency of such solutions. To shed more light on this issue, we now more formally assess the association of various national-, county-, and ZIP code-level variables. In particular, we analyze how much variation in local variables-which might be used in ex ante and ex post policies - can be explained by variables at different levels of geographic granularity. As will become clear, doing so allows us to better explain how to assess and predict these local variables.

The first exercise we undertake is a simple statistical analysis of what fraction of local variation can be explained at various levels of aggregation. In our analysis, we will focus on five variables that we discussed earlier in the paper: house prices, CLTVs, debt-to-income ratios (DTIs), delinquency rates, and foreclosures. We analyze several levels of geographic granularity. At the most granular level, a local housing market is here defined by its ZIP code (out of 14,250 ZIP codes). Similarly, we also assess geographic granularity at the level of the city $(7,600)$, county $(1,000)$, metropolitan area (730), state (51), and nation (1). Our ZIP code analysis uses a sample that spans January 1997 to December 2017 for house prices and July 2005 to December 2017 for CLTVs, DTIs, delinquency rates, and foreclosures. We focus on variations in both the levels of these variables and their growth rates. Additionally, we demean the series by ZIP code to absorb time-invariant, cross-sectional heterogeneity. To make the analysis robust to outliers, we winsorize the tails at the 1 percent level. Online appendix table A4 reports the summary statistics for the housing market variables on which we focus.

To characterize the importance of local economic variables in capturing the state of the local housing market, we estimate the fraction of variation that can be explained by geography-time fixed effects. Formally, we regress

$$
Y_{i, t}=\sum_{\tau=1}^{T} \beta_{j(i), \tau} \text { Geography }_{j(i)} \times d_{\tau}+\varepsilon_{i, t},
$$

where $Y_{i, t}$ is the housing market variable for ZIP code $i$ in period $t$. In particular, the housing market variables we consider include real house prices, CLTVs, DTIs, delinquency rates, and foreclosures, as discussed above in the data section. The term $d_{\tau}$ is a time dummy variable taking the value of 1 when $\tau=t$ and 0 otherwise, and we measure Geography $y_{j i}$ by different levels of aggregation: city, county, metropolitan area, state, and national levels. Hence, $\sum_{\tau=1}^{T}$ Geography $_{j(i)} \times d_{\tau}$ is a series of geography-time fixed effects. 
Table 5. The Importance of Local Economic Variables: The Upper Bound of $R^{2 a}$

\begin{tabular}{|c|c|c|c|c|c|}
\hline Aggregation & $\begin{array}{l}\text { (1) } \\
\text { House } \\
\text { prices }\end{array}$ & $\begin{array}{c}\text { (2) } \\
\text { Combined } \\
\text { loan-to-value } \\
\text { ratio }\end{array}$ & $\begin{array}{c}\text { (3) } \\
\text { Debt-to-income } \\
\text { ratio }\end{array}$ & $\begin{array}{c}\text { (4) } \\
\text { Delinquency } \\
\text { rate }\end{array}$ & $\begin{array}{l}\text { (5) } \\
\text { Foreclosure } \\
\text { rate }\end{array}$ \\
\hline \multicolumn{6}{|l|}{ Levels } \\
\hline National & 34.44 & 39.39 & 13.00 & 26.57 & 13.81 \\
\hline State & 67.17 & 58.45 & 21.24 & 37.52 & 27.73 \\
\hline Metro & 80.48 & 69.02 & 29.64 & 43.51 & 35.45 \\
\hline County & 80.32 & 67.86 & 30.42 & 43.85 & 35.36 \\
\hline City & 85.93 & 83.04 & 68.84 & 76.05 & 71.45 \\
\hline ZIP code & 100 & 100 & 100 & 100 & 100 \\
\hline \multicolumn{6}{|l|}{ Growth rates } \\
\hline National & 24.91 & 4.45 & 1.13 & 1.06 & 0.58 \\
\hline State & 36.88 & 6.89 & 1.83 & 1.92 & 1.50 \\
\hline Metro & 52.23 & 14.47 & 8.75 & 8.36 & 9.25 \\
\hline County & 55.67 & 16.60 & 10.75 & 10.49 & 12.01 \\
\hline City & 77.05 & 62.17 & 60.41 & 60.59 & 56.93 \\
\hline ZIP code & 100 & 100 & 100 & 100 & 100 \\
\hline
\end{tabular}

Sources: Zillow; Equifax; authors' calculations.

a. This table shows the upper bound of ZIP code-level variables that can be explained by different levels of aggregation. Specifically, the ZIP code-level variable is regressed on contemporaneous geography-time fixed effects, and the unadjusted $R^{2}$, expressed as a percentage, is reported. All variables are demeaned at the ZIP code level and winsorized at 1 percent. Real house price data are from January 1997 to December 2017. The remaining variables are from July 2005 to December 2017.

The setup for this regression puts an upper bound on the variation of $Y_{i, t}$ that can be explained by any economic variable at aggregation level $j$. For example, suppose we included ZIP code-time fixed effects. This specification soaks up all the variation in $Y_{i, t}$, yielding an $R^{2}$ of 1 . Clearly, the upper bound on explanatory power is agnostic about which underlying economic variable explains variation in a given housing market variable. This effectively estimates an upper bound to $R^{2}$ that could be generated from a contemporaneously measured variable at the level of aggregation $j$. The regression results are reported in table 5 .

The top panel of table 5 shows the results for the variation in the levels of housing variables. It documents how the fraction of variation explained at the local level increases with the granularity of the geographic area. In each cell, we report the unadjusted $R^{2}$ (expressed as a percentage) of the ZIP code-level housing variable regressed on different levels of geographic aggregation-time dummies, as in the equation given above. First, when geographic aggregation is at the ZIP code level, the $R^{2}$ is 100 percent, as ZIP code-time dummies span the full panel data set. Note that we report unadjusted $R^{2}$ because doing so provides a clear benchmark 
of 100 percent explained variation when we use the data with the highest level of granularity.

Next, consider aggregation at the city level to explain ZIP code-level variation in housing markets. Looking across columns 1 to 5 of the top panel of table 5, note that a city-level variable can explain a significant amount of the variation (which ranges between 71 percent and 85 percent) for local ZIP code-level housing variables. For example, 71 percent of the local variation in the foreclosure rate can be explained by a city-level variable (column 5), while about 86 percent of the variation of ZIP code-level house prices can be explained by a city-level economic variable (column 1). However, note that at the city level, we have, on average, fewer than two ZIP codes grouped together in our data. Hence, this upper bound on $R^{2}$ would likely be tighter in the broader sample of ZIP codes.

Explanatory power monotonically decreases as we consider coarser geographic areas. For example, the fractions of the mortgage delinquency and foreclosure rates that can be explained by county-level aggregation are, respectively, about 44 percent and 35 percent. This pattern suggests a large local variation at the ZIP code level that is not captured by county-, state-, or national-level data.

Finally, we move to national-level aggregation, which means using a national time series trend to explain the ZIP code-level time series patterns for the housing market. We see that for the house price growth rate, this time series can explain about 34 percent of the local variation (column 1 of table 5, top panel). Though a decent fraction, this still represents a significant drop from the county-level result (80 percent). For delinquency and foreclosure rates, the national-level time series pattern can merely explain 27 percent and 14 percent of the local pattern, respectively (columns 4 and 5).

As a robustness check, we also consider the heterogeneity of growth rates for housing variables. The bottom panel of table 5 presents the corresponding results. As in the case of the level variables, the explanatory power substantially decreases as we consider coarser geographic areas. For example, the fraction of house price growth variation that can be explained by county-level aggregation is 56 percent. Explained variation decreased by 21 percentage points when moving from city-level aggregation (from 77 percent to 56 percent). The drop is more extreme for other housing variables. For DTIs, CLTVs, delinquency rates, and foreclosure rates, the variation explained drops significantly, from about 60 percent to slightly above 10 percent, when we move from the city to county levels. This interesting pattern suggests a large local variation at the city (or even finer) level that is not captured by county-, state-, or national-level data. 
Finally, when we move to national-level aggregation, we see that this time series can explain about 25 percent of the local variation in the house price growth rate (column 1 of table 5, bottom panel). Though a decent fraction, this still represents a significant drop from the city-level result. For all other variables, including delinquency and foreclosure rates, the national time series pattern can explain merely 0.5 to 4.5 percent of the local pattern (columns 2 through 5, bottom panel).

Overall, the upper bound to $R^{2}$ is uniformly lower for growth rates relative to levels of variables at all levels of aggregation. This decrease is likely because there is typically more variation in growth rates than level variables, which might be very persistent. This is especially true for variables such as delinquency and foreclosure rates. Finally, for robustness, online appendix table A5 shows the results for the variables measured at monthly changes. We find very consistent evidence with our analysis given above for the level and growth rates of housing variables.

The statistical exercise above identified an upper bound on the informativeness of various economic variables by their level of geographic aggregation. We next assess the actual association of various national-, county-, and ZIP code-level variables with ZIP code-level delinquency and foreclosure rates. We begin by investigating the association between ZIP code-level delinquency rates and lagged national-level variables, including the average unemployment rate, house price growth, income growth, federal funds rate, CLTV, DTI, and VantageScore. We consider four lags for each independent variable. All the variables are measured at a quarterly frequency, with the exception of income growth. Income growth is only available on an annual basis, so each quarter is given the value of that year's annual income growth. That is, the lagged income growth for all four quarters of a year receives the value of annual income growth of the previous year.

More specifically, we run a regression of the following form for the quarterly delinquency rate in ZIP code $i$ :

$$
\text { delinquency }_{i, t}=\alpha+\sum_{n \in N} \sum_{j=1}^{4} \beta_{n, j} X_{n, t-j}+\varepsilon_{t} .
$$

We consider two variants of this regression: one without and one with nonlinear (squared) terms for the independent variables.

The first row of column 1 in table 6 shows the adjusted $R^{2}$ from this regression. Column 2 shows the corresponding results from the specification with nonlinear terms. As we observe, national economic variables account 
Table 6. The Relative Importance of Local Economic Indicators in Accounting for Variation in Mortgage Delinquency and Foreclosure Rates ${ }^{\mathrm{a}}$

\begin{tabular}{lcccccc} 
& \multicolumn{2}{c}{$\begin{array}{c}\text { ZIP code-level } \\
\text { delinquency rate }\end{array}$} & & \multicolumn{2}{c}{$\begin{array}{c}\text { ZIP code-level } \\
\text { foreclosure rate }\end{array}$} \\
\cline { 2 - 3 } Independent variables & $(1)$ & & $(2)$ & & $(3)$ & $(4)$ \\
\hline National $^{\mathrm{b}}$ & 19.5 & 19.6 & & 8.1 & 8.1 \\
County $^{\mathrm{c}}$ & 39.2 & 42.4 & & 54.0 & 54.7 \\
ZIP code $^{\mathrm{d}}$ & 66.5 & & 87.1 & & 74.1 & 75.7 \\
ZIP code and county $^{\mathrm{c}, \mathrm{d}}$ & 70.0 & & 88.4 & & 76.2 & 72.9 \\
ZIP code, county, and national $^{\mathrm{b}, \mathrm{c}, \mathrm{d}}$ & 71.3 & & 89.4 & & 78.3 & 79.3 \\
Squared independent variables & No & & Yes & & No & Yes \\
No. of observations & 262,258 & 262,258 & & 262,258 & 262,258 \\
& & & & &
\end{tabular}

Sources: U.S. Bureau of Economic Analysis; U.S. Bureau of Labor Statistics; U.S. Department of the Treasury; Zillow; Freddie Mac; Standard \& Poor's; Federal Reserve Economic Data; Equifax; authors' calculations.

a. This table shows the association of various national-, county-, and ZIP code-level variables with ZIP code-level delinquency and foreclosure rates. We perform a series of simple linear regressions, with four lags for each independent variable, and with or without squared independent variables. The adjusted $R^{2}$, expressed as a percentage, is reported.

b. The national variables include the unemployment rate, real house price growth, real income growth, the federal funds rate, the combined loan-to-value ratio, the debt-to-income ratio, and the national average VantageScore.

c. The county variables include the unemployment rate, real house price growth, the combined loan-tovalue ratio, the debt-to-income ratio, and the county average VantageScore.

d. The ZIP code variables include real house price growth, the combined loan-to-value ratio, the debtto-income ratio, and the ZIP code average VantageScore of mortgage borrowers.

for about 20 percent of within-sample variation in the ZIP code-level delinquency rate.

We next estimate the above specification when instead we explore the association between quarterly ZIP code-level delinquency rates and the four quarterly lags of the county-level variables to which a given ZIP code belongs. The county-level variables include the unemployment rate, house price growth, CLTVs, DTIs, and the county average VantageScore. Note that the county unemployment rate is only available on an annual basis, so we convert it to quarters, as we also do with annual income data. The second row of columns 1 and 2 in table 5 shows the adjusted $R^{2}$ from these regressions. As we observe, county-level economic variables account for about 39 to 42 percent of within-sample variation in the ZIP code-level delinquency rate, a substantial improvement over national indicators.

Next, we move to an even more granular level and consider regressions with lagged ZIP code-level variables. Unfortunately, we do not have unemployment or income data at this level. The ZIP code-level variables only include house price growth, CLTVs, DTIs, and the average 
ZIP code-level credit scores of mortgage borrowers. The third row of columns 1 and 2 in table 5 shows the adjusted $R^{2}$ from these regressions. As we observe, ZIP code-level variables account for about 67 to 87 percent of within-sample variation in the ZIP code-level mortgage delinquency rate, a very substantial improvement over both national- and county-level indicators. Moreover, the fourth, fifth, and sixth rows of columns 1 and 2 in table 5 show that adding national- and county-level indicators to ZIP codelevel ones leads to only minor increases in the adjusted $R^{2}$.

Columns 3 and 4 of table 5 show the corresponding analysis for the ZIP code-level foreclosure rate. Again, as in the case of the delinquency rate and consistent with our analysis given above, we see that ZIP code-level indicators account for much more of the variation in ZIP code-level foreclosure rates than county- or national-level indicators.

We conclude this analysis by conducting additional robustness checks on our inferences. We do so by studying the predictability of local housingrelated variables with corresponding lagged variables at different levels of geographic aggregation. Formally, we estimate a simple AR(12) process for each of the ZIP code-level local housing variables:

$$
Y_{i, t}=\sum_{\tau=1}^{12} \beta_{\tau} Y_{j(i), t-\tau}+\varepsilon_{i, t}
$$

Again, $Y_{i, t}$ refers to the monthly ZIP code-level housing variables: house prices, CLTV, DTI, delinquency rate, foreclosure rate, and real house prices. All these variables are measured as demeaned growth rates. We regress this on 12 lagged terms of $Y_{j(i), t \tau}$ with different degrees of aggregation. In particular, $j$ is measured at the ZIP code and national levels.

We measure the performance of predictability $R^{2}$, that is, the percentage of variation explained by the 12 lagged terms of the same variable. For ease of illustration, we compare the predictability performance between ZIP code-ZIP code and ZIP code-national levels. We measure the predictability of housing variables in growth rate measures rather than level measures. The primary reason for this is that level variables exhibit strong autocorrelation. In this sense, a good fit of the level of housing market variables may not translate into a good prediction of the change of variables.

In unreported regressions, we find that real house price growth exhibits high predictability at the ZIP code level, using lagged ZIP code information. Lagged, ZIP code-level house price growth explains roughly 69 percent of the variation in house price growth, with a reduction in the root mean squared error of 0.56 percent. When using national house price growth, 
only 18 percent of the variation is explained. The other local housing variables are much more difficult to predict, even when using lagged local data. The adjusted $R^{2}$ for CLTVs is 2.64 percent; for DTIs 12.47 percent; for delinquency rates, 20 percent; and for foreclosures, 3.6 percent. At the national level, the explanatory power is approximately 0 .

For ease of illustration, we present these inferences in online appendix figure A6, where we illustrate the predictability at the local (ZIP code) and national levels by plotting the 12 autoregressive regression coefficients of local variable growth regressed on lagged local variable growth and lagged national variable growth, respectively. All these local variables exhibit mean reversion except local house prices, which exhibit short-term momentum. ${ }^{20}$ For instance, an increase in the local delinquency growth rate of 1 percent predicts a subsequent decrease in the delinquency growth rate of 0.5 percent in the next month and 0.3 percent in the subsequent month. Similar patterns of mean reversion are also found for DTIs, CLTVs, and foreclosure rates. In contrast, national-level housing variables have little to no predictive power, with $R^{2} \approx 0$.

\section{III.D. Summary}

Overall, our evidence indicates that regional economic conditions display significant heterogeneity across U.S. states, counties, and ZIP codes, and over time. This heterogeneity, along with our analysis given above, suggests significant gains from using indexes that capture the local component of economic conditions in assessing the condition of the local housing markets relative to indexes at coarser levels of geographic aggregation. We also find evidence of significant instability over time in the strength of the relationships between key economic variables. In the next section, we discuss the implications of these findings for the design of mortgage contracts and debt relief policies.

\section{Implications for Mortgage Contract Design and Debt Relief Policies}

In the previous section, we presented evidence of significant heterogeneity in local economic conditions across space and time. Moreover, the strength of the relationships between key economic variables affecting households, such as housing and income risk, does not appear to be that stable over time,

20. For a recent, comprehensive analysis of house price dynamics, see DeFusco, Nathanson, and Zwick 2017. 
pointing to a time-varying distribution of these variables. Recall that our simple framework in subsection II.B illustrates that the successful implementation of indexed mortgage contracts or debt relief policies crucially depends on a correct understanding of the underlying structure of income and housing risk and its relation to the indexes on which such contracts or policies will be based. We now discuss the practical considerations in implementing temporary debt relief during economic downturns, drawing on insights from section II. We consider solutions that rely, in turn, on the design of mortgage contracts, ex post private renegotiation, and mortgage debt relief policies.

\section{IV.A. Mortgage Contract Design}

We start by considering implementation of debt relief through changes in mortgage contract terms. We focus on different methods of mortgage contract indexation. As noted above, such indexation effectively implements an automatic temporary debt relief during economic downturns and can potentially circumvent the frictions discussed in section I.

NATIONAL-LEVEL INTEREST RATE INDEXATION In practice, the most commonly used state-contingent mortgages are ARMs. Our discussion in section II suggests that contracts indexed to national-level interest rate indexes may implement debt relief efficiently, as long as such indexes closely co-move with house prices and borrowers' incomes. Having said this, two points are worth emphasizing. First, as the top panel of figure 16 shows, there is large spatial variation in the ARM share of mortgages in a ZIP code. This implies that an automatic pass-through of low interest rates would be differentially passed through across regions, to the extent that FRMs would remain a popular contract choice. ${ }^{21}$ Second, the empirical evidence we presented in section III suggests that, due to significant regional heterogeneity, ARMs based on national indexes may not be as effective, especially in some regions.

One could argue that the most relevant aspect in successfully implementing debt relief through this mechanism is the close co-movement of interest rates on which ARMs are indexed with relevant local economic variables during recessions. Indeed, figure 5 shows that during the Great Recession, all U.S. states experienced some decline in economic activity, though substantial heterogeneity remained in the strength of this effect.

21. This share, however, needs to be interpreted with caution, because many subprime ARM contracts feature various caps and floors that may limit the extent of downward adjustment of their rates in response to a decline in interest rate indexes. 


\section{Adjustable-rate mortgage share ${ }^{a}$}

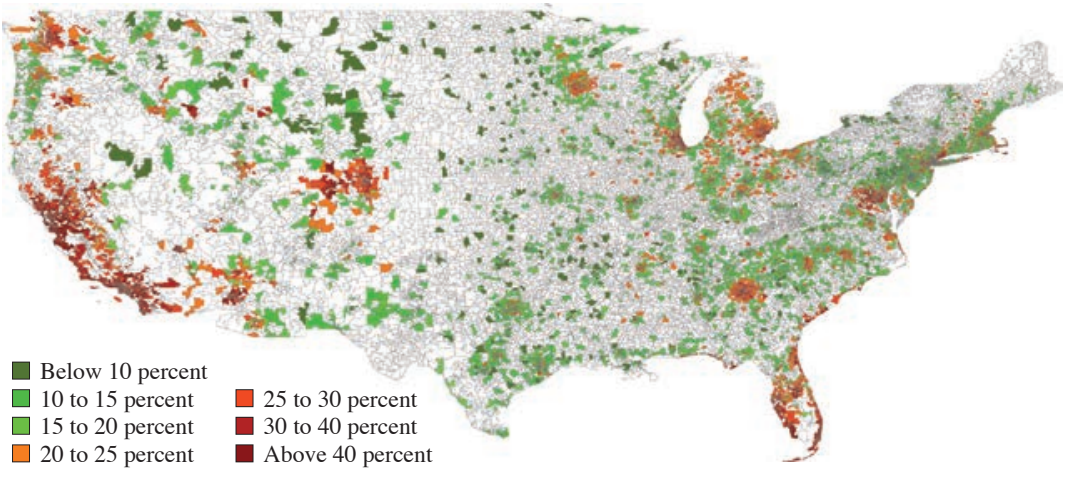

Share of loans serviced by high organizational capacity intermediaries

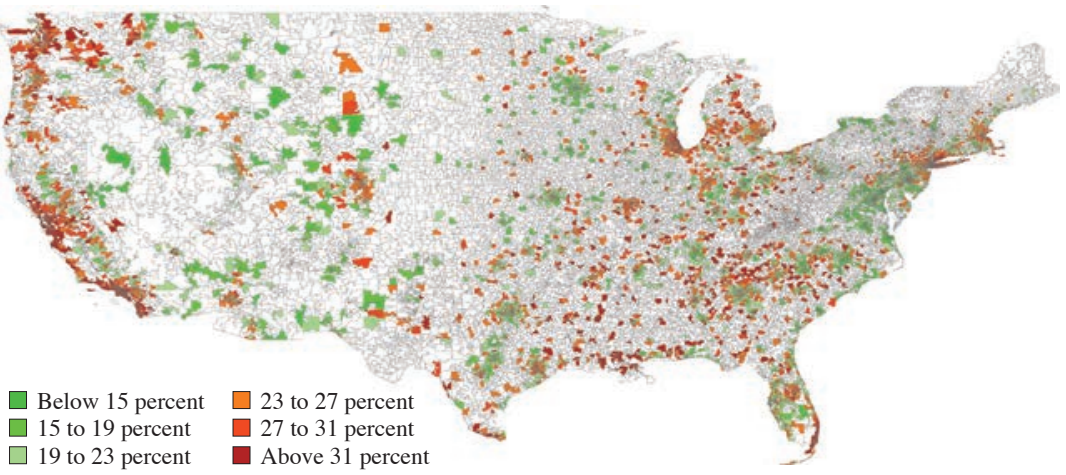

HARP-eligible share ${ }^{b}$

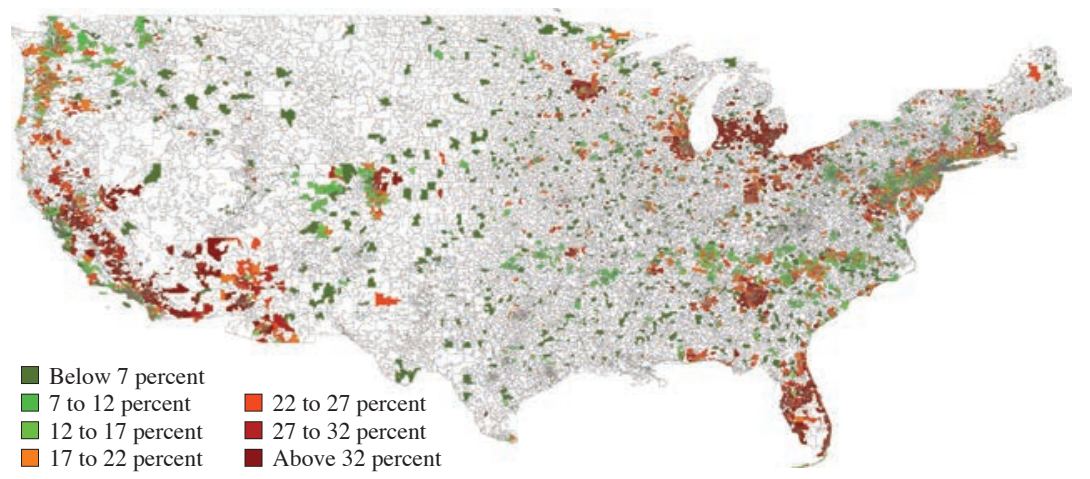

Sources: DiMaggio and others (2017); Agarwal and others (2017a, 2017b).

a. We note that adjustable-rate mortgages can experience a quick automatic pass-through of low interest rates. This share should be interpreted with caution because many subprime adjustable-rate mortgage contracts feature various caps and floors that may limit the extent of their rate adjustments.

b. HARP eligibility is based on loan-to-value ratios and the presence of a GSE guarantee. 
During this period, all main interest rate indexes also reached historically low levels. Consistent with this observation, the empirical evidence finds that ARMs resetting to a low rate after 2009 had a direct positive impact across borrowers and regions by reducing the default rate and increasing consumption, house prices, and local employment (Di Maggio and others 2017; Fuster and Willen 2017).

One should be careful, however, not to overstate the benefits of ARM contracts. First, there were periods in the past, such as the stagflation episode, when interest rate indexes reached high levels during an economic downturn. In such an environment, a high share of ARMs in an economy could exacerbate the severity of the economic crisis. In particular, after a substantial increase in interest rate indexes along with the federal funds rate (see online appendix figure A7), the ARMs reset to much higher rates during the period from late 2006 to early 2008. As a consequence, these ARM borrowers faced substantial rate increases, along with vanishing refinancing opportunities, due to the collapse of the subprime mortgage market by mid-2007. This aspect could have contributed to the mortgage default rate and the severity of the initial stage of the financial crisis.

To illustrate this more formally, we use monthly, loan-level panel data from BlackBox Logic on more than 1.8 million two-year, subprime ARMs that reset during this period. These two-year ARM contracts are loans that were mainly originated during the 2004-06 period. They faced a fixed initial rate for the first two years and subsequently a reset to the variable rate based on a short-term interest rate index (for example, the London Interbank Offered Rate). The top panel of table 7 shows the summary statistics for these loans, including the mortgage interest rate before and after the first reset.

Columns 1 and 2 in the bottom panel of table 7 show the regression results of the monthly mortgage interest rate and the default rate for twoyear ARM borrowers on the time dummies for the three quarters before and four quarters after the change in the interest rate, with the fourth quarter before the reset period serving as the excluded category. This specification controls for a variety of borrower, loan, and regional characteristics, including the borrower's FICO credit score and the loan-to-value ratio. As we observe from the top panel, two-year ARM borrowers experience an increase of about 1.3 percentage points in their monthly interest rates after the reset, amounting to a relative increase of more than 17 percent. Column 1 in the bottom panel shows similar effects. The top panel of figure 17 shows the corresponding monthly mean default rate (serious delinquency rate) for these loans around the first reset date that happens after month 24 of the 
Table 7. The Impact of Adjustable-Rate Mortgage Resets on Mortgage Default at the Outset of the Great Recession

\begin{tabular}{|c|c|c|c|c|}
\hline \multirow[b]{2}{*}{ Summary statistics } & \multicolumn{2}{|c|}{ Two-year ARM sample } & \multicolumn{2}{|c|}{ Three-year ARM sampleb } \\
\hline & Mean & $\begin{array}{l}\text { Standard } \\
\text { deviation }\end{array}$ & Mean & $\begin{array}{l}\text { Standard } \\
\text { deviation }\end{array}$ \\
\hline FICO credit score & 623 & 58 & 682 & 64 \\
\hline Loan balance (dollars) & 199,435 & 130,569 & 221,966 & 172,646 \\
\hline $\begin{array}{l}\text { Initial loan-to-value ratio } \\
\text { (percent) }\end{array}$ & 82.25 & 10.96 & 78.72 & 14.78 \\
\hline Initial interest rate (percent) & 7.80 & 1.67 & 6.31 & 1.43 \\
\hline $\begin{array}{l}\text { Interest rate after reset } \\
\quad \text { (percent) }\end{array}$ & 9.13 & 2.10 & 7.90 & 2.23 \\
\hline \multirow[t]{3}{*}{ No. of observations } & \multicolumn{2}{|c|}{$1,815,178$} & \multicolumn{2}{|c|}{146,078} \\
\hline & \multicolumn{2}{|c|}{ Two-year ARM sample } & \multicolumn{2}{|c|}{ Three-year ARM sample } \\
\hline & $\begin{array}{l}\text { Interest } \\
\text { rate }\end{array}$ & $\begin{array}{l}\text { Default } \\
\text { rate }\end{array}$ & $\begin{array}{l}\text { Interest } \\
\text { rate }\end{array}$ & $\begin{array}{l}\text { Default } \\
\text { rate }\end{array}$ \\
\hline \multirow[t]{2}{*}{ Three quarters before } & -0.0672 & 0.164 & -0.0109 & 0.110 \\
\hline & $(0.001)$ & $(0.014)$ & $(0.004)$ & $(0.032)$ \\
\hline \multirow[t]{2}{*}{ Two quarters before } & -0.183 & 0.296 & -0.0151 & 0.236 \\
\hline & $(0.002)$ & $(0.015)$ & $(0.004)$ & $(0.033)$ \\
\hline \multirow[t]{2}{*}{ One quarter before } & -0.268 & 0.679 & 0.0345 & 0.417 \\
\hline & $(0.002)$ & $(0.016)$ & $(0.004)$ & $(0.034)$ \\
\hline \multirow[t]{2}{*}{ One quarter after } & 1.502 & 2.226 & 2.117 & 1.213 \\
\hline & $(0.002)$ & $(0.018)$ & $(0.004)$ & $(0.041)$ \\
\hline \multirow[t]{2}{*}{ Two quarters after } & 1.426 & 3.081 & 1.901 & 1.968 \\
\hline & $(0.002)$ & $(0.021)$ & $(0.005)$ & $(0.045)$ \\
\hline \multirow[t]{2}{*}{ Three quarters after } & 1.600 & 2.500 & 0.455 & 1.816 \\
\hline & $(0.002)$ & $(0.025)$ & $(0.005)$ & $(0.047)$ \\
\hline \multirow[t]{2}{*}{ Four quarters after } & 1.546 & 2.314 & 1.323 & 2.009 \\
\hline & $(0.003)$ & $(0.030)$ & $(0.006)$ & $(0.050)$ \\
\hline Other controls & Yes & Yes & Yes & Yes \\
\hline No. of observations & $13,036,083$ & $13,036,083$ & $1,089,761$ & $1,089,761$ \\
\hline$R^{2}$ & 0.278 & 0.0130 & 0.564 & 0.0284 \\
\hline
\end{tabular}

Sources: BlackBox Logic; authors' calculations.

a. The sample of two-year adjustable-rate mortgages consists of loans that were mainly originated during 2004-06. The loans faced a fixed initial rate for the first two years and subsequently were reset to a variable rate based on a short-term interest rate index.

b. The sample of three-year adjustable-rate mortgages consists of loans that were mainly originated between March 2004 and January 2005, when interest rates were at a historically low level. These loans experienced an interest rate reset three years after their origination, corresponding to the period April 2007 to January 2008, when interest rates were at a relatively high level. The relatively high interest rates during this period induced substantial rate increases after resets, and the private-label refinancing market virtually collapsed, limiting refinancing opportunities.

c. The independent variables are time dummies corresponding to the number of quarters before or after the interest rate reset. The omitted category is four quarters before. The specifications control for a variety of borrower, loan, and regional characteristics. Standard errors are in parentheses. 
Figure 17. The Impact of Adjustable-Rate Mortgage Resets on Defaults, Mid 2006-Early 2008

Default rate for 2-year $\mathrm{ARMs}^{\mathrm{a}}$

\section{Percent}

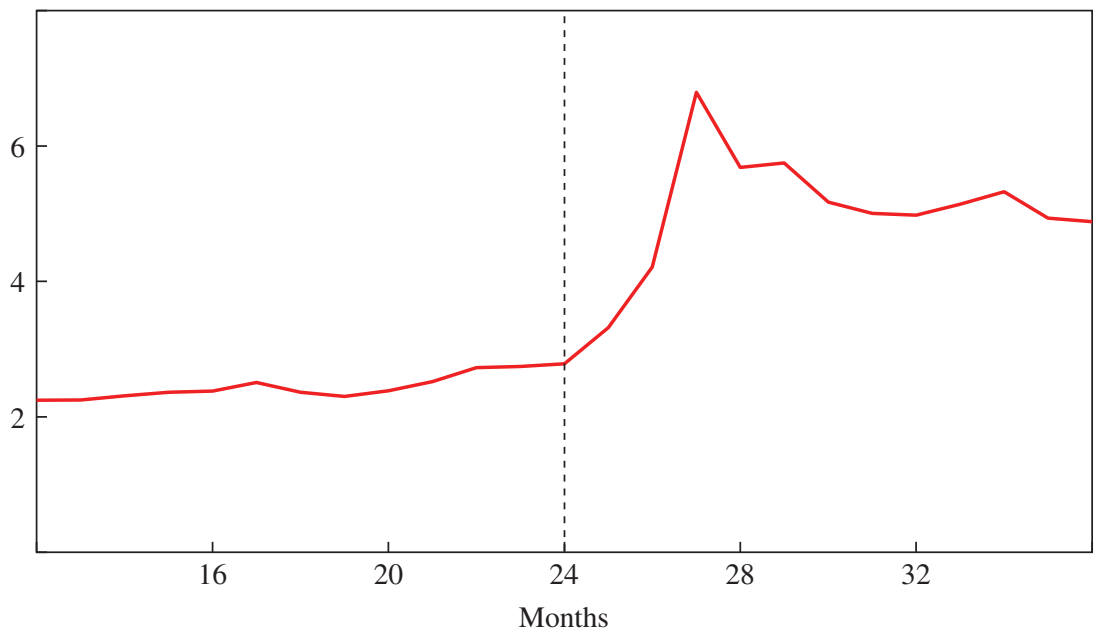

Default rate for 3-year ARMs ${ }^{\mathrm{b}}$

Percent

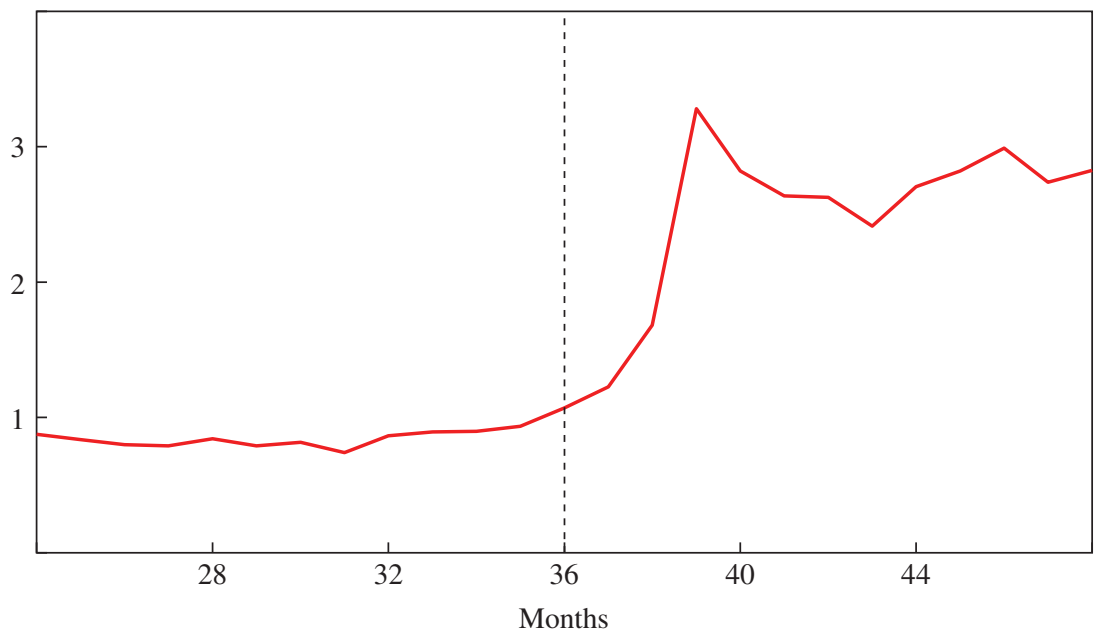

Sources: BlackBox Logic; authors' calculations.

a. This panel shows the mortgage default rate for two-year, subprime, adjustable-rate mortgages mainly originated during 2004-06. The loans faced a fixed initial rate for the first two years and subsequently were reset to a variable rate based on a short-term interest rate index. The vertical line marks two years.

b. This panel shows the mortgage default rate for three-year, subprime, adjustable-rate mortgages mainly originated between March 2004 and January 2005. The loans faced a fixed initial rate for the first three years and subsequently were reset to a variable rate based on a short-term interest rate index. The vertical line marks three years. 
loan's life. Note that it would take at least two months to see the effects of the reset, because for a loan to be considered seriously delinquent, it needs to be 60 days or more past due on payments. We observe a very substantial increase in the default rate just after the first reset date. Column 2 in the bottom panel of table 7 confirms this inference by showing that these borrowers experience an estimated absolute increase in the monthly default rate of between 2.2 and 3 percent during the four quarters after the first reset, a very substantial effect (a relative increase of more than 100 percent).

One could worry that some of these effects reflect selection on unobservables, due to refinancings around the reset date. In particular, if betterquality borrowers refinance their loans before the reset, the increase in the default rate could reflect the change in the sample composition. To address this concern, we also consider a sample of more than 180,000 three-year ARMs that were originated between March 2004 and January 2005, when interest rates were at a historically low level (the top panel of table 7 shows summary statistics for this sample). These loans experienced the first reset three years after their origination, which corresponds to the period April 2007 to January 2008. During this period, interest rates were at a relatively high level (see online appendix figure A7), inducing substantial rate increases after resets and the private label refinancing market virtually collapsed, limiting refinancing opportunities. The two right-most columns show that there is also a strong association between the interest rate reset and the increase in the default rate in this sample (also see the bottom panel of figure 17). In particular, three-year ARM borrowers in our sample experienced a rate increase of about 1.58 percentage points after the reset (a relative increase of about 25 percent) and an associated increase in the monthly default rate of between 1.2 and 2 percentage points (a relative increase in the default rate of more than 100 percent). Overall, this evidence suggests that an increase in interest rate indexes at the outset of the Great Recession contributed to the high default rate among ARM borrowers, possibly exacerbating the initial stage of the recent housing crisis. This effect could have been quite important, given that the majority of subprime loans originated before the crisis were ARMs.

The ability of mortgages indexed to national-level rate indexes to serve as effective debt relief also depends on the nature of monetary policy. In particular, policymakers could take into account ARMs' potential role as an automatic stabilizer in setting national-level interest rates indexes. This, however, would require a careful and up-to-date assessment of economic conditions faced by borrowers, because ARM contracts could also accelerate the pass-through of policy mistakes to households and the real 
economy. Moreover, a system with a larger share of ARMs could also complicate the central bank's price stability objective, given that increases in interest rates can be highly unpopular with homeowners, creating political pressure to keep rates low for an extended period (Campbell 2013). Finally, in our analysis we have not considered inflation risk. In an environment with significant relative price instability, FRM contracts may provide additional benefits to borrowers by insuring them against fluctuations in nominal interest rates and the associated potential increase in their debt payments relative to their incomes (Campbell and Cocco 2003).

Regardless of such factors, the significant regional heterogeneity we document in the previous section indicates that one-size-fits-all contract indexation based on national-level variables may reduce the effectiveness of such solutions. Instead, there may be gains from pegging mortgage contracts to more granular regional conditions. Of course, such gains would need to be traded off with the potential costs of implementing such indexation, as noted above, including the costs of introducing new contracts with limited prior market experience.

HOUSE PRICE INDEXATION An alternative indexation form consists of mortgages that depend on local house price indexes. Given significant regional heterogeneity, one key advantage of such contracts is that their terms can be more closely tied to local economic conditions, as opposed to ARMs that are tied to national-level interest rates. Robert Shiller (2008) has long advocated for such "continuous workout mortgages." Piskorski and Tchistyi (2017) show that home equity insurance mortgages that are indexed to house prices, by alleviating incentives to default strategically, arise as an equilibrium contract in the private lending market, with empirically relevant frictions. Moreover, Greenwald, Landvoigt, and Van Nieuwerburgh (2018) show that indexation to local house prices can reduce financial fragility and improve risk-sharing if intermediaries retain a significant portion of loans on their balance sheets.

The widespread adoption of mortgages indexed to house prices would require timely and accurate regional house price indexes. Such indexes were unavailable in the past. ZIP code-level house price indexes have only recently been developed and started being offered by data providers such as Zillow (see online appendix figure A8 for an example).

LABOR INCOME INDEXATION Our discussion in section II suggests that conditioning mortgages on indexes capturing both local labor market conditions and house prices may provide additional efficiency. However, such arrangements would require timely and accurate regional local labor market indexes, which as of today are not commercially available. Having said 
this, current unemployment insurance programs implicitly provide a form of labor income indexation-partly insuring households against income shocks-which helps distressed households service their mortgage debt obligations (Hsu, Matsa, and Melzer 2018). Moreover, one could consider social transfer programs that directly provide temporary subsidies, reducing the mortgage payments of unemployed borrowers. Such programs could condition the terms of the transfers on the specific financial position of the borrower (for example, their debt burdens or DTIs). A potential downside of such approaches is that they could result in moral hazard risk for borrowers (Mayer and others 2014), which we discussed in section I. For example, providing mortgage payment support to unemployed borrowers may erode their incentives to find a new job. The potential for such unintended consequences of social transfers for the unemployed has long been recognized in the unemployment insurance literature.

DISCUSSION It is important to note that we have not suggested designing contracts just based on individual CLTVs, house prices, or employment rates. Although potentially more efficient in capturing the risk dynamics of individuals, such contracts may create moral hazard in terms of incentives to pay or maintain a house. For this reason, we focus our discussion on indexes capturing these variables at the regional level (for example, at the ZIP code level).

It is worth discussing the fact that such indexation forms have not been widely implemented in the past, for several reasons. First, substantial government involvement in the mortgage market through a system of subsidies and regulations favors traditional contracts like FRMs and ARMs. This potentially suppresses the adoption of new mortgage designs.

Second, the implementation of a new mortgage design may require a significant amount of time due to private market inertia, learning, or a low perceived value of such innovations from the ex ante perspective. For example, before the Great Depression, mortgage contracts were predominantly short-term loans. The inability to roll these loans over was a major factor in the collapse of the financial and housing markets. As a result, the government helped the private market develop and standardize the fully amortizing, long-term contracts, such as FRMs, that currently dominate the U.S. housing market.

Third, the widespread adoption of contracts indexed to local economic conditions would require timely and accurate regional indexes. Such indexes were unavailable in the past, and only recently have some been developed and started being offered by data providers (for example, house price indexes). As we discussed in subsection III.C, given significant regional 
heterogeneity, the lack of such indexes at a sufficiently granular level may have significantly reduced the potential efficiency of such solutions, stifling incentives for their development. ${ }^{22}$

Fourth and finally, it is not clear that private market innovation would lead to the successful development of such contracts. In particular, Piskorski and Tchistyi (2017) show that in the competitive equilibrium setting with empirically relevant frictions, unrestricted competition in mortgage design may lead in some cases to market instability (that is, the nonexistence of equilibrium). Their findings highlight the potential, understudied role of the government-sponsored enterprises (GSEs): By subsidizing a restricted contract choice through their guarantee system, the GSEs may help facilitate the existence of a stable mortgage market by limiting private competition in mortgage design. In this regard, the government may also play a potentially important role in the practical implementation of new mortgage designs by promoting certain contracts through its system of subsidies. The downside of this approach is that it would require continued operation of the GSEs and the Federal Housing Administration-institutions that are plagued by political economy concerns surrounding implicit and explicit government guarantees. Such an approach would also limit the ability to use market pricing for assessing the cost of insurance embedded in new mortgage designs.

\section{IV.B. Leveraging Regulation and Down Payment Limits}

Intuitively, as we discussed in section II, the benefits of indexed mortgage contracts or debt relief policies are much smaller for borrowers with significant housing equity. Hence, an alternative approach to decrease the likelihood and costs of future housing crises is preventing households from becoming highly leveraged in the first place. ${ }^{23}$ This approach would also alleviate the impact of the frictions discussed in section I by simply limiting the number of borrowers who require debt relief in the first place. One way to implement this in practice would be to impose contract restrictions, like stricter minimum down payment limits, in the current mortgage market setting. Of course, such policies, though potentially simpler to implement than other approaches, could result in additional welfare costs

22. In addition, Hartman-Glaser and Hébert (2017) point out that if there are informational asymmetries between borrowers and lenders about the ability of such indexes to measure underlying states, the risk-sharing ability of state-contingent contracts based on such indexes can be limited.

23. For a recent analysis of such policies, see DeFusco, Johnson, and Mandragon (2017). 
by delaying or preventing homeownership for some borrowers. There are also political economy considerations that might prevent such regulation from being imposed, especially when the housing market is booming. Finally, given significant evidence of misreporting the true extent of down payment and housing equity by financial intermediaries before the recent crisis (Ben-David 2011; Piskorski, Seru, and Witkin 2015; Griffin and Maturana 2016), such policies may face additional implementation hurdles.

\section{IV.C. Private Mortgage Renegotiation}

Another approach to implementing debt relief is to rely on private renegotiation efforts. Because foreclosure can induce significant deadweight costs, there should be instances where both borrowers and lenders would find it beneficial to temporarily reduce their household debt burden during economic downturns. As we discussed in section I, this approach faced a number of limitations during the Great Recession that were related to organizational frictions and capacity constraints in the intermediary sector, agency conflicts in securitization, ex post moral hazard concerns of intermediaries, and the inability of intermediaries to identify instances when renegotiation might be beneficial for both borrowers and lenders. More broadly, private ex post renegotiation may not take into account the positive externalities of debt relief and may also be of limited scope relative to solutions that rely on ex ante committed changes in contract terms.

\section{IV.D. Public Debt Relief Programs}

An alternative approach to implementing debt relief policies is to leave the structure of the mortgage contracts intact and instead rely on largescale government programs or monetary policy. Indeed, during the Great Recession the Federal Reserve reduced short-term interest rates and made large purchases of mortgage-backed securities in one attempt, among others, to support the prices of assets such as houses and lower the incidence of foreclosures.

Moreover, in response to the recent crisis, the administration passed two unprecedented and large-scale debt relief programs: HARP, aimed, again, at stimulating the mortgage refinancing activity of up to 8 million heavily indebted borrowers; and HAMP, aimed at stimulating a mortgage restructuring effort for up to 4 million borrowers at risk of foreclosure. Other notable programs during the Great Recession included first-time buyer tax credits aimed at stimulating house purchases (Berger, Turner, and Zwick 2016) and programs aimed at stimulating consumer spending, such 
as economic stimulus payments (Parker and others 2013) and subsidies for new car purchases (Mian and Sufi 2012).

As we discussed in section I, various implementation frictionsincluding the nature of mortgage contracts and the ability of financial intermediaries to quickly implement debt relief — can hamper the effectiveness of ex post solutions. For example, Di Maggio and others (2017) show that a significant heterogeneity in the ARM share across regions (see the top panel of figure 16) resulted in a significant differential pass-through of lower interest rates to households.

Unlike one-size-fits-all monetary policy, HAMP and HARP implemented a form of specific, individual targeting. This, given the evidence of significant regional and borrower heterogeneity, could in principle increase their efficiency. HAMP was mainly targeted at distressed borrowers with high DTIs. However, the need to verify such program criteria, coupled with the limited organizational ability of financial intermediaries, significantly hindered its effectiveness (Agarwal and others 2017a). The middle panel of figure 16 shows significant regional variation in the share of intermediaries with an organizational design that is conducive to renegotiation, suggesting that debt relief through a program like HAMP would be differentially passed through across space.

Wide-scale refinancing programs such as HARP may be easier to implement because they stimulate a more routine activity like refinancing rather than loan renegotiation. Moreover, a program like HARP, which was based on CLTVs, implicitly indexed local house prices on a granular level. However, because the implementation of this program was through intermediaries, its effectiveness was hampered both by intermediary friction, such as capacity constraints, and by market design, such as competition in the refinancing market (Agarwal and others 2017b; Fuster and others 2017). Moreover, the program targeted only loans issued with prior GSE guarantees (agency loans), which usually correspond to more creditworthy borrowers than subprime borrowers. The bottom panel of figure 16 illustrates significant regional heterogeneity in the fraction of loans eligible for HARP (Agarwal and others 2017b). This suggests that debt relief through refinancing would be less likely in some regions than others.

To illustrate the importance of such factors, we conduct a simple analysis of the change in ZIP code-level quarterly delinquency and foreclosure growth after the period starting in 2009 relative to the prior period. We note that 2009 coincides with the introduction of various debt relief programs, including HARP and HAMP, and with a firm commitment to the prolonged policy of low interest rates. In particular, table 8 shows the 


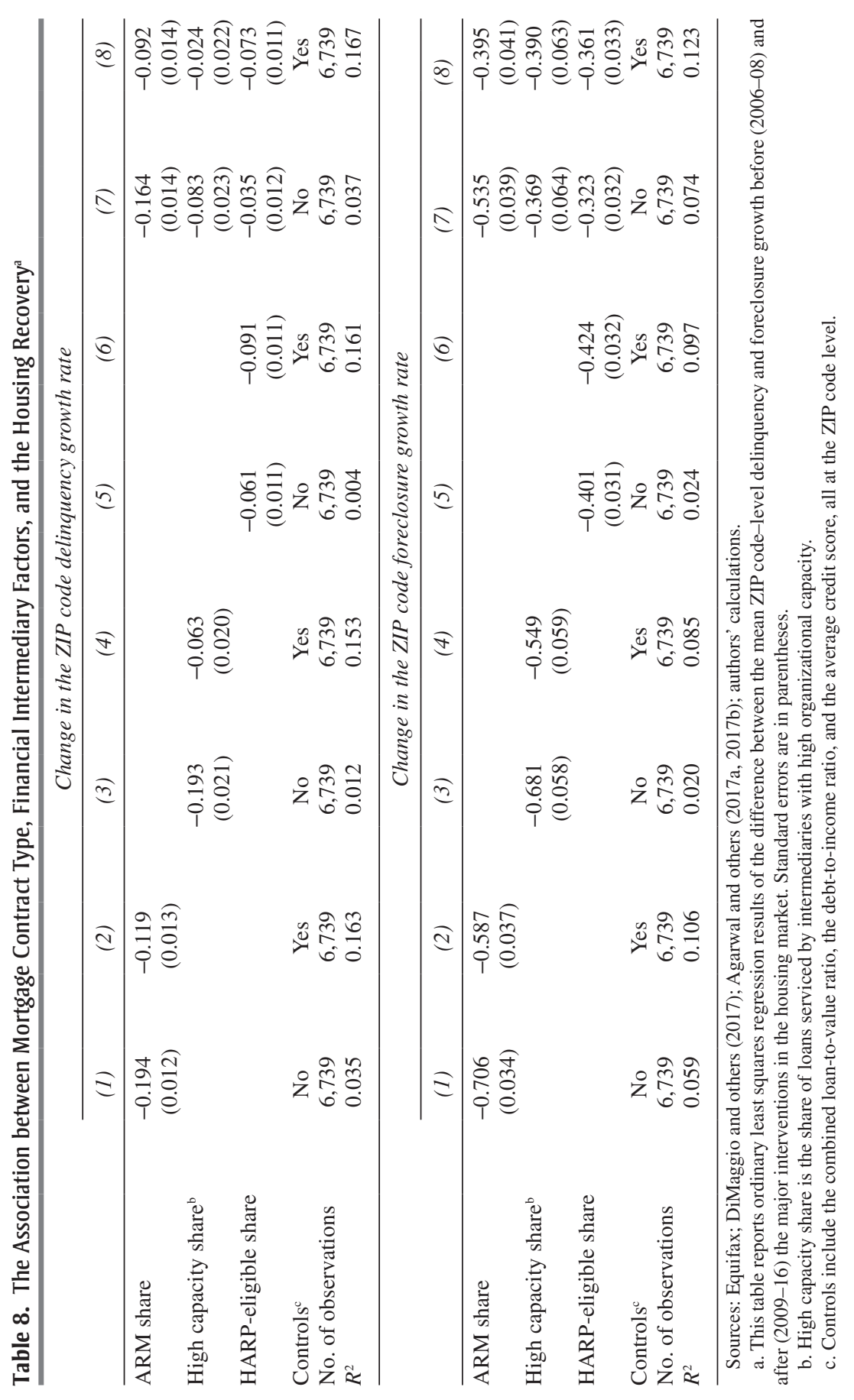


results of regressions of the difference in mean ZIP code-level delinquency or foreclosure growth on the ZIP code-level ARM share, high-intermediary capacity share, and HARP-eligible share.

The top panel of table 8 shows the results for changes in ZIP codelevel delinquency growth. Columns 1 through 6 regress the change in delinquency growth separately on each of the independent variables. We find that all coefficients in these columns are negative, indicating that ZIP codes with higher shares of ARMs, high-capacity servicers, and HARPeligible loans experience faster declines in delinquency growth. Columns 7 and 8 include all these variables together and show that all the coefficients remain negative. The bottom panel of the table shows the results for ZIP code-level foreclosure growth. Consistent with results in the top panel, we find that ZIP codes with higher shares of ARMs, higher shares of loans serviced by high-capacity intermediaries, and higher shares of HARPeligible loans experienced faster declines in foreclosures after 2009. This evidence is consistent with the findings of Agarwal and others (2017a, 2017b) and Di Maggio and others (2017), who show that these factors played an important role in the effectiveness of debt relief measures undertaken during the Great Recession and their differential impact across regions.

Overall, these findings provide guidance for designing large-scale debt relief programs in the future. First, in the case of programs aimed at stimulating mortgage renegotiation activity, such as HAMP, it may have been productive for the program to have allowed the easy transfer of distressed mortgages from inefficient servicers to those more capable of conducting many renegotiations. One way to address this issue in the future is to rely more heavily on special servicers, as is common in the commercial real estate market. Upon the occurrence of certain specified adverse events, the nonperforming loans would be automatically transferred to organizations better equipped to handle such assets. Moreover, there is a likely trade-off between screening more intensively-which limits the potential costs of such programs, including strategic defaults-and the reach and pace of the program.

Wide-scale refinancing programs such as HARP may be easier to implement because they stimulate a more routine activity like refinancing rather than loan renegotiation. Moreover, a program like HARP, which was based on CLTVs, was implicitly indexed on a granular level (local house prices) relative to national-level indexes. However, because the implementation of this program was through intermediaries, its effectiveness was hampered both by intermediary frictions, such as capacity constraints, and market design, such as competition in the refinancing market (Agarwal and others 2017b; 
Fuster and others 2017), and by its eligibility being restricted to loans issued with prior GSE guarantees. Such programs critically rely on the ability of the government to guarantee mortgage debt during a crisis (for example, through the GSEs). Their success also particularly depends on the speed and extent to which interest rates reach sufficiently low levels during housing market downturns, which may impose additional constraints on the conduct of monetary policy. HARP-like policies could also become a part of permanent market arrangements by automatically relaxing housing equity refinancing constraints in regions that have experienced sufficient declines in house prices.

\section{Conclusion}

In this paper, we have focused on understanding design and implementation challenges of ex ante and ex post debt relief solutions aimed at a more efficient sharing of aggregate risk between borrowers and lenders. Our analysis and discussion highlight an important trade-off that warrants more research. The indexed mortgage contracts have the advantage of circumventing financial intermediary and other frictions by facilitating a quick ("automatic") implementation of debt relief during economic downturns. However, as illustrated in subsection II.B, for such contracts to be effective, lenders, policymakers, and borrowers may need a good ex ante understanding of the underlying distribution of risk and its relation to indexes being used when designing and choosing such contracts. Errors in beliefs about the structure of risk can reduce the benefits of such solutions. Given the vast heterogeneity in the nature of risk across space and time, such errors are likely, especially because a major change in the nature of mortgage contracts or housing policy can on its own significantly alter relationships between market equilibrium outcomes in a way that is potentially hard to quantify. Thus, it seems prudent to also rely on ex post debt relief solutions.

Ex post debt relief solutions, on one hand, have the advantage of being more fine-tuned to the specific realization of economic risk. On the other hand, they have limitations. As our analysis and discussion illustrate, these solutions are subject to various implementation frictions that could significantly delay debt relief and hinder its effectiveness.

More broadly, our evidence suggests that an effective mortgage design approach to debt relief requires a more in-depth analysis of the nature of relevant income and housing risk and its evolution across regions and borrowers. This could include the development of new and sufficiently granular indexes on which such contracts could be based. The recent 
"big data" revolution is promising in this regard. Such an analysis could also identify mortgage designs that effectively implement debt relief across a range of possible environments. As well, the approach relying on ex post solutions should focus on alleviating frictions that may hinder the effective implementation of policies like the ones we discussed in section I. Big data might again be useful here, because they could enable the development of an effective and easy-to-verify set of eligibility criteria for debt relief policies.

Our understanding of the design and implementation challenges for ex ante and ex post debt relief solutions suggests that a more resilient mortgage market system will involve a combination of ex ante and ex post policies with state contingencies. At minimum, the state contingency should involve the national-level variables; but as our analysis suggests, it would benefit from more granular variables to better address the variation faced by the borrowers (for example, by incorporating local house price indexes). It is clear that a better designed ex ante state contingency would limit the need to rely on ex post solutions. This may be desirable because a large quantity of distressed loans and the presence of intermediary frictions may not allow for the necessary level of debt relief (such as refinancing) to combat the crisis. This would also alleviate the pressure on financial intermediaries to implement large-scale debt relief (such as loan modifications) during a national crisis. Nonetheless, despite the best laid plans ex ante, it is likely that severe housing market downturns would require interventions ex post. What our analysis and discussion have demonstrated is that, though such ex post policies are easier to design, the implementation challenges are immense and must be thought about carefully. Finally, because the GSEs are likely to dominate the residential lending market, at least in the short to medium terms (Buchak and others 2017), a more resilient, redesigned mortgage system would likely require their active participation, an aspect about which we have been silent. Whether their presence would alleviate the various coordination and implementation hurdles of moving to a new mortgage market architecture remains an open area for discussion and research.

ACKNOWLEDGMENTS We thank Janice Eberly and James Stock for guidance, and Anthony DeFusco and Paul Willen for helpful comments and discussion. We also thank Erik Hurst, Arvind Krishnamurthy, Karen Pence, and Richard Stanton for useful comments. We thank Monica Clodius, Susan Cherry, Sam Liu, Jonathan Wallen, and Yang Zhao for outstanding research assistance. 


\section{References}

Adelino, Manuel, Kristopher Gerardi, and Paul S. Willen. 2014. "Why Don't Lenders Renegotiate More Home Mortgages? Redefaults, Self-Cures and Securitization." Journal of Monetary Economics 60, no. 7: 835-53.

Adelino, Manuel, Antoinette Schoar, and Felipe Severino. 2016. "Loan Originations and Defaults in the Mortgage Crisis: The Role of the Middle Class." Review of Financial Studies 29, no. 7: 1635-70.

Agarwal, Sumit, Gene Amromin, Itzhak Ben-David, Souphala Chomsisengphet, and Douglas D. Evanoff. 2011. "The Role of Securitization in Mortgage Renegotiation." Journal of Financial Economics 102, no. 3: 559-78.

Agarwal, Sumit, Gene Amromin, Itzhak Ben-David, Souphala Chomsisengphet, Tomasz Piskorski, and Amit Seru. 2017a. "Policy Intervention in Debt Renegotiation: Evidence from the Home Affordable Modification Program." Journal of Political Economy 125, no. 3: 654-712.

Agarwal, Sumit, Gene Amromin, Souphala Chomsisengphet, Tim Landvoigt, Tomasz Piskorski, Amit Seru, and Vincent Yao. 2017b. "Mortgage Refinancing, Consumer Spending, and Competition: Evidence from the Home Affordable Refinancing Program.” Working Paper no. 21512. Cambridge, Mass.: National Bureau of Economic Research.

Agarwal, Sumit, Souphala Chomsisengphet, Neale Mahoney, and Johannes Stroebel. 2018. "Do Banks Pass Through Credit Expansions to Consumers Who Want to Borrow?" Quarterly Journal of Economics 133, no. 1: 129-90.

Andersen, Steffen, John Y. Campbell, Kasper Meisner Nielsen, and Tarun Ramadorai. 2014. "Inattention and Inertia in Household Finance: Evidence from the Danish Mortgage Market.” Working Paper no. 21386. Cambridge, Mass.: National Bureau of Economic Research.

Auclert, Adrien. 2017. "Monetary Policy and the Redistribution Channel." Working Paper no. 23451. Cambridge, Mass.: National Bureau of Economic Research.

Ben-David, Itzhak. 2011. "Financial Constraints and Inflated Home Prices during the Real-Estate Boom." American Economic Journal: Applied Economics 3, no. 3: 55-87.

Benmelech, Efraim, Ralf R. Meisenzahl, and Rodney Ramcharan. 2017. "The Real Effects of Liquidity during the Financial Crisis: Evidence from Automobiles." Quarterly Journal of Economics 132, no. 1: 317-65.

Beraja, Martin, Andreas Fuster, Erik Hurst, and Joseph Vavra. 2017. "Regional Heterogeneity and Monetary Policy." Working Paper no. 23270. Cambridge, Mass.: National Bureau of Economic Research.

Berger, David, Nicholas Turner, and Eric Zwick. 2016. "Stimulating Housing Markets." Working Paper no. 22903. Cambridge, Mass.: National Bureau of Economic Research.

Bhutta, Neil, and Benjamin J. Keys. 2016. "Interest Rates and Equity Extraction during the Housing Boom.” American Economic Review 106, no. 7: 1742-74. 
Buchak, Greg, Gregor Matvos, Tomasz Piskorski, and Amit Seru. 2017. "Fintech, Regulatory Arbitrage, and the Rise of Shadow Banks.” Working Paper no. 23288. Cambridge, Mass.: National Bureau of Economic Research.

Campbell, John Y. 2013. "Mortgage Market Design.” Review of Finance 17, no. 1: $1-33$.

Campbell, John Y., and João F. Cocco. 2003. "Household Risk Management and Optimal Mortgage Choice." Quarterly Journal of Economics 118, no. 4: 1449-94.

. 2015. "A Model of Mortgage Default." Journal of Finance 70, no. 4: $1495-554$.

Campbell, John Y., Stefano Giglio, and Parag Pathak. 2011. "Forced Sales and House Prices." American Economic Review 101, no. 5: 2108-31.

Caplin, Andrew, Noël Cunningham, Mitchell Engler, and Frederick Pollack. 2008. "Facilitating Shared Appreciation Mortgages to Prevent Crashes and Affordability Crises." Discussion Paper no. 2008-12. Brookings, Hamilton Project.

Chen, Hui, Michael Michaux, and Nikolai Roussanov. 2013. "Houses as ATMs? Mortgage Refinancing and Macroeconomic Uncertainty." Working Paper no. 19421. Cambridge, Mass.: National Bureau of Economic Research.

DeFusco, Anthony, Stephanie Johnson, and John Mondragon. 2017. "Regulating Household Leverage." Working paper. https://ssrn.com/abstract=3046564

DeFusco, Anthony A., Charles G. Nathanson, and Eric Zwick. 2017. "Speculative Dynamics of Prices and Volume." Working Paper no. 23449. Cambridge, Mass.: National Bureau of Economic Research.

Di Maggio, Marco, Amir Kermani, Benjamin J. Keys, Tomasz Piskorski, Rodney Ramcharan, Amit Seru, and Vincent Yao. 2017. "Interest Rate Pass-Through: Mortgage Rates, Household Consumption, and Voluntary Deleveraging." American Economic Review 107, no. 11: 3550-88.

Di Maggio, Marco, Amir Kermani, and Christopher Palmer. 2016. "How Quantitative Easing Works: Evidence on the Refinancing Channel." Working Paper no. 22638. Cambridge, Mass.: National Bureau of Economic Research.

Drechsler, Itamar, Alexi Savov, and Philipp Schnabl. 2017. "The Deposits Channel of Monetary Policy." Quarterly Journal of Economics 132, no. 4: 1819-76.

Dunn, Kenneth B., and Chester S. Spatt. 1985. "An Analysis of Mortgage Contracting: Prepayment Penalties and the Due-on-Sale Clause." Journal of Finance 40, no. 1: 293-308.

Eberly, Janice, and Arvind Krishnamurthy. 2014. "Efficient Credit Policies in a Housing Crisis." Brookings Papers on Economic Activity, Fall: 73-118.

Favilukis, Jack, Sydney C. Ludvingson, and Stijn Van Nieuwerburgh. 2017. "The Macroeconomic Effects of Housing Wealth, Housing Finance, and Limited Risk Sharing in General Equilibrium.” Journal of Political Economy 125, no. 1: 140-223.

Foote, Christopher L., Kristopher Gerardi, and Paul S. Willen. 2008. "Negative Equity and Foreclosure: Theory and Evidence." Journal of Urban Economics 64, no. 2: 234-45. 
Fuster, Andreas, Laurie Goodman, David Lucca, Laurel Madar, Linsey Molloy, and Paul Willen. 2013. "The Rising Gap between Primary and Secondary Mortgage Rates." Economic Policy Review 19, no. 2: 17-39.

Fuster, Andreas, Stephanie H. Lo, and Paul S. Willen. 2017. "The Time-Varying Price of Financial Intermediation in the Mortgage Market." Staff Report no. 805. Federal Reserve Bank of New York.

Fuster, Andreas, and Paul S. Willen. 2017. "Payment Size, Negative Equity, and Mortgage Default." American Economic Journal: Economic Policy 9, no. 4: 167-91.

Ganong, Peter, and Pascal Noel. 2017. “The Effect of Debt on Default and Consumption: Evidence from Housing Policy in the Great Recession." Working paper. https://scholar.harvard.edu/files/noel/files/ganong_noel_housing_2017-12-16.pdf

Glaeser, Edward L., Joseph Gyourko, and Albert Saiz. 2008. "Housing Supply and Housing Bubbles." Journal of Urban Economics 64, no. 2: 198-217.

Green, Richard K., and Susan M. Wachter. 2005. "The American Mortgage in Historical and International Context." Journal of Economic Perspectives 19, no. 4: 93-114.

Greenwald, Daniel L. 2018. “The Mortgage Credit Channel of Macroeconomic Transmission." Job market paper. http://www.dlgreenwald.com

Greenwald, Daniel L., Tim Landvoigt, and Stijn Van Nieuwerburgh. 2018. "Financial Fragility with SAM?" Working paper. http://www.dlgreenwald.com

Griffin, John M., and Gonzalo Maturana. 2016. "Who Facilitated Misreporting in Securitized Loans?” Review of Financial Studies 29, no. 2: 384-419.

Guerrieri, Veronica, and Harald Uhlig. 2016. "Housing and Credit Markets: Booms and Busts." In Handbook of Macroeconomics, Volume 2B, edited by John B. Taylor and Harald Uhlig. Amsterdam: North-Holland.

Guren, Adam M., Arvind Krishnamurthy, and Timothy J. McQuade. 2017. "Mortgage Design in an Equilibrium Model of the Housing Market." Working Paper no. 24446. Cambridge, Mass.: National Bureau of Economic Research.

Hartman-Glaser, Barney, and Benjamin Hébert. 2017. “The Insurance Is the Lemon: Failing to Index Contracts.” Working Paper no. 3569. Stanford, Calif.: Stanford University, Graduate School of Business.

Hsu, Joanne W., David A. Matsa, and Brian T. Melzer. 2018. "Unemployment Insurance as a Housing Market Stabilizer." American Economic Review 108, no. 1: 49-81.

Hurst, Erik, Benjamin J. Keys, Amit Seru, and Joseph Vavra. 2016. "Regional Redistribution through the US Mortgage Market." American Economic Review 106, no. 10: 2982-3028.

Kaplan, Greg, Kurt Mitman, and Giovanni L. Violante. 2017. “The Housing Boom and Bust: Model Meets Evidence." Working Paper no. 23694. Cambridge, Mass.: National Bureau of Economic Research.

Keys, Benjamin J., Tanmoy Mukherjee, Amit Seru, and Vikrant Vig. 2010. "Did Securitization Lead to Lax Screening? Evidence from Subprime Loans." Quarterly Journal of Economics 125, no. 1: 307-62. 
Keys, Benjamin J., Tomasz Piskorski, Amit Seru, and Vikrant Vig. 2013. "Mortgage Financing in the Housing Boom and Bust." In Housing and the Financial Crisis, edited by Edward L. Glaeser and Todd Sinai. University of Chicago Press.

Keys, Benjamin J., Devin G. Pope, and Jaren C. Pope. 2016. "Failure to Refinance." Journal of Financial Economics 122, no. 3: 482-99.

Kruger, Samuel. Forthcoming. "The Effect of Mortgage Securitization on Foreclosure and Modification." Journal of Financial Economics.

Kung, Edward. 2015. "Mortgage Market Institutions and Housing Market Outcomes." Working paper. https://sites.google.com/site/edwardkung

Landvoigt, Tim, Monika Piazzesi, and Martin Schneider. 2015. "Housing Market(s) of San Diego.” American Economic Review 105, no. 4: 1371-407.

Maturana, Gonzalo. 2017. "When Are Modifications of Securitized Loans Beneficial to Investors?" Review of Financial Studies 30, no. 11: 3824-57.

Mayer, Christopher, Edward Morrison, Tomasz Piskorski, and Arpit Gupta. 2014. "Mortgage Modification and Strategic Behavior: Evidence from a Legal Settlement with Countrywide." American Economic Review 104, no. 9: 2830-57.

Mayer, Christopher, Karen Pence, and Shane M. Sherlund. 2009. "The Rise in Mortgage Defaults." Journal of Economic Perspectives 23, no. 1: 27-50.

Mayer, Christopher J., Tomasz Piskorski, and Alexei Tchistyi. 2013. "The Inefficiency of Refinancing: Why Prepayment Penalties Are Good for Risky Borrowers." Journal of Financial Economics 107, no. 2: 694-714.

Melzer, Brian T. 2017. "Mortgage Debt Overhang: Reduced Investment by Homeowners at Risk of Default." Journal of Finance 72, no. 2: 575-612.

Mian, Atif, and Amir Sufi. 2009. "The Consequences of Mortgage Credit Expansion: Evidence from the U.S. Mortgage Default Crisis." Quarterly Journal of Economics 124, no. 4: 1449-96.

—. 2011. "House Prices, Home Equity-Based Borrowing, and the US Household Leverage Crisis." American Economic Review 101, no. 5: 2132-56.

_. 2012. "The Effects of Fiscal Stimulus: Evidence from the 2009 Cash for Clunkers Program." Quarterly Journal of Economics 127, no. 3: 1107-42.

- 2014a. House of Debt: How They (and You) Caused the Great Recession, and How We Can Prevent It from Happening Again. University of Chicago Press.

- 2014b. "What Explains the 2007-2009 Drop in Employment?" Econometrica 82, no. 6: 2197-223.

Parker, Jonathan A., Nicholas S. Souleles, David S. Johnson, and Robert McClelland. 2013. "Consumer Spending and the Economic Stimulus Payments of 2008." American Economic Review 103, no. 6: 2530-53.

Piskorski, Tomasz, Amit Seru, and Vikrant Vig. 2010. "Securitization and Distressed Loan Renegotiation: Evidence from the Subprime Mortgage Crisis." Journal of Financial Economics 97, no. 3: 369-97.

Piskorski, Tomasz, Amit Seru, and James Witkin. 2015. “Asset Quality Misrepresentation by Financial Intermediaries: Evidence from the RMBS Market." Journal of Finance 70, no. 6: 2635-78. 
Piskorski, Tomasz, and Alexei Tchistyi. 2010. "Optimal Mortgage Design." Review of Financial Studies 23, no. 8: 3098-140. . 2011. "Stochastic House Appreciation and Optimal Mortgage Lending." Review of Financial Studies 24, no. 5: 1407-46.

—. 2017. "An Equilibrium Model of Housing and Mortgage Markets with State-Contingent Lending Contracts." Working Paper no. 23452. Cambridge, Mass.: National Bureau of Economic Research.

Purnanandam, Amiyatosh. 2011. "Originate-to-Distribute Model and the Subprime Mortgage Crisis." Review of Financial Studies 24, no. 6: 1881-915.

Rajan, Uday, Amit Seru, and Vikrant Vig. 2015. "The Failure of Models That Predict Failure: Distance, Incentives, and Defaults." Journal of Financial Economics 115, no. 2: 237-60.

Scharfstein, David S., and Adi Sunderam. 2016. "Market Power in Mortgage Lending and the Transmission of Monetary Policy." Working paper. https:// www.hbs.edu/faculty/Pages/item.aspx?num=44239

Shiller, Robert J. 2008. The Subprime Solution: How Today's Global Financial Crisis Happened, and What to Do About It. Princeton University Press.

Sinai, Todd. 2013. "House Price Moments in Boom-Bust Cycles." In Housing and the Financial Crisis, edited by Edward L. Glaeser and Todd Sinai. University of Chicago Press.

Wong, Arlene. 2018. "Transmission of Monetary Policy to Consumption and Population Aging." Job market paper. http://www.arlene-wong.com/research/ 


\section{Comments and Discussion}

\section{COMMENT BY}

ANTHONY A. DeFUSCO In this paper, Tomasz Piskorski and Amit Seru bring new data and recent experiences from the Great Recession to bear on an old question in mortgage finance: What is the optimal way to design a mortgage contract? The answer to this question has far-reaching implications for both macroeconomic stability and individual household welfare. Residential mortgages were at the heart of the 2008-09 financial crisis, and several features of their design directly impeded policy efforts aimed at providing debt relief and economic stimulus to households during the recession.

As in much prior work on this topic, Piskorski and Seru's primary focus is on the nature and extent of risk-sharing between borrowers and lenders in the mortgage market. Broadly speaking, their paper can be read as both a clarion call for greater state contingency in mortgage contract design and a set of practical suggestions for how to best achieve this goal. To build their argument, Piskorski and Seru proceed in three steps. First, they provide a review of the theoretical literature on mortgage market design and a taxonomy of the various mortgage contract rigidities that held back policy efforts to relieve household debt during the Great Recession. Second, they present a simple model that incorporates insights from this literature to highlight the potential welfare gains from state-contingent mortgage contracts that index borrower payments to economic conditions such as house prices or income. Finally, they document a set of new empirical facts about the spatial and time-series variation in local economic conditions, which together underscore the potential benefits of indexing mortgage payments to local rather than national conditions.

This is an interesting and thought-provoking paper that should serve as a starting point for much future research. The literature review is exhaustive 
and well organized; the conceptual framework, though stylized, is helpful for elucidating the authors' main points; and the empirical work takes an important step toward addressing some of the more practical questions surrounding the design of state-contingent mortgage contracts. My comments all center on the basic and natural next question: Where do we go from here?

THE \$10.5 TRILLION QUESTION Both this paper and the broader literature on mortgage market design are premised on the notion that injecting more state dependence into the standard mortgage contract would be beneficial for both individual households and the macroeconomy. This is consistent with the large body of empirical evidence reviewed in this paper that documents the benefits of state contingencies of various types at both the individual and regional levels. If we grant this premise, which I am generally inclined to do in light of the empirical evidence, one of the most puzzling features of the U.S. mortgage market immediately becomes its lack of flexibility. In my mind, the key question that needs to be addressed before any real progress can be made is why these products do not exist in the first place.

REGULATORY BARRIERS Many of the reasons why state-contingent mortgage contracts have failed to be adopted at any significant scale arise from regulatory constraints. Although not particularly interesting from an intellectual point of view, these constrains place real and first-order limitations on the viability of many innovative mortgage products. Widespread adoption of such products will require that these constraints be lifted, which will likely depend on political rather than economic solutions.

Unclear tax treatment. Chief among these constraints is the ambiguity with which the tax code treats mortgage contracts that base borrower payments on changes in house prices. These contracts include both the standard shared appreciation mortgage (SAM) and its more complex variants, such as the continuous workout mortgage proposed by Robert Shiller (2008). Because such contracts give lenders direct exposure to changes in the value of the home being financed, they operate as hybrids between a traditional debt contract and a direct equity investment in the property. As such, it is unclear whether the borrower will be able to deduct the interest payments that he or she makes to the lender from income when determining his or her personal tax liability. Similarly, because the lender is taking a position in the equity, it is not clear whether the taxes paid on the payments received from the borrower would be assessed at the corporate income or capital gains rate. The answers to these questions would depend on the specifics of the product under consideration, and, unfortunately, the Internal Revenue Service has maintained a policy since the early 1980s of not issuing advance 
rulings on such products. The consequences of this uncertainty for mortgage contract innovation are described in colorful terms by Andrew Caplin and others (2008, p. 19), who lament:

To understand the damage this does the market one need only consider the aborted effort of Bear Stearns to reintroduce SAMs into the United States in the 1990s. Given that tax uncertainties could not be resolved via a ruling, the brochures introducing these novel mortgages to borrowers included the following stark warning: "The application of the federal income tax rules to a SAM is both uncertain and complicated, and the rules will affect each borrower differently. Accordingly, you must talk to your tax advisor about the federal income tax consequences to you of borrowing under a SAM." . . . No wonder the product was swiftly withdrawn!

A concrete resolution to these tax issues will likely be required before mortgage contracts that index payments to changes in house prices can be widely adopted.

The lack of secondary market demand. In addition to having clear guidance on tax issues, the viability of state-contingent mortgage contracts also requires the existence of a robust secondary market. Here, too, several regulatory barriers may severely impede the development of such markets. First among these is the fact that most new state-contingent contracts would likely be deemed "nonconforming." This immediately eliminates the possibility for mortgage originators to sell such loans to either of the two large government-sponsored enterprises (GSEs), Fannie Mae and Freddie Mac, that dominate the secondary mortgage market.

Without being able to sell to the GSEs, lenders looking to offer innovative new mortgage products would need to turn to private-market investors for funding. Historically, these investors would have either been large financial institutions that hold loans on portfolio or investors in private-label mortgage-backed securities. Since 2008, however, the private-label market has largely disappeared, meaning that in current market conditions the primary investor in state-contingent contracts would likely need to be a large bank that would hold these loans on portfolio. It is unlikely, however, that many banks would be willing to do so. One reason for this is that it is not clear how such loans would be treated for the purposes of determining bank capital ratios. For example, there is no clear guidance on what the risk weighting for a hybrid debt/equity product like a SAM would be. Would such products be treated like standard mortgages or like a direct investment in residential real estate? Resolution of this situation is likely needed if these products are to become commonplace alternatives to the standard fixed-rate mortgage. 
Finally, regardless of who the ultimate investor is, regulatory considerations may also limit the appeal of state-contingent mortgage contracts among originators. Since 2014, lenders making loans that do not meet the definition of a qualified mortgage (QM) have faced the potential for additional legal liability under Dodd-Frank's Ability-to-Repay rule. ${ }^{1}$ Existing empirical evidence suggests that this potential legal risk has led many lenders to avoid making non-QM loans (DeFusco, Johnson, and Mondragon 2017). Because most state-contingent mortgage contracts would not satisfy the QM definition, this rule could potentially also play a role in limiting the adoption of these products in the future.

CLASSIC MARKET FRICTIONS Even in the absence of the regulatory barriers mentioned above, there are economic reasons why it may be difficult to sustain an equilibrium in which state-contingent mortgage contracts exist alongside the standard fixed-rate product. At their core, state-contingent mortgages are insurance contracts, which means they are plagued by all the same information asymmetries that would be present in any private insurance market.

Shiller (2014, p. 73), for example, noted the potential role of adverse selection in his comments on the lack of innovation in mortgage contract design when he stated:

Selection bias may compromise experimentation that would work better if the innovation were widely adopted. This is especially significant for products as important as mortgages. . . Early adopters of innovative new mortgage forms may have special circumstances or exploitative motivations.

Of course, whether such "exploitative motivations" are large enough to prevent the existence of a market for products like mortgages indexed to house prices is an empirical question to which we do not yet have an answer. Indeed, answering this question is difficult precisely because such products do not exist.

Anecdotal evidence, however, suggests that there may be scope for a nontrivial degree of adverse selection in such markets. Consider, for example, the recent experiences of the Northwest Home Equity Assurance Plan in Chicago, which was one of the earliest known attempts at providing households with a form of insurance against large falls in house prices. Created in 1988, this program provides local homeowners with full insurance against house price falls that is financed by levying a special local tax on neighborhood residents. To be eligible for the insurance, a homeowner 
must have lived in his or her home for at least five years and must also sign up for the program and pay an additional fee to have his or her initial property value assessed. Historically, take-up of this program has been very low, in part because prices in the neighborhood have been steadily rising. Recently, however, there has been a surge of interest in the program, with many new homeowners signing up and existing owners applying to update the base appraised value of their homes. This surge of interest was documented by the Chicago Tribune, which quoted the program director as attributing it to concerns about the proposed development of a new sevenstory housing complex that would include 80 units designated to be rented out at below-market rates and an additional 20 set aside for households with Chicago Housing Authority vouchers:

While Larson [the program director] doesn't ask callers why they're signing up for the home equity plan, she said many offer their motivations unprompted.

"They say, 'You won't believe this bleep bleeping development they want to put in over here,", she said. (Byrne 2017)

Presumably, these households are signing up out of fear that the new development will reduce the value of their own homes.

Although this is clearly only one example, it is not difficult to see a similar scenario playing out in the case of house price-contingent mortgages. Given the option of a mortgage contract that adjusts payments to reflect movements in house prices, homeowners who believe that house prices are likely to fall in their area might rationally choose to refinance out of their fixed-rate loans and into a state-contingent contract at precisely the time that it would be least beneficial to the lender for them to do so. Moreover, if homeowners have private information about local developments in their neighborhood, then the scope of this problem may increase with the granularity of the house price index to which payments are tied. Needless to say, this type of strategic selection may make it very difficult for lenders to price these products and could even lead to market unraveling. Thus, though the benefits of state-contingent mortgage contracts may be large, we have quite a way to go before we will be able to overcome all the barriers currently preventing these benefits from being realized.

\section{REFERENCES FOR THE DEFUSCO COMMENT}

Byrne, John. 2017. "Northwest Side Development Reignites Interest in Program Aimed at Preventing White Flight." Chicago Tribune, May 22.

Caplin, Andrew, Noël Cunningham, Mitchell Engler, and Frederick Pollock. 2008.

"Facilitating Shared Appreciation Mortgages to Prevent Housing Crashes and 
Affordability Crises.” Discussion Paper no. 2008-12. Brookings, Hamilton Project.

DeFusco, Anthony A., Stephanie Johnson, and John Mondragon. 2017. "Regulating Household Leverage." Working paper. http://www.kellogg.northwestern.edu/ faculty/defusco/documents/regulating_leverage.pdf

Shiller, Robert J. 2008. The Subprime Solution: How Today's Global Financial Crisis Happened, and What to Do about It. Princeton University Press.

2014. "Why Is Housing Finance Still Stuck in Such a Primitive Stage?" American Economic Review 104, no. 5: 73-76.

\section{COMMENT BY}

PAUL WILLEN ${ }^{1}$ In this thoughtful and provocative paper, Tomasz Piskorski and Amit Seru consider innovations in mortgage design. They argue that though theory suggests that indexing mortgage payments to economic conditions can increase welfare, implementing such a plan presents many challenges. The big issue is that indexes need to be highly correlated with individual risks to provide a significant improvement, and the authors document that even geographically localized indexes have a low correlation with relevant risks.

The authors interpret their evidence in the paper normatively, as showing the challenges to policymakers who want to use financial innovations to increase welfare. But I propose an alternative, complementary interpretation. I think the evidence in the paper explains why markets have never adopted indexation of mortgage contracts to local economic variables. The intellectual foundations for indexed mortgages have existed for a long time. The insight that financial assets tied to states of the world allow households to share risk goes back at least as far as Kenneth Arrow (1953) and Gerard Debreu (1959), and economists have been thinking about how to use indexes to facilitate these contracts ever since. ${ }^{2}$ The Bureau of Labor Statistics started publishing consistent, monthly, state-level unemployment rates in 1976, and the Office of Federal Housing Enterprise Oversight released quarterly, state-level, repeat-sales indexes for all 50 states starting

1. I thank Christopher Foote and Lara Loewenstein for help formulating this discussion, and Andreas Fuster and Joe Peek for comments. The views expressed in this comment are my own and do not necessarily reflect the views of the Federal Reserve Bank of Boston or the Federal Reserve System.

2. See Brainard and Dolbear (1971), Shiller (1994), and Davis and Willen (2000). Fuster and Willen (2011) argue that borrowing limits reduce the appeal of using financial assets to share risk. 
in 1996. Both theory and data point to the benefits of indexing mortgages to macroeconomic variables, yet we have no successful examples. Piskorski and Seru provide an answer for why: Viable indexes do not covary strongly enough with the individual risks we care about.

In the remainder of my discussion, I go one step further and argue that the existing system of defaultable mortgages has emerged because, despite its many flaws, it enables a significant amount of risk-sharing. To understand how default shares risk, consider a homeowner with a $\$ 500,000$ house. If the value of the house falls by $\$ 100,000$, the homeowner's wealth falls by the same amount. Now suppose the homeowner has a $\$ 475,000$ mortgage on the house. The mortgage gives the borrower the option to default, in which case the house is sold and the lender writes off the debt. ${ }^{3}$ In this case, the homeowner's wealth only falls by $\$ 25,000$, while the lender absorbs the other $\$ 75,000$, meaning that the lender absorbs 75 percent of the loss.

Pradeep Dubey, John Geanakoplos, and Martin Shubik (2005) first explored the idea that default provides an alternative approach to risksharing in theoretical general equilibrium models. William Zame (1993, p. 1142), building on their work, writes that in these models, "default improves the efficiency of markets and does so in a way that simply opening new markets cannot." The intuition is that default "[allows] traders to enter into contracts that they will be able to execute with high probability, but not with certainty" (p. 1143). In the Dubey, Greanakoplos, and Shubik world, large numbers of defaults are not a bad thing; they are evidence of widespread risk-sharing.

How much risk did default share in the crisis? To address this, I do a simple empirical exercise, as displayed in my figure 1. The horizontal axis shows changes in housing wealth, and the vertical axis measures changes in financial wealth. If there is no risk-sharing, then financial wealth responds one-for-one to changes in housing wealth and all outcomes land on the 45-degree line. Full risk-sharing means that the lender absorbs all gains and losses and the homeowner's financial wealth is unaffected by changes in house prices-all outcomes fall on the horizontal line at zero. My goal

3. I am assuming here that the loan is "nonrecourse." Lenders can, in many cases, petition the court to convert the deficiency-the difference between the unpaid principal balance and the auction price of the house-into an unsecured debt, but in practice, lenders almost never do. Some states prevent deficiency judgments, but for various reasons, lenders often set the auction reserve price equal to the unpaid principal balance, ensuring that there is no deficiency. 
Figure 1. Ex Post Risk-Sharing for a Sample of Mortgages Originated between 1995 and 2007

Change in financial wealth (percent) ${ }^{\mathrm{b}}$

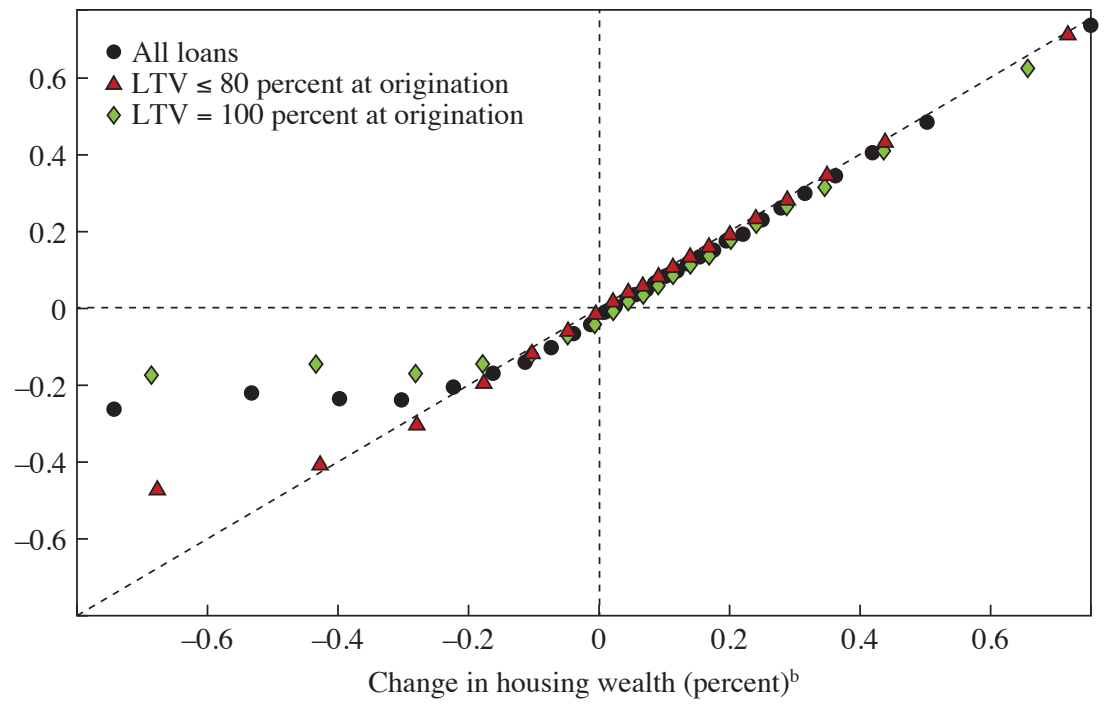

Sources: CoreLogic; author's calculations.

a. The figure shows the average changes in housing wealth for 20 equally sized bins of changes in home value. LTV stands for loan-to-value ratio, and includes second liens.

b. The change in wealth is measured as a percentage of the initial value of the home.

is to see how well mortgage markets shared risk. Were they closer to full risk-sharing or to no risk-sharing?

The sample includes subprime, Alt-A, and jumbo mortgages. ${ }^{4}$ I follow borrowers from origination through December 2017 or the termination of the loan, whichever comes first, and compare two numbers. The first number is the change in the value of the house, which I measure using the reported value of the house at origination, updated using ZIP code-level repeat sale indexes from CoreLogic. For the second number, I trace the evolution of the mortgage debt. I start with the original principal balance and subtract from it any reductions in the principal due to modifications or short sales. If the borrower defaults, I also subtract the deficiencythe difference between what the borrower owes and the value of the house

4. I use the CoreLogic securities data set, which contains all loans from private-label securities deals from 1995 until 2007, and CoreLogic house price indexes. 
at the time of the default. The variable on the vertical axis-the change in financial wealth-equals the change in the value of the house less the change in the value of the debt plus any principal repayment that occurred after origination.

The circles in my figure 1 show risk-sharing in the data. On the gain side, there is, unsurprisingly, no risk-sharing. Borrowers whose houses increase in value either sell or refinance and capture all the gains. On the loss side, there is significant risk-sharing. Homeowners absorb roughly the first 20 percent of losses and lenders absorb the rest. This picture will appear familiar to a finance student; it is the graph of the payoff on a call option with a strike price equal to 80 percent of the value of the house. This follows because one way to think about a mortgage contract is that when taking out a mortgage, the borrower sells the house to the lender with the right to buy it back for the outstanding balance on the mortgage. If the homeowner has a loan-to-value (LTV) ratio of 80 percent, then our call option would exactly describe the picture. In fact, LTV ratios in the data are substantially higher than 80 percent; and in the figure, I break down the loans into those with an LTV of 100 percent (diamonds) and those with LTVs less than 80 percent (triangles), which appear with, respectively, higher and lower strike prices than the sample as a whole.

Several features of the picture warrant elucidation. First, the fact that borrowers absorb some of the loss, even with an LTV of 100 percent, is what the Dubey, Geanakoplos, and Shubik (2005) model predicts. Their crucial insight is that for default to exist in equilibrium, borrowers must be punished, and they do this by including utility penalties in their equilibrium concept. In other words, some borrowers will prefer to absorb losses rather than suffer the default penalty. The second important point is that even borrowers who end up gaining still benefit from the possibility of default. A buyer with an LTV ratio of 100 percent who is down 20 percent has an out-of-the-money call option that still, of course, has positive value. So a homeowner who suffered through a 20 percent price decline but then sold for a gain later would still have enjoyed risk-sharing, even if, in the end, he or she made a gain.

Default is obviously not a first-best solution. No institution in the real world is a first-best solution. But, as Piskorski and Seru show, finding alternatives to the existing system is harder than it may at first appear. The deep challenge with sharing house price risk is that only a relatively small percentage of people default. In the worst year of the crisis, data from the Mortgage Bankers Association show that lenders started foreclosures on only 5 percent of all mortgages. Even in Nevada, the figure 
only ever reached 15 percent. Default provides for a lot of risk-sharing with this 5 percent, but comparatively little with the rest of the population. Indexation provides a much smaller amount of risk-sharing to a much larger fraction of the population, much of which is not at risk. To paraphrase Winston Churchill, default is the worst possible way to share risk, "except for all those other forms that have been tried."

\section{REFERENCES FOR THE WILLEN COMMENT}

Arrow, Kenneth J. 1953. "Le Rôle des Valeurs Boursières dans l'Allocation Optimale des Risques." Économétrie 40: 41-47. Reprinted in English as "The Role of Securities in the Optimal Allocation of Risk-Bearing," Review of Economic Studies 31, no. 2 (1964): 91-96.

Brainard, William, and F. Trenery Dolbear. 1971. "Social Risk and Financial Markets." American Economic Review 61, no. 2: 360-70.

Davis, Steven J., and Paul Willen. 2000. "Using Financial Assets to Hedge Labor Income Risks: Estimating the Benefits.” Working paper. http://faculty.chicago booth.edu/steven.davis/pdf/31.pdf

Debreu, Gerard. 1959. Theory of Value: An Axiomatic Analysis of Economic Equilibrium. New York: John Wiley \& Sons.

Dubey, Pradeep, John Geanakoplos, and Martin Shubik. 2005. "Default and Punishment in General Equilibrium." Econometrica 73, no. 1: 1-37.

Fuster, Andreas, and Paul S. Willen. 2011. "Insuring Consumption Using IncomeLinked Assets." Review of Finance 15, no. 4: 835-73.

Shiller, Robert J. 1994. Macro Markets: Creating Institutions for Managing Society's Largest Economic Risks. Oxford University Press.

Zame, William R. 1993. "Efficiency and the Role of Default When Security Markets Are Incomplete." American Economic Review 93, no. 5: 1142-64.

GENERAL DISCUSSION Arvind Krishnamurthy first reacted to commenter Paul Willen's point about default and the completing of markets. Willen's proposal for completing markets through default, he noted, involves much distress cost: As a household approaches default, it cuts back on consumption in order to prevent it, and banks, worrying about default, change their lending behaviors. This process seemed to Krishnamurthy to be an inefficient way to include contingencies. One would hope that a shared appreciation mortgage would create a contingency that avoids such deadweight costs. The default option seemed to him like a third-best way to complete the markets.

Both commenters mentioned mortgages that are indexed to house prices. Krishnamurthy noted that he became educated about such mortgages when 
writing a paper with Janice Eberly. ${ }^{1}$ In a bad state of the world, the lender transfers present value benefits to the borrower through debt being written down, so that payments are lower for the entire life of the mortgage, and the benefits to the borrower are spread over the entire life of the mortgage contract. For example, if debts are written down from 100 percent to 80 percent, the borrower cuts his or her payment for the life of the mortgage by 20 percent. He noted, drawing on his analysis with Eberly, that this type of indexation can be improved upon further. For any given decrease in present value, a liquidity-constrained borrower would be far better served by front-loading these benefits; that is, tilting the payments by cutting current payments significantly while increasing later payments by more. This is not a feature of shared appreciation mortgages, which is why Eberly and Krishnamurthy developed the idea that a good mortgage would be a fixed-rate mortgage with the option to convert into a variable rate, so that in a recession, when the yield curve is upward-sloping, exercising the option will reduce the borrower's current payments relative to future payments.

Finally, Krishnamurthy noted that the correlation between national and regional indexes is really a quantitative question. It is clear that more granular indexes are preferred over more aggregated indexes; but an important question is, How well can we do using the national indexes? A paper Krishnamurthy wrote with Timothy McQuade and Adam Guren tries to answer this question by replicating the 2007-09 financial crisis using the Eberly-Krishnamurthy mortgage design. ${ }^{2}$ The authors compute roughly that, in consumption-equivalent terms, households would have been better off- on the order of 1 percent of annual consumption - if the EberlyKrishnamurthy mortgage design had been implemented during the crisis.

Philip Swagel asked about the effect of interest rate resets. The authors' table 7 and the accompanying text show that the interest rate on two-year, adjustable-rate mortgages rose from 7.8 percent to 9.1 percent, a rate reset of 1.3 percentage points. He asked if this was based on actual interest rates or on an index such as the London Interbank Offered Rate. He noted that there was a significant effort at the end of 2007—-spearheaded by then-chair of the Federal Deposit Insurance Corporation Sheila Bair — to get mortgage issuers to turn off the interest rate resets. This might lead one to suspect that the numbers reported by the authors are overstated.

1. Janice Eberly and Arvind Krishnamurthy, "Efficient Credit Policies in a Housing Debt Crisis," Brookings Papers on Economic Activity, Fall 2014: 73-118.

2. Adam M. Guren, Arvind Krishnamurthy, and Timothy J. McQuade, "Mortgage Design in an Equilibrium Model of the Housing Market," Working Paper no. 24446 (Cambridge, Mass.: National Bureau of Economic Research, 2018). 
Swagel then discussed the ability to refinance during the crisis. The authors hint about the lawsuit risk that made banks hesitate to refinance loans made by other banks. At the time, it seemed as if the U.S. Department of Justice was suing anyone associated with a bad mortgage, so a lender would not want to become exposed to liability from mistakes made at the initial origination. Finally, he remarked about ex post policy with regard to mortgage modifications, which is an issue in the current debate on affordable housing. Consider the situation in which government-insured fixed-rate mortgages during a crisis are turned into the Eberly-Krishnamurthy style product, in which borrowers get the benefits of a one-way interest rate adjustment, with resets to take advantage of lower rates but not higher ones. He suspected that this would raise the equilibrium mortgage interest rate because providers of mortgage funds would want compensation for the one-way adjustment, even if it is welfare-improving.

N. Gregory Mankiw noted that economists are historically bad at figuring out why contingencies do not exist in contracts. This is discussed in many contexts besides mortgages, such as that for student loans; for example, student loans could include some sort of equity component, so that the risks of going to college are shared. Such a proposal makes sense from an economist's perspective, but the private market has been reluctant to implement the idea. Mankiw recalled that when Treasury-indexed bonds were introduced in the late 1990s, economists said, "Of course it is better to have real bonds rather than nominal bonds," and they suspected that once the U.S. Treasury implemented them, the rest of the world would follow. But this was not the case, and today there are essentially no private indexed bonds. Economists do not really understand why that is, and it does not seem to be a regulatory or tax issue. He suggested that behavioral economists come on board to help other economists to explain this phenomenon.

Martin Baily proposed that the United States might be going about derisking the mortgage market in the wrong way. Perhaps the best strategy would be to get more of the riskier buyers out of the market. It seems almost a matter of faith in the United States that increasing the rate of homeownership is a good thing. Scholars have pointed to neighborhood effects associated with homeownership; but Baily suspected that if there were more effective ways to help renters, then these effects would be less substantial. For example, low-income homeowners might get foreclosed upon, while low-income renters might get evicted. Both types of people may need help, but the homeowner facing foreclosure is clearly in a worse state. But aside from low-income borrowers, other risky borrowers include people who buy second homes or use their homes' equity as lines of credit. 
Such people, Baily believes, should be kept out of the mortgage market, or at least be better controlled. Higher down payments or more effective ways of monitoring income stability could make it easier to administer more elaborate mortgage designs, such as the one proposed by the authors.

Picking up on Baily's comments, Alan Blinder stated that the most obvious way to make mortgages safer is to require larger down payments, and by regulation or law having fewer low-percentage down payment options. According to Blinder, it is probably not a coincidence that in countries with macroprudential authority —of which the United States is not one-loan-to-value ratios are a key part of the macroprudential package. If one were worried about poor people buying houses, another approach —in addition to Baily's suggestions-would be to offer an old-style government guarantee, targeted only at low-income people.

Frederic Mishkin brought up the maintenance issues associated with "the joys of homeownership." One problem with nontraditional mortgage contract designs is the incentive for the homeowner not to keep up the house. In the case of shared appreciation mortgages, there is the issue of whether the homeowner will invest to meaningfully improve the house, or whether he or she might overinvest, such as by installing a $\$ 100,000$ swimming pool that only adds $\$ 50,000$ of value. During the crisis, once homeowners were underwater they often stopped taking care of their homes, or the homes were abandoned and people pillaged all the copper pipes and other raw materials. This calls into question whether the sorts of contracts envisioned by the authors would set up moral hazard problems. Such problems can be seen in the case of home insurance: If the homeowner takes out home insurance and actually lives in the house, the rates are much lower than if the homeowner only rents out the house to, say, his or her children, who have less of an incentive to maintain the home.

Seru first commented on default as a way of sharing risk. Default is costly for borrowers, because it can result in significant deadweight losses; and it is possibly also costly for highly leveraged banks, which might not take borrower default into account. If everyone defaults, that could trigger strategic defaults. And if this were to become a social norm, it could have significant ramifications; contracts with a default option designed on an individual basis might not take such externalities into account. All this is to say that the authors are not suggesting that default not be available, but rather that there may be more efficient ways to achieve risk-sharing.

On Krishnamurthy's point about the correlation between regional and national indexes, Seru agreed that it is a quantitative question. But the authors' point is that, given the heterogeneity, mortgages based only on 
national-level indexes may not be enough to mitigate shocks that emerge during a crisis. It is important to recognize regional heterogeneity, and regional indexes have a better probability of capturing this heterogeneity relative to the national index. If one were to index all the way to the ZIP code level, then policymakers would want to have a good sense of how such local indexes could be constructed. But there are also political constraints when one wants to tailor policies to the local level. In general, region-based policies have not worked out well in the United States.

On the question of why most contracts do not have contingencies, Seru stated that this is still an open question. In some markets, the problem clearly is not access, and it may have to do with regulation or other political economy considerations.

Seru noted that there has been much conversation about shared appreciation mortgages, of the sort proposed by Eberly and Krishnamurthy. He presumed everyone would agree that once shocks that cause a crisis are realized, post interventions would still be required, because it is hard to capture everything ex ante. However, post interventions come with their own set of barriers, which are often not appreciated in terms of effectively implementing debt relief. Federal programs such as the Home Affordable Refinance Program and the Home Affordable Modification Program are in a sense trying to take into account the heterogeneous nature of realized shocks; but to get debt relief to the borrower involves understanding the nature and business models of intermediaries, competition among banks, and other factors-all of which the authors point to as having nontrivial effects on effective implementation of such policies.

Piskorski stated that an elephant in the room is the system of subsidies from the government-sponsored enterprises (GSEs): Fixed-rate mortgages are unlikely the best contract design one can come up with, they are the main subsidized contract type. GSE subsidies essentially suppress many incentives for financial innovation. So one should ask, Are fixed-rate mortgage contracts still the best contract design we can come up with, given today's data availability, financial technology, and computer processing power? Although fixed-rate mortgages will likely fall out of favor given these technological advances, it is hard to compete in the mortgage contract space as long as the GSEs will only subsidize fixed-rate and certain adjustable-rate mortgages. Piskorski agreed with Krishnamurthy that the Eberly-Krishnamurthy convertible-rate mortgage design could be a sensible option that does not deviate too much from the currently available contract types; but the question should also be, Can we do better? 